OECD Series on Adverse Outcome Pathways No. 19

Adverse Outcome Pathway

on Cyp2E1 activation leading to liver cancer

\section{Francina Webster,}

lain B. Lambert,

Carole L. Yauk 


\section{Adverse Outcome Pathway on Cyp2E1 Activation Leading to Liver Cancer}

Series on Adverse Outcome Pathways No. 19

AOP No. 220 in the AOP Wiki platform 


\section{Foreword}

This Adverse Outcome Pathway (AOP) on Cyp2E1 Activation Leading to Liver Cancer, has been developed under the auspices of the OECD AOP Development Programme, overseen by the Extended Advisory Group on Molecular Screening and Toxicogenomics (EAGMST), which is an advisory group under the Working Party of the National Coordinators of the Test Guidelines Programme (WNT). The AOP has been reviewed internally by the EAGMST, externally by experts nominated by the WNT, and has been endorsed by the WNT and the Working Party on Hazard Assessment (WPHA) on 22 July 2021.

Through endorsement of this AOP, the WNT and the WPHA express confidence in the scientific review process that the AOP has undergone and accept the recommendation of the EAGMST that the AOP be disseminated publicly. Endorsement does not necessarily indicate that the AOP is now considered a tool for direct regulatory application.

The OECD's Chemicals and Biotechnology Committee agreed to declassification of this AOP on 7 October 2021.

This document is being published under the responsibility of the OECD's Chemicals and Biotechnology Committee.

The outcome of the internal and external reviews are publicly available respectively in the AOP Wiki and the eAOP Portal of the AOP Knowledge Base at the following links: [internal review] [external review]. 


\section{Authors:}

Francina Webster, Health Canada

lain B. Lambert, Carleton University

Carole L. Yauk, University of Ottawa 


\section{Abstract}

Cyp2E1 is a cytochrome P450 mono-oxygenase that bioactivates over 85 substrates, thereby creating electrophilic metabolites and oxidative stress. Substrates are low molecular weight compounds that include acetone, acetaminophen, ethanol, chloroform, carbon tetrachloride, furan and molecular oxygen. Mono-oxygenation of these substrates to their reactive metabolites, and the accompanying oxidative stress produced during metabolism, pose health risks because they lead to hepatotoxicity and, often, to liver cancer.

Here we describe the AOP for the prolonged activation of Cyp2E1 (MIE) leading to liver cancer (AO). The intervening KEs are oxidative stress (KE1), hepatocytotoxicity (KE2), and sustained/persistent cellular proliferation (KE3). These events occur in the liver, which is the primary site of xenobiotic metabolism in the body. Briefly, the MIE occurs when Cyp2E1 binds a substrate. The Cyp2E1 catalytic cycle is prone to decoupling (adjacent KER1, non-adjacent KER1), which produces oxidative stress (KE1), and mono-oxidation of substrates produces reactive metabolites. Both reactive oxygen species and metabolites cause cytotoxicity (KE2). However, following injury, the liver is able to regenerate itself through an increase in cellular proliferation (KE3). Under conditions of chronic activation of Cyp2E1, excessive chronic increases in levels of reactive oxygen species and cell death, and subsequent dysregulated cellular proliferation, leads to tumour formation (AO).

We evaluate the essentiality of the KEs and the biological plausibility of and empirical support for the KERs and report that most are well supported by a large body of scientific literature. Here, we've focused on data generated in rodent studies using the Cyp2E1 substrates carbon tetrachloride, chloroform, ethanol and furan. These compounds are all liver carcinogens, but generate negative or equivocal results in short-term genotoxicity tests. In fact, they are widely thought to cause cancer through a cytotoxicity and regenerative proliferation mode of action.

We expect that the data and information summarized here will be useful to scientists and regulators that are investigating chemical carcinogens that act through this mechanism. Given the importance of oxidative stress and cytotoxicity in a broad array of toxicological effects, the $\mathrm{KE}(\mathrm{R}) \mathrm{s}$ described should be broadly useful for development of other AOPs.

Finally, this AOP describes an important widely acknowledged pathway to toxicity and thus should have many regulatory applications. Further development of the quantitative aspects of this AOP will enable the development of more predictive models of effects resulting from oxidative stress. 


\section{Contents}

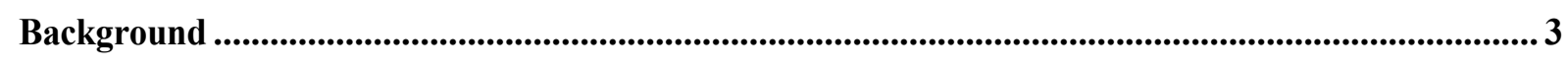

Graphical Representation ..................................................................................................................

Summary of the AOP........................................................................................................................... 4

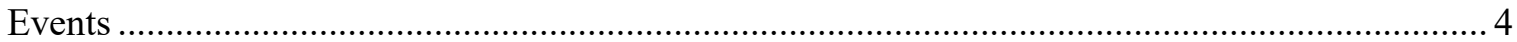

Key Event Relationships …………………………………………………………………

Overall Assessment of the AOP ...............................................................................................5

Domain of Applicability .....................................................................................................

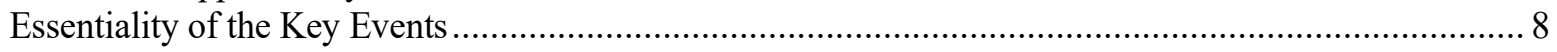

Weight of Evidence Summary ................................................................................................. 8

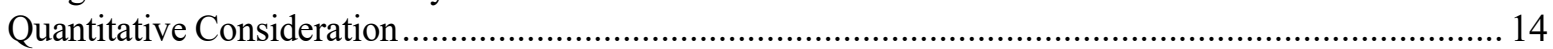

Considerations for Potential Applications of the AOP (optional) ............................................................15

Appendix 1- MIE, KEs and AO...................................................................................................20

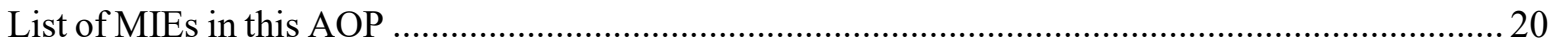

Event: 1391: Activation of Cyp2E1 (https://aopwiki.org/events/1391) ……………………………......2 20

Evidence for Perturbation by Stressor ......................................................................................... 20

Domain of Applicability ………………………………………………………………………2 2

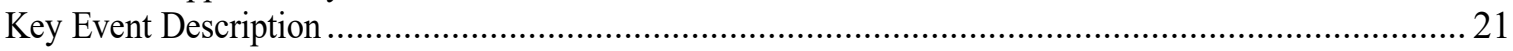

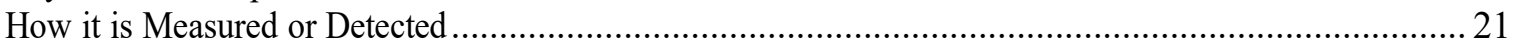

List of Key Events in the AOP .............................................................................................2

Event: 1392: Oxidative Stress (https://aopwiki.org/events/1392) ......................................................24

Domain of Applicability ......................................................................................................... 25

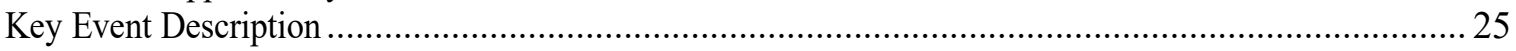

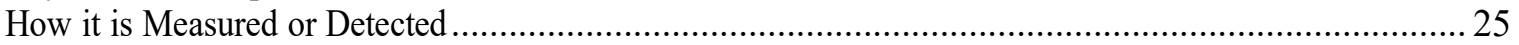

Event: 1393: Hepatocytotoxicity (https://aopwiki.org/events/1393) ………………………………….....2

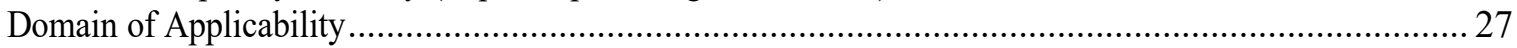

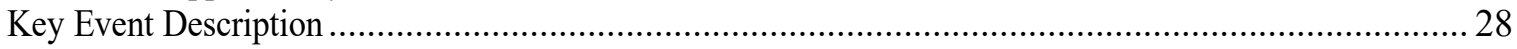

How it is Measured or Detected ………………………………………………………………...2 28

Event: 1394: Induction, persistant proliferation/sustained proliferation (https://aopwiki.org/events/1394) ......30

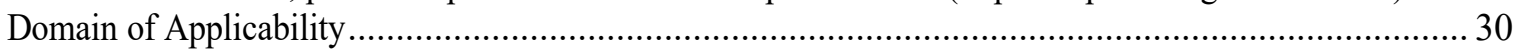

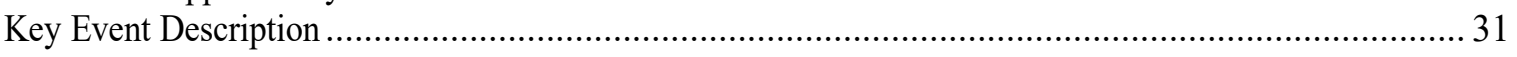

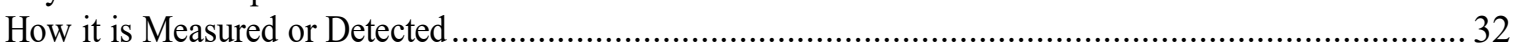

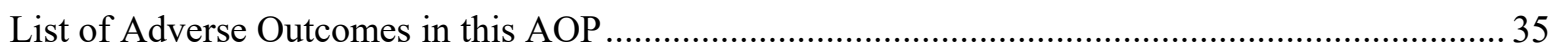

Event: 1395: Liver Cancer (https://aopwiki.org/events/1395) .............................................................35

Evidence for Perturbation by Stressor............................................................................................35

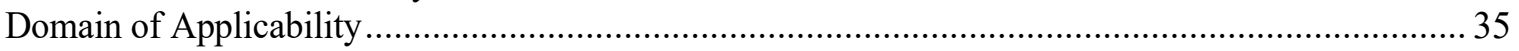

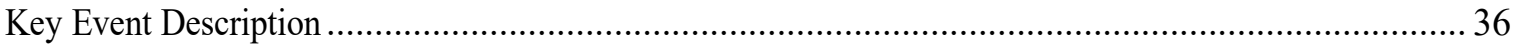

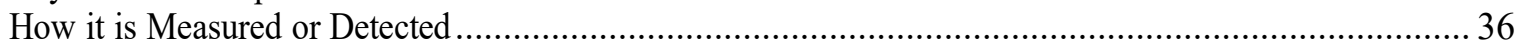

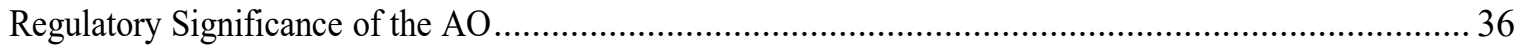

Appendix 2: List of Key Event Relationships in the AOP ......................................................................37

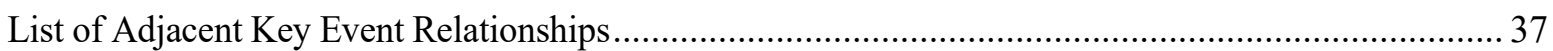

Relationship: 1512: Activation of Cyp2E1 leads to Oxidative Stress (https://aopwiki.org/relationships/1512). 37

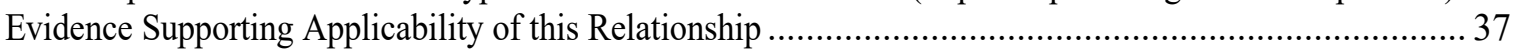

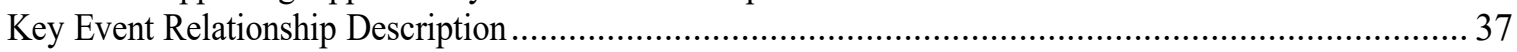

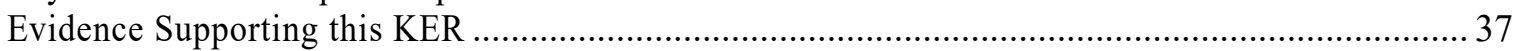

Relationship: 1513: Oxidative Stress leads to Hepatocytotoxicity (https://aopwiki.org/relationships/1513) .... 40

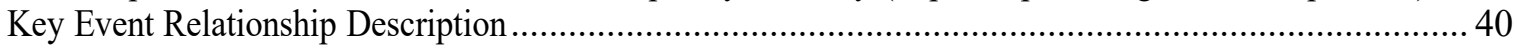


Evidence Supporting this KER 40

Relationship: 1514: Hepatocytotoxicity leads to Sustained proliferation (https://aopwiki.org/relationships/1514)42

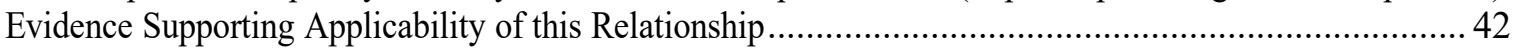

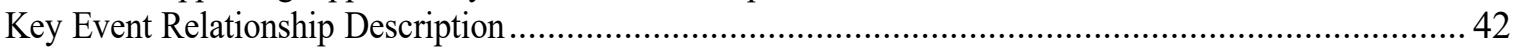

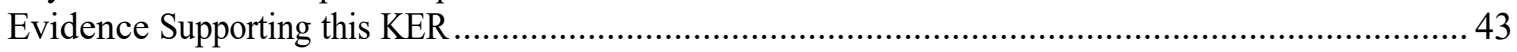

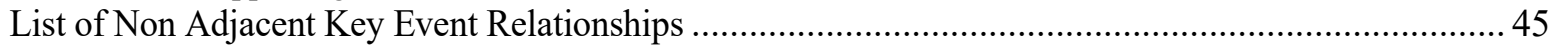

Relationship: 1515: Activation of Cyp2E1 leads to Hepatocytotoxicity (https://aopwiki.org/relationships/1515)45

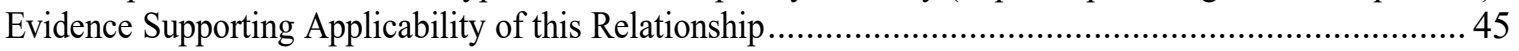

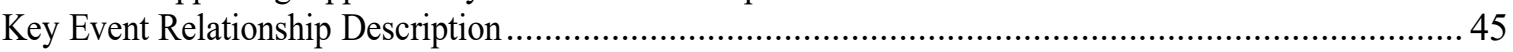

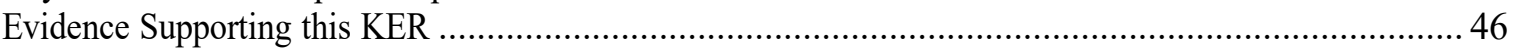

Relationship: 1516: Oxidative Stress leads to Liver Cancer (https://aopwiki.org/relationships/1516) ............ 47

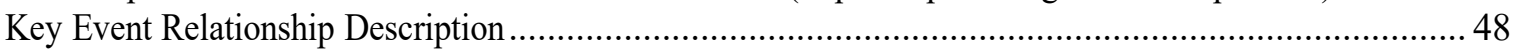

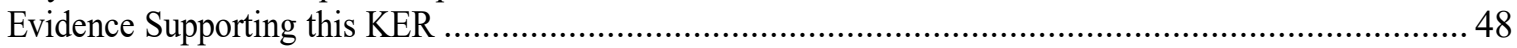

Relationship: 1517: Hepatocytotoxicity leads to Liver Cancer (https://aopwiki.org/relationships/1517).........52

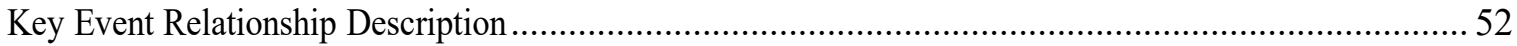

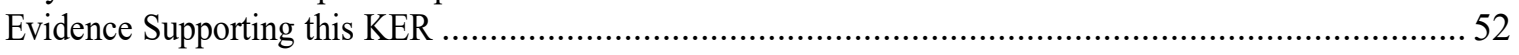

Relationship: 1518: Sustained proliferation leads to Liver Cancer (https://aopwiki.org/relationships/1518) ....54

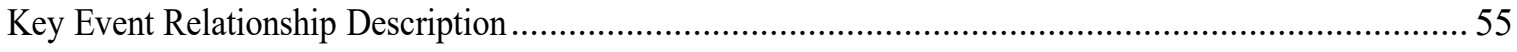

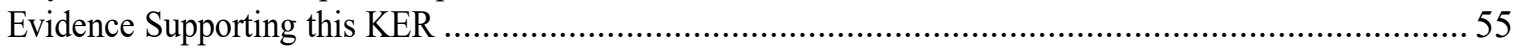




\section{Background}

The subject of this AOP is xenobiotic metabolism by Cyp2E1 (MIE) during prolonged exposures, leading to liver cancer (AO). The intervening KEs are chronic oxidative stress, cytotoxicity, and regenerative proliferation. The setting for these events is the liver, which is the body's primary venue for chemical detoxification.

Xenobiotic metabolism typically occurs in three phases: (I) the chemical substrate is enzymatically bioactivated to its primary metabolite; (II) the metabolite(s) produced is (are) made less reactive through conjugation; and (III) the modified chemical(s) is (are) excreted. Cyp2E1 is a phase I P450 monooxygenase that bio-activates its substrates through the addition of an oxygen, thereby producing an electrophilic metabolite. Acting as an electrophile following metabolic activation is a key characteristic of a carcinogen (Smith, et al. 2015). While this reactive species often undergoes conjugation (phase II metabolism), sometimes it will react with cellular nucleophiles (e.g., proteins or DNA), which results in formation of adducts that produce cytotoxicity in extreme cases. Another feature of Cyp2E1 is that its catalytic cycle is prone to uncoupling, which leads to the production of reactive oxygen species (ROS). ROS are an important source of cytotoxicity (e.g., via lipid peroxidation) and are a source of oxidative lesions to DNA (which may be a source of cancer-causing mutations) (Caro and Cederbaum 2004). Redox-sensitive proteins are modified by oxidation; importantly, changes in gene expression are carried out by the redox-sensitive transcription factor Nrf2. Nrf2 increases the expression of genes that encode cyto-protective products, such as anti-oxidants and phase II conjugating enzymes (Furfaro, et al. 2016, Ma and He 2012, Sporn and Liby 2012, Tkachev, et al. 2011). At the same time, dying cells release pro-inflammatory signals and, together, these signals encourage regenerative proliferation of hepatocytes (Brenner, et al. 2013, Luedde, et al. 2014). However, when chronically activated, these molecular signals can produce dysregulated cellular proliferation in which the cytoprotective cellular mechanisms that are intended to promote tissue repair instead may lead to pre-malignant and malignant lesions.

This AOP explores these mechanisms in greater detail. Because exposure to Cyp2E1substrates is relatively common, this AOP will be an important tool for understanding the adverse health impacts of these potentially harmful substances. Cyp2E1 is well studied and is involved in the metabolism of a large number of substrates (Lieber 1997, Tanaka, et al. 2000), so it is impossible to summarize all of the evidence. Therefore, we report illustrative studies that support each KE and KER. In addition, because no single study has looked at each key event, supporting evidence is gathered from many studies that have used a variety of in vitro and in vivo systems, as well as a collection of Cyp2E1 substrates. We focus on evidence gathered from: furan (a group 2B carcinogen), ethanol (group 1), chloroform (group 2B), and carbon tetrachloride (group 2B). These compounds are established Cyp2E1 substrates that are known to be rodent carcinogens and are (group 1) or are suspected (group 2B) human carcinogens based on their International Agency for Research on Carcinogens (IARC) evaluations. 


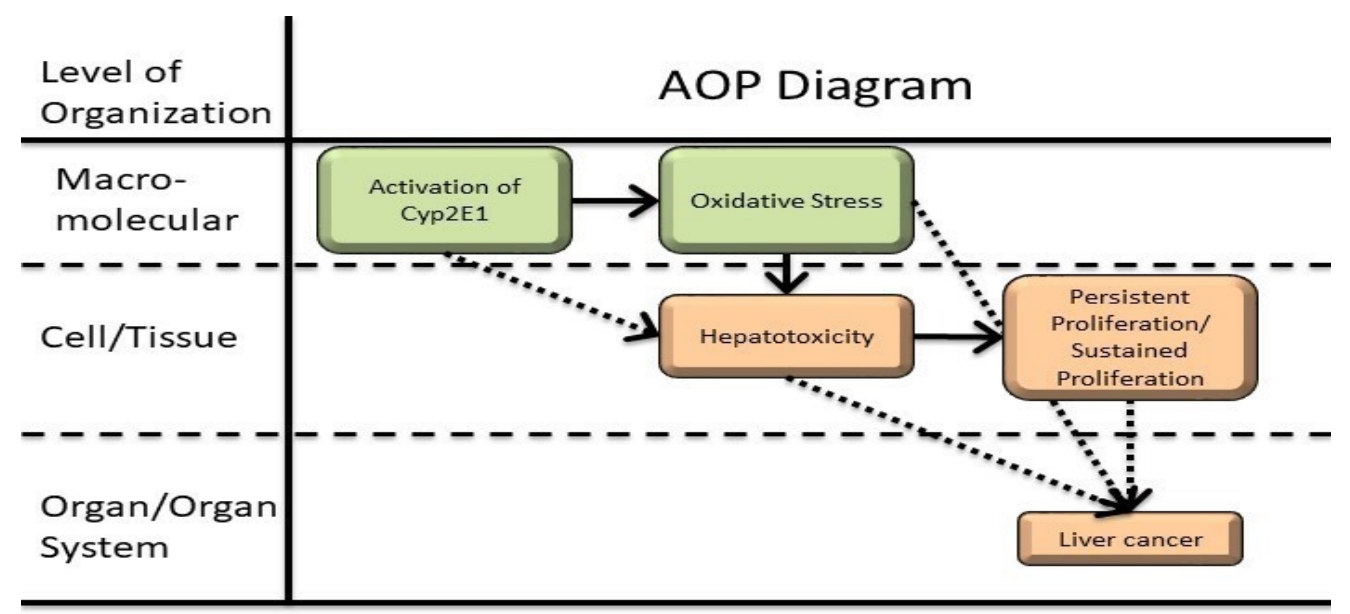

Note that chronic or prolonged activation of Cyp2E1 is required for this AOP to lead to liver cancer.

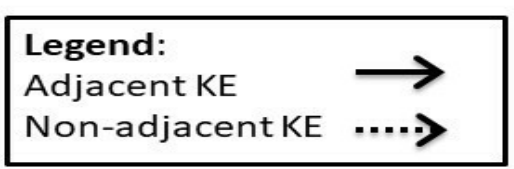

\section{Summary of the AOP}

\section{Events}

Molecular Initiating Events (MIE), Key Events (KE), Adverse Outcomes (AO)

\begin{tabular}{|l|l|l|l|l|}
\hline $\begin{array}{l}\text { Sequenc } \\
\mathrm{e}\end{array}$ & Type & $\begin{array}{l}\text { Event } \\
\text { ID }\end{array}$ & Title & Short name \\
\hline 1 & MIE & 1391 & Activation of Cyp2E1 (https://aopwiki.org/events/1391) & $\begin{array}{l}\text { Activation of } \\
\text { Cyp2E1 }\end{array}$ \\
\hline & & & & \\
\hline 2 & KE & 1392 & Oxidative Stress (https://aopwiki.org/events/1392) & Oxidative Stress \\
\hline 3 & KE & 1393 & Hepatocytotoxicity (https://aopwiki.org/events/1393) & Hepatocytotoxicity \\
\hline 4 & KE & 1394 & $\begin{array}{l}\text { Induction, persistant proliferation/sustained proliferation } \\
\text { (https://aopwiki.org/events/1394) }\end{array}$ & $\begin{array}{l}\text { Sustained } \\
\text { proliferation }\end{array}$ \\
\hline & & & & \\
\hline 5 & AO & 1395 & Liver Cancer (https://aopwiki.org/events/1395) & Liver Cancer \\
\hline
\end{tabular}

Key Event Relationships

\begin{tabular}{|l|l|l|l|l|}
\hline & $\begin{array}{l}\text { Relation } \\
\text { ship } \\
\text { Type }\end{array}$ & Downstream Event & $\begin{array}{l}\text { Quantitative } \\
\text { Evid } \\
\text { ence }\end{array}$ & $\begin{array}{l}\text { Understandin } \\
\text { g }\end{array}$ \\
\hline $\begin{array}{l}\text { Activation of Cyp2E1 } \\
\text { (https:/aopwiki.org/relationships/1512) }\end{array}$ & adjacent & Oxidative Stress & High & Not Specified \\
\hline $\begin{array}{l}\text { Oxidative Stress } \\
\text { (https://aopwiki.org/relationships/1513) }\end{array}$ & adjacent & Hepatocytotoxicity & High & Not Specified \\
\hline $\begin{array}{l}\text { Hepatocytotoxicity } \\
\text { (https://aopwiki.org/relationships/1514) }\end{array}$ & adjacent & $\begin{array}{l}\text { Induction, persistant } \\
\text { proliferation/sustained } \\
\text { proliferation }\end{array}$ & High & Not Specified \\
\hline
\end{tabular}




\begin{tabular}{|l|l|l|l|l|}
\hline & & & & \\
\hline $\begin{array}{l}\text { Activation of Cyp2E1 } \\
\text { (https:/aopwiki.org/relationships/1515) }\end{array}$ & $\begin{array}{l}\text { non- } \\
\text { adjacent }\end{array}$ & Hepatocytotoxicity & High & Not Specified \\
\hline $\begin{array}{l}\text { Oxidative Stress } \\
\text { (https://aopwiki.org/relationships/1516) }\end{array}$ & $\begin{array}{l}\text { non- } \\
\text { adjacent }\end{array}$ & Liver Cancer & $\begin{array}{l}\text { Mode } \\
\text { rate }\end{array}$ & Not Specified \\
\hline $\begin{array}{l}\text { Hepatocytotoxicity } \\
\text { (https://aopwiki.org/relationships/1517) }\end{array}$ & $\begin{array}{l}\text { non- } \\
\text { adjacent }\end{array}$ & Liver Cancer & $\begin{array}{l}\text { Mode } \\
\text { rate }\end{array}$ & Not Specified \\
\hline $\begin{array}{l}\text { Induction, persistant proliferation/sustained } \\
\text { proliferation } \\
\text { (https://aopwiki.org/relationships/1518) }\end{array}$ & $\begin{array}{l}\text { non- } \\
\text { adjacent }\end{array}$ & Liver Cancer & $\begin{array}{l}\text { Mode } \\
\text { rate }\end{array}$ & Not Specified \\
\hline
\end{tabular}

Stressors

Name

Evidence

$>85$ known Cyp2E1 substrates

High

$>85$ known Cyp2E1 substrates:

Low molecular weight compounds, including: molecular oxygen, acetone, acetaminophen, carbon tetrachloride, pyrazole, vinyl chloride, furan, chloroform, ethanol, benzene, acrylonitrile, trichloroethylene, aniline, Nnitrosodimethylamine, N-nitrosodiethylamine, diethylnitrosamine, thioacetamide, and toluene. A variety of substrates have been described (Lieber 1997, Tanaka, et al. 2000).

\section{Overall Assessment of the AOP}

\section{Biological plausibility:}

Biological plausibility is based on fundamental understanding of the structural or functional relationship between the key events in the normal biological state. In general, there is high biological plausibility and coherence for the direct and (some of) the indirect relationships in this AOP. It is established that Cyp2E1 is stabilized upon substrate binding and generates ROS during metabolism. The link between ROS-induced lipid and DNA damage has been carefully mapped out, with a broad understanding of the spectrum of damage induced by ROS in a cell, and the signalling cascades induced that lead to cell death. There is extensive understanding that the liver regenerates following injury and cytotoxicity. Chronic toxicity would cause the liver to be undergoing increased cellular proliferation over a prolonged period of time in this tissue that, under normal circumstances, would have a relatively low mitotic index. There is a strong association, with some defined intervening steps, between liver regeneration and the probability of developing hepatocellular carcinoma, which is likely due to increased probability of incurring cancer-driver mutations with more DNA replication [e.g., tissues undergoing more cellular division have higher incidences of cancer (Tomasetti and Vogelstein 2015, Wu, et al. 2016)]. Moreover, chronic inflammation caused by increased and sustained levels of hepatotoxicity also contributes to increased probability of developing hepatocellular carcinoma. It is important to emphasize that the adverse effects observed are the product of chronic activation of Cyp2E1, which leads to sustained production of ROS, cytotoxicity and regenerative proliferation. A case study of this mode of action is presented in Meek et al (2003) using chloroform as an example. The case study describes 'sustained cytotoxicity and regenerative cell proliferation' as key events for a range of animal tumors, including for chloroform leading to liver tumours in mice. Thus, the overall biological plausibility for this AOP, especially in rodent models, is strong. 


\section{Time- and dose-response concordance:}

Time- and dose-response concordance evaluation considers the available empirical data to determine if upstream events occur before downstream, and at lower or the same doses. A major assumption is that all KEs can be measured with equal precision and sensitivity. Overall, there is an extensive database of studies on Cyp2E1 substrates (furan, carbon tetrachloride, ethanol, etc.) that supports that the events occur in the correct order temporally, and that the upstream events occur at lower doses than the downstream events. Within each of the KERs, the example of furan is mapped out in detail, demonstrating the ability to measure increased levels of ROS and hepatotoxicity at lower doses than those causes liver regeneration and cancer.

\section{Essentiality:}

Essentiality refers to evidence that supports the idea that if a given KE is blocked or prevented, the downstream events in the sequence represented in the AOP will not occur (unless impacted by another pathway sharing those events). In this AOP, there is strong evidence of essentiality of activation of Cyp2E1, with knock-out studies demonstrating that the downstream key events do not occur in the absence of this. For example, hydrogen peroxide production and lipid peroxidation are blocked in rat microsomes following inhibition of Cyp2E1 with anti-Cyp2E1 IgG (Ekstrom and Ingelman-Sundberg 1989). Cyp2E1 over-expressing HepG2-E47 cells have higher baseline levels of oxidative stress than wildtype HepG2 cells that do not express Cyp2E1. Moreover, Ethanol-dependent lipid peroxidation can be prevented by treatment with Cyp2E1 inhibitors/antioxidants in Cyp2E1 over-expressing human HepG2 cells (Wu and Cederbaum 2005). Cyp2E1-null mice exposed to chloroform do not present with either hepatotoxicity or regenerative proliferation (Constan, et al. 1999). Chloroform-dependent hepatotoxicity and regenerative proliferation do not occur in Cyp2E1-null mice (Constan, et al. 1999). Blocking Cyp2E1 gene transcription (using the drug Bortezomib) blocks acetaminophen-, carbon tetrachloride-, and thioacetamidedependent hepatotoxicity in a dose and time dependent manner (Park, et al. 2016).

Treatment with anti-oxidants to reduce oxidative stress reduces cytotoxicity and removal of antioxidants has the opposite effect. Key evidence to support the link between oxidative stress and cell death involves glutathione levels. Severity of cytotoxicity and levels of glutathione are inversely related (Smith, et al. 1979). Cyp2E1 over-expressing HepG2-E47 cells have higher baseline levels of oxidative stress than wildtype HepG2 cells that do not express Cyp2E1. For example, increasing cellular ROS through the depletion of thioredoxin or glutathione, or the addition of pro-oxidants in Cyp2E1-over-expressing E47 cells results in cell death (Cederbaum, et al. 2012, Yang, et al. 2011)(Wu and Cederbaum 2008). Ethanol-dependent hepatotoxicity in rats can be prevented by treatment with L2-oxothiazolidine-4-carboxylic acid (OTC, a prodrug that maintains glutathione levels and thus reduces ROS) (Iimuro, et al. 2000). Ethanol-dependent lipid peroxidation can be prevented by treatment with antioxidants in CYP2E1 over-expressing human HepG2 cells (Wu and Cederbaum 2005). Non-induced or phenobarbital-induced, glutathione-depleted mice treated with $0.5 \mathrm{ml} / \mathrm{kg}$ carbon tetrachloride exhibited increases in liver lipid peroxidation and significant elevation of liver-specific serum enzyme activities (Younes and Siegers 1985). In mice, pre-treatment with the iron-chelating agent desferrioxamine (DFO) suppressed lipid peroxidation and inhibited hepatotoxicity; whereas, depletion of glutathione exacerbated it (Younes and Siegers 1985). Primary rat hepatocytes exhibit a dosedependent increase in thiobarbituric acid reactive substances (TBARS) and increased cytotoxicity following exposure to fumonisin B1 (FB1) (Abel and Gelderblom 1998). However, addition of the antioxidant alphatocopherol significantly decreases cytotoxicity and decreases TBARS to basal levels, supporting the essentiality of lipid peroxidation. Carbon tetrachloride is converted by Cyp2E1 to the trichloromethyl radical, which reacts with oxygen to form the trichloromethyl peroxy radical. The latter initiates lipid peroxidation, which is the main cause of carbon tetrachloride-dependent cytotoxicity (Kadiiska, et al. 2005, Manibusan, et al. 2007, Weber, et al. 2003). Lipid peroxidation has been shown to occur before liver injury and necrosis in rats (Hartley, et al. 1999). Inhibition of lipid peroxidation (using desferrioxamine, an iron chelator) prevents the associated hepatotoxicity; whereas, depletion of glutathione exacerbates it in mice (Younes and Siegers 1985). Another study that tested both carbon tetrachloride and chloroform found that cytotoxicity only occurred at doses at which glutathione was depleted in human HepG2 cells (Beddowes, et al. 2003). Male Wistar rats exposed for one month to $35 \%$ ethanol had abasic 
sites, Ogg1-sensitive sites, and increased expression of BER genes in liver DNA; this ROS-dependent DNA damage occurs at earlier time points than the corresponding carcinogenesis. Importantly, when this experiment was repeated in wild type, humanized Cyp2E1 (hCyp2E1), and Cyp2E1-null mice, wild type and hCyp2E1 mice had similar responses to ethanol: increased Cyp2E1 protein levels, increased expression of BER genes, and an increase in abasic sites; whereas, Cyp2E1-null mice had no oxidative or DNA damage phenotype (Bradford, et al. 2005).

Cytototoxicity is known (and needs) to occur before regenerative proliferation. Molecular signals that are released from dying cells trigger regenerative proliferation of existing cells. AP-1 (particularly the c-Jun monomer) and NFkappaB are important transcription factors for this signaling pathway. Both are up-regulated following partial hepatectomy and are required for hepatic regeneration. Rodents lacking either of these transcription factors display impaired liver regeneration, often leading to death (Behrens, et al. 2002, Schrum, et al. 2000). C-Jun and NF-kappaB have also been shown to be required for normal liver development and loss of function in either molecule is embryonic lethal due to impaired liver development (Hilberg, et al. 1993, Jochum, et al. 2001, Rudolph, et al. 2000).

Wild type and humanized Cype2E1 knock-in mice have dose-dependent increases in Cyp2E1 protein and activity levels when exposed to ethanol, whereas Cyp2E1 knock-out mice do not. Further, the humanized mice show the largest increases in necrosis, inflammation, Aspartate-aminotransferase (AST), Alanine-aminotransferase (ALT) and TBARS, and the largest decrease in glutathione (GSH) levels of all three groups ( $\mathrm{Lu}$, et al. 2010).

\section{Uncertainties, inconsistencies, and data gaps:}

The current major uncertainty in this AOP is the mechanistic link between liver regeneration and cancer. There are also agents that are substrates of Cyp2E1 that do not cause liver cancer. For example, acetaminophen is a Cyp2E1 substrate that does not cause cancer (IARC group 3). However, it is a very strong hepatocytotoxicant and oxidant (Hinson, et al. 2010). The extreme cytotoxicity caused by high levels of acetaminophen leads to liver failure and death, which preclude liver regeneration or tumour development. In addition, Cyp2E1 is not uniquely responsible for producing ROS and inflammation in the liver. There are other well-known modes of action that can also produce these effects that may be occurring in parallel with this AOP. For example, ROS production was shown to be driven by inflammatory cytokines (as opposed to Cyp2E1) in non-alcoholic fatty liver disease (NAFLD) and non-alcoholic steatohepatitis (NASH). In this case, hepatocellular carcinoma was driven by the production of carcinogenic exocyclic etheno-DNA adducts (Linhart et al., 2015).

\section{Domain of Applicability}

Life Stage Applicability

\begin{tabular}{|l|l|}
\hline Life Stage & Evidence \\
\hline All life stages & \\
\hline
\end{tabular}

Taxonomic Applicability

\begin{tabular}{|l|l|l|l|}
\hline Term & $\begin{array}{l}\text { Scientific } \\
\text { Term }\end{array}$ & $\begin{array}{l}\text { Evidenc } \\
\text { e }\end{array}$ & Links \\
\hline rodents & rodents & High & $\begin{array}{l}\text { NCBI } \\
\text { (http://www.ncbi.nlm.nih.gov/Taxonomy/Browser/wwwtax.cgi?mode=Info\&i } \\
\text { d=0) }\end{array}$ \\
\hline $\begin{array}{l}\text { Homo } \\
\text { sapiens }\end{array}$ & Homo sapiens & $\begin{array}{l}\text { Moderat } \\
\text { e }\end{array}$ & $\begin{array}{l}\text { NCBI } \\
\text { (http://www.ncbi.nlm.nih.gov/Taxonomy/Browser/wwwtax.cgi?mode=Info\&i } \\
\text { d=9606) }\end{array}$ \\
\hline
\end{tabular}

Sex Applicability

\begin{tabular}{|l|l}
\hline Sex & Evidence \\
\hline
\end{tabular}


This AOP is relevant to animals exposed chronically to chemicals that activate Cyp2E1. Thus, it is relevant during development and through to adulthood. In addition, cancer induced by chemicals thought to operate via this pathway affect both sexes. Studies to support it were conducted primarily in mouse, rat, rabbit, hamster, and immortalized human hepatoma cells.

While this AOP appears to be relevant in both sexes (the Moser et al. 2009 was done in female mice and the NTP 1993 cancer bioassay was done in both genders), a recent study has suggested that male mice might be more sensitive to the Cyp2E1-dependent oxidative stress causing cancer mode of action (Wang, et al. 2015). The ability of estrogen to inhibit IL-6 has been identified as an important factor (Naugler, et al. 2007). Gender differences in furan- dependent gene expression were also reported in furan-exposed rats (Dong, et al. 2015).

The evidence for this AOP is primarily derived from rodent models. Human cells in culture were also used in some investigations, demonstrating a link between ROS, cytotoxicity and genotoxicity. Humanized Cyp2E1 (hCyp2E1) mice have been used to demonstrate relevance to humans for progression from MIE and oxidative stress (Bradford, et al. 2005). There is an association between ROS and liver cancer in humans (Poungpairoj, et al. 2015, Wang, et al. 2016a). A variety of lines of evidence support the relationship between oxidative stress with the development and progression of hepatocellular carcinoma. For example, reduced superoxide dismutase 2 (an antioxidant gene) mRNA and protein expression is associated with mortality of hepatocellular carcinoma patients in a mutant p53dependent manner (Wang, et al. 2016a). This decrease in expression is accompanied by decreased copy number of the gene in tumours, supporting a genetic basis for the molecular phenotype. Plasma protein carbonyl content (biomarker of oxidative stress) is significantly higher, whereas plasma Total Antioxidant Capacity (TAC) (biomarker of antioxidant capacity) is significantly lower in Hepatocellular Carcinoma (HCC) patients than healthy controls (Poungpairoj, et al. 2015).

\section{Essentiality of the Key Events}

Studies in Cyp2E1 knockout mice include: carbon tetrachloride (Wong, et al. 1998), acetone (Bondoc, et al. 1999), benzene (Powley and Carlson 2001), thioacetamide (Chilakapati, et al. 2007), trichloroethylene (Kim and Ghanayem 2006), acrylonitrile (El Hadri, et al. 2005), urethane (Hoffler, et al. 2003, Hoffler and Ghanayem 2005), acetaminophen (Lee, et al. 1996, Zaher, et al. 1998), and ethanol (Bardag-Gorce, et al. 2000).

Cyp2E1 constitutive activation and inhibition in Sprague-Dawley rat liver in the context of diethylnitrosamineinduced hepatocarcinogenesis (DEN) exposure is described by Gao et al. (2018a, 2018b).

The effects of ethanol exposure on the liver are well studied. The role of chronic alcohol exposure leading to inflammation, oxidative stress and DNA damage, and cancer is reviewed by Song et al. (2019). The role of Cyp2E1 in ethanol metabolism leading to the production of ROS, which contribute to carcinogenesis, is explored in Seitz and Mueller (2019). The associated etheno DNA adducts are described in Mueller et al. (2018) and Peccerella et al. (2018).

\section{Weight of Evidence Summary}

\section{Extent of Biological Plausibility of each KER}

Defining question: Is there a mechanistic (e.g., structural or functional) relationship between KE-up and KE-down consistent with established biological knowledge? 
Strong: Extensive

understanding of the KER

based on extensive

previous documentation

and broad acceptance (e.g.,

mutations leads to

tumours); Established

mechanistic basis
Moderate: The KER is

plausible based on analogy

to accepted biological

relationships, but scientific

understanding is not

completely

established
Weak: there is empirical support for a statistical association between KEs, but the structural or functional relationship between them is not understood.

Table 1: Support for biological plausibility of KERs

\begin{tabular}{|c|c|c|}
\hline Adjacent KER 1 & $\begin{array}{l}\text { MIE-->KE1: } \\
\text { Activation of } \\
\text { Cyp2E1 leading } \\
\text { to oxidative } \\
\text { stress }\end{array}$ & $\begin{array}{l}\text { Level of Support: Strong } \\
\text { Mechanism: It is well known that uncoupling of Cyp2E1 catalytic cycle } \\
\text { results in the release of harmful reactive oxygen species in the cell. }\end{array}$ \\
\hline Adjacent KER2 & $\begin{array}{l}\text { KE1-->KE2: } \\
\text { Oxidative stress } \\
\text { leading to } \\
\text { cytotoxicity }\end{array}$ & $\begin{array}{l}\text { Level of Support: Strong. } \\
\text { Mechanism: Cellular oxidative damage, especially by lipid peroxidation, } \\
\text { leads to cell death. The mechanisms linking these events are well defined. }\end{array}$ \\
\hline Adjacent KER3 & $\begin{array}{l}\text { KE2-->KE3: } \\
\text { Hepatotoxicity } \\
\text { leading to } \\
\text { sustained cellular } \\
\text { proliferation }\end{array}$ & $\begin{array}{l}\text { Level of Support: Strong. } \\
\text { Mechanism: It is well established that liver cells will proliferate to replace dead } \\
\text { cells following chemical or surgical injury. }\end{array}$ \\
\hline $\begin{array}{l}\text { Non- adjacent } \\
\text { KER1 }\end{array}$ & $\begin{array}{l}\text { MIE-->KE2: } \\
\text { Activation of } \\
\text { Cyp2E1 leading } \\
\text { to hepatotoxicity }\end{array}$ & $\begin{array}{l}\text { Level of Support: Strong. } \\
\text { Mechanism: Metabolite-dependent toxicity is a well known side-effect of } \\
\text { cytochrome P450 mono-oxygenase metabolism of xenobiotics in the liver. }\end{array}$ \\
\hline $\begin{array}{l}\text { Non- adjacent } \\
\text { KER2 }\end{array}$ & $\begin{array}{l}\text { KE1-->AO: } \\
\text { Oxidative stress } \\
\text { leading to liver } \\
\text { cancer }\end{array}$ & $\begin{array}{l}\text { Level of Support: Moderate. } \\
\text { Mechanism: ROS-dependent DNA damage causing harmful mutations is } \\
\text { known to occur. It is also well known that DNA mutations can lead to } \\
\text { cancer. However, the mechanism by which the specific mutations generated } \\
\text { in this context promote malignant transformation is incompletely } \\
\text { understood. }\end{array}$ \\
\hline $\begin{array}{l}\text { Non- adjacent } \\
\text { KER3 }\end{array}$ & $\begin{array}{l}\text { KE2-->AO: } \\
\text { Hepatotoxicity } \\
\text { leading to liver } \\
\text { cancer }\end{array}$ & $\begin{array}{l}\text { Level of Support: Moderate. } \\
\text { Mechanism: Cell death by necrosis and necroptosis produces damage- } \\
\text { associated molecular patterns (DAMPs) that trigger inflammation. } \\
\text { Inflammation is widely considered to be an important risk factor that sets } \\
\text { the stage for malignant transformation; however, mechanistically, it is } \\
\text { unclear how it does so. }\end{array}$ \\
\hline $\begin{array}{l}\text { Non- adjacent } \\
\text { KER4 }\end{array}$ & $\begin{array}{l}\text { KE3-->AO: } \\
\text { Sustained } \\
\text { cellular } \\
\text { proliferation } \\
\text { leading to liver } \\
\text { cancer }\end{array}$ & $\begin{array}{l}\text { Level of Support: Strong. } \\
\text { Mechanism: Highly dividing cells are at greater risk of obtaining and fixing } \\
\text { a mutation. If appropriately placed in the genome, such a mutation can } \\
\text { facilitate the malignant transformation of the cell. }\end{array}$ \\
\hline
\end{tabular}


Defining question: Are downstream KEs and/or the AO prevented is an upstream KE is blocked?

\begin{tabular}{|c|c|c|}
\hline $\begin{array}{l}\text { Strong: Direct } \\
\text { evidence from } \\
\text { specifically designed } \\
\text { experimental studies } \\
\text { illustrating essentiality } \\
\text { for at least one of the } \\
\text { important KEs (e.g., } \\
\text { stop/reversibility } \\
\text { studies, antagonism, } \\
\text { knock out models, etc.) }\end{array}$ & $\begin{array}{l}\text { Moderate: Indirect } \\
\text { evidence that sufficient } \\
\text { modification of an expected } \\
\text { modulating factor } \\
\text { attenuates or augments a } \\
\text { KE (e.g., augmentation of } \\
\text { proliferative response } \\
\text { (KEup) leading to increase } \\
\text { in KEdown or AO). }\end{array}$ & $\begin{array}{l}\text { Weak: No or contradictory experimental evidence of the } \\
\text { essentiality of any of the KEs. }\end{array}$ \\
\hline
\end{tabular}

Table 2: Support for essentiality of KEs.

\begin{tabular}{|c|c|}
\hline MIE: Activation of Cyp2E1. Strong. & Refs. \\
\hline $\begin{array}{l}\text { MIE-->KE1: Hydrogen peroxide production and lipid peroxidation are } \\
\text { blocked in rat microsomes following inhibition of Cyp2E1 with an anti- } \\
\text { Cyp2E1 antibody. }\end{array}$ & $\begin{array}{l}\text { (Ekstrom and } \\
\text { Ingelman- Sundberg } \\
\text { 1989) }\end{array}$ \\
\hline $\begin{array}{l}\text { MIE-->KE1,KE2,KE3 (furan): ROS increase following furan exposure, } \\
\text { which can be inhibited in a dose-dependent way by apigenin (a secondary } \\
\text { plant pigment). Mouse lymphoma cells can tolerate exposure to furan at } \\
\text { extremely high doses (up to } 3100 \mathrm{uM} \text { ) without experiencing cytotoxicity; } \\
\text { however, cells experiences } 50 \% \text { mortality at much lower concentrations ( } 50 \\
\text { uM) of furan's primary metabolite, BDA. Therefore, cytotoxicity observed } \\
\text { following exposure to furan is caused by BDA (not furan), which is produced } \\
\text { by Cyp2E1. In addition, in vivo hepatotoxicity and cellular proliferation } \\
\text { following furan exposure can be prevented by treatment with a cytochrome } \\
\text { P450 inhibitor (ABT). }\end{array}$ & $\begin{array}{l}\text { (Fransson- Steen, et al. } \\
\text { 1997, Kellert, et al. } \\
\text { 2008, Wang, et al. } \\
2014 \text { ) }\end{array}$ \\
\hline $\begin{array}{l}\text { MIE-->KE1, KE2 (carbon tetrachloride): Cytotoxicity and lipid peroxidation } \\
\text { are prevented in rats and mice by pre-treatment with cytochrome P450 } \\
\text { inhibitors (colchicine or SKF-525A). Cytotoxicity is exacerbated in cell lines } \\
\text { that over-express Cyp2E1. Wild-type mice exposed to carbon tetrachloride } \\
\text { experience increases in hepatotoxicity and associated liver pathologies; these } \\
\text { do not occur in Cyp2E1-null mice. }\end{array}$ & $\begin{array}{l}\text { (Bechtold, et al. 1982, } \\
\text { Letteron, et al. 1990, } \\
\text { Martinez, et al. 1995, } \\
\text { Mourelle, et al. 1989, } \\
\text { Takahashi, et al. 2002) }\end{array}$ \\
\hline $\begin{array}{l}\text { MIE-->KE2, KE3 (chloroform): Cyp2E1-null mice do not experience } \\
\text { chloroform-dependent hepatotoxicity or subsequent increases in cellular } \\
\text { proliferation. }\end{array}$ & (Constan, et al. 1999) \\
\hline \multicolumn{2}{|l|}{ KE1: Oxidative stress. Strong. } \\
\hline $\begin{array}{l}\text { KE1-->KE2 (carbon tetrachloride): Treatment of mice with an anti-oxidant } \\
\text { (silymarin) prevents lipid peroxidation. Depletion of glutathione (by dithyl } \\
\text { maleate, DEM) leads to an increase in lipid peroxidation in carbon } \\
\text { tetrachloride fed rats. }\end{array}$ & $\begin{array}{l}\text { (Bechtold, et al. 1982, } \\
\text { Letteron, et al. 1990) }\end{array}$ \\
\hline
\end{tabular}


KE1-->KE2, AO (ethanol): Levels of glutathione, ROS and lipid peroxidation are higher in HepG2 cells that stably over-express Cyp2E1 compared to wild-type HepG2 cells (that do not express Cyp2E1); glutathione depletion using buthionine sulfoximine (BSO), thioredoxin knock-down, or ethanol exposure in E47 cells results in elevated cytotoxicity, which does not occur in wild-type HepG2 cells. Apoptotic phenotype in ethanol treated HepG2-Cyp2E1 cells can be rescued by treatment with 4-MP (a cyp2e1 inhibitor), trolox (an antioxidant), or a caspase inhibitor. Rats exposed to ethanol present with time-dependent increases in cytotoxicity and inflammation, which can be blocked by treatment with OTC (a compound that sustains glutathione levels). Wild type and hCyp2E1 mice present with oxidative DNA adducts, which do not occur in Cyp2E1-null mice.

KE1-->KE2 (chloroform): A study in rats showed that cytotoxicity only occurs at doses that are sufficient to deplete glutathione.

\section{KE2: Hepatotoxicity}

Weak. We are not aware of any experiments that have specifically blocked cytotoxicity following chemical exposure.

\section{KE3: Sustained or persistent proliferation}

Moderate. It is well understood that cellular proliferation is a precursor to cancer; however, a better understanding of the molecular signals involved is required to experimentally demonstrate this using knock-down or knock-out models.

Rodents lacking AP-1 or NF-kappaB display impaired liver regeneration, often leading to death.

In TNF receptor type 1 knockout mice and JNK-1 knockout mice, cellular proliferation was impaired, accompanying by decreased liver carcinogenesis (Knight et al., 2000; Hui et al., 2008). In the JNK-1 knockout mice, genetic inactivation of $\mathrm{p} 21$ restored hepatocyte proliferation and also liver carcinogenesis (Hui et al. 2008). Conversely, there is evidence suggesting that sustained proliferation is not the only mechanism by which preneoplastic cells gain selective growth advantage in the liver; for example, inhibition of cell loss/cell growth can also contribute to altered homeostasis (e.g., Melnick and Huff (1993)).
(Bradford, et al. 2005, Iimuro, et al. 2000, $\mathrm{Wu}$ and Cederbaum 1996, Yang, et al. 2011)

(Beddowes, et al. 2003)

(Behrens, et al. 2002, Schrum, et al. 2000)

(Knight et al., 2000; Hui et al., 2008; Melnick and Huff, 1993).

\section{Extent of Empirical Support for each KER}

Defining question 1: Does the empirical evidence support that a change in KE-up leads to an appropriate change in KE-down? Does KE-up occur at a lower dose and earlier time-point than KE-down? Is the incidence of KE-up $>$ than KE-down?

Defining question 2: Are there inconsistencies in the empirical support across taxa, species, and stressors that don't align with the expected pattern for hypothesized AOP? 


\begin{tabular}{|c|c|c|}
\hline $\begin{array}{l}\text { Strong: } \\
\text { studies } \\
\text { dependent change ing } \\
\text { both events following } \\
\text { exposure to a wide } \\
\text { range of specific } \\
\text { stressors (extensive } \\
\text { evidence for temporal, } \\
\text { dose- response, and } \\
\text { incidence concordance) } \\
\text { and or few critical data } \\
\text { gaps or conflicting data }\end{array}$ & $\begin{array}{l}\text { Moderate: Demonstrated } \\
\text { dependent change in both events } \\
\text { following exposure to a small } \\
\text { number of specific stressors and } \\
\text { some evidence inconsistent with } \\
\text { expected pattern that can be } \\
\text { explained by factors such as } \\
\text { experimental design, technical } \\
\text { considerations, differences among } \\
\text { labs, etc. }\end{array}$ & $\begin{array}{l}\text { Weak: limited or no studies reporting } \\
\text { dependent change in both events following } \\
\text { exposure to a specific stressor (ie, endpoints } \\
\text { never measured in the same study or not at } \\
\text { all); and/or significant inconsistencies in } \\
\text { empirical support across taxa and species that } \\
\text { don't align with expected pattern for } \\
\text { hypothesized AOP }\end{array}$ \\
\hline
\end{tabular}

Table 3: Empirical support for KERs.

\begin{tabular}{|c|c|c|}
\hline Adjacent KER1 & $\begin{array}{l}\text { MIE-->KE1: } \\
\text { Activation ofCyp2E1 leading to } \\
\text { oxidative stress }\end{array}$ & $\begin{array}{l}\text { Level of Support: Strong. } \\
\text { Defining question 1: There is extensive } \\
\text { evidence in hepatic cell lines and rodent } \\
\text { models that demonstrates that when Cyp2E1 is } \\
\text { active there is an increase in oxidative stress, } \\
\text { particularly lipid peroxidation. The doses at } \\
\text { which the effects are measured are concordant. } \\
\text { Further, when Cyp2E1 substrate is present, } \\
\text { Cyp2E1 protein levels increase. } \\
\text { Defining question 2: There are no } \\
\text { contradictions to the proposed KER in the } \\
\text { literature. }\end{array}$ \\
\hline Adjacent KER2 & $\begin{array}{l}\text { KE1-->KE2: } \\
\text { Oxidative stress leading to } \\
\text { hepatotoxicity }\end{array}$ & $\begin{array}{l}\text { Level of Support: Strong. } \\
\text { Defining question 1: It is clear that oxidative } \\
\text { stress and cytotoxicity are downstream of } \\
\text { Cyp2E1 activation (occur later and at higher } \\
\text { doses). It is also known that oxidative stress is } \\
\text { harmful to cells and, in extreme cases, causes } \\
\text { loss of cell viability. } \\
\text { Defining question 2: There are no } \\
\text { contradictions to the proposed KER in the } \\
\text { literature. }\end{array}$ \\
\hline Adjacent KER3 & $\begin{array}{l}\text { KE2-->KE3: } \\
\text { Hepatotoxicity leading to cellular } \\
\text { proliferation }\end{array}$ & $\begin{array}{l}\text { Level of Support: Strong. } \\
\text { Defining question 1: That hepatotoxicity } \\
\text { leads to cellular proliferation has been } \\
\text { demonstrated for a number of liver toxicants } \\
\text { (as well as surgical resection of the liver). } \\
\text { Increased regenerative proliferation occurs } \\
\text { following toxicity, and at higher doses than } \\
\text { the cytotoxicity. }\end{array}$ \\
\hline
\end{tabular}




\begin{tabular}{|c|c|c|}
\hline & & $\begin{array}{l}\text { Defining question 2: We are not aware of } \\
\text { any instance in which an injured liver (that is } \\
\text { genetically normal) will not regenerate itself. }\end{array}$ \\
\hline Non- adjacent KER1 & $\begin{array}{l}\text { MIE-->KE2: } \\
\text { Activation of Cyp2E1 leading to } \\
\text { hepatotoxicity }\end{array}$ & $\begin{array}{l}\text { Level of Support: Strong. } \\
\text { Defining question 1: There is a large amount } \\
\text { of published data that demonstrate the cytotoxic } \\
\text { effects of Cyp2E1 substrates following } \\
\text { metabolic activation. } \\
\text { Defining question 2: While the prevailing } \\
\text { opinion in the literature is that the toxicity of } \\
\text { these metabolites is the result of non- genotoxic } \\
\text { mechanisms, there are studies that argue in } \\
\text { favour of direct genotoxic effects. It is widely } \\
\text { thought that any observed genotoxicity is } \\
\text { actually 'indirect' and is the product of } \\
\text { oxidative stress. }\end{array}$ \\
\hline Non- adjacent KER2 & $\begin{array}{l}\text { KE1-->AO: } \\
\text { Oxidative stress leading to liver cancer }\end{array}$ & $\begin{array}{l}\text { Level of Support: Weak. } \\
\text { Defining question 1: Carcinogens that cause } \\
\text { cancer by 'cytotoxicity and regenerative } \\
\text { proliferation' are generally accepted to be } \\
\text { indirectly genotoxic. The most realistic source } \\
\text { of indirect genotoxicity for these compounds } \\
\text { are reactive oxygen species. } \\
\text { Defining question 2: An alternative } \\
\text { mechanism-that is not mutually exclusive to the } \\
\text { 'defining question 1'-is that the } \\
\text { transcriptional actions of chronic Nrf2 } \\
\text { activation provide a molecular environment that } \\
\text { promotes malignant transformation. }\end{array}$ \\
\hline Non- adjacent KER3 & $\begin{array}{l}\text { KE2-->AO: } \\
\text { Cytotoxicity leading to liver cancer }\end{array}$ & $\begin{array}{l}\text { Level of Support: Moderate. } \\
\text { Defining question 1: Published studies } \\
\text { support the idea that inflammation (caused by } \\
\text { cellular necrosis and necroptosis) proceeds and } \\
\text { somehow facilitates malignant transformation. } \\
\text { Defining question 2: } \\
\text { That inflammation precedes liver cancer } \\
\text { appears to be consistent across studies. The } \\
\text { contradictory nature of NF-kappaB's role in } \\
\text { carcinogenesis remains under active } \\
\text { investigation. } \\
\text { This relationship appears to be valid for } \\
\text { toxicants that produce moderate levels of } \\
\text { cytotoxicity. Acetaminophen is a Cyp2E1 } \\
\text { substrate that produces extremely high levels of } \\
\text { hepatotoxicity. Acetaminophen does not cause } \\
\text { liver cancer because death by liver failure } \\
\text { occurs before cancer can develop. }\end{array}$ \\
\hline
\end{tabular}




\begin{tabular}{|l|l|l|}
\hline Non- adjacent KER4 & $\begin{array}{l}\text { Level of Support: Moderate } \\
\text { Defining question 1: There is extensive evidence that an increase in } \\
\text { cellular proliferation precedes tumour formation. } \\
\text { Defining question 2: Not all cases of increased cellular proliferation } \\
\text { produce tumours (some simply regenerate the liver to its healthy form). } \\
\text { Sustained or } \\
\text { persistent } \\
\text { cellular } \\
\text { proliferation } \\
\text { leading to liver } \\
\text { cancer }\end{array}$ & $\begin{array}{l}\text { Therefore, it is evident that malignant transformation is accompanied by } \\
\text { perturbations in cellular signaling that ultimately impair tissue } \\
\text { homeostasis and normal regenerative processes. }\end{array}$ \\
\hline
\end{tabular}

\section{Quantitative Consideration}

Degree of Quantitative Understanding of each KER

Dose-response, temporal and incidence concordance for furan in mouse (unless otherwise specified).

\begin{tabular}{|c|c|c|c|c|c|}
\hline & MIE & KE1 & KE2 & KE3 & $\mathrm{AO}$ \\
\hline \multicolumn{6}{|c|}{ Dose (mkd) } \\
\hline In vitro & $\begin{array}{l}\text { Studies in mouse, } \\
\text { rat and human } \\
\text { hepatocytes d,e }\end{array}$ & & & & \\
\hline 0.5 & & & $(3 \text { weeks })^{-}$ & ${ }^{-}$ & \\
\hline 1 & & & $\begin{array}{c}+ \\
(3 \text { weeks })^{\text {a }}\end{array}$ & $(3 \text { weeks })^{-}$ & $(2 \text { years })^{-}$ \\
\hline 2 & & & $\begin{array}{r}+ \\
(3 \text { weeks })^{\text {a }}\end{array}$ & $(3 \text { weeks })^{-}$ & $(2 \text { years })^{-}$ \\
\hline 4 & & $\begin{array}{c}+ \\
(4 \text { days })^{g} \\
\text { (rat) }\end{array}$ & $\begin{array}{c}++ \\
(3 \text { weeks })^{a}\end{array}$ & $\begin{array}{c}- \\
(3 \text { weeks })^{a}\end{array}$ & $\begin{array}{c}+ \\
(2 \text { years })^{\text {a }}\end{array}$ \\
\hline 8 & & $\begin{array}{c}++ \\
(4 \text { days })^{\mathrm{g}} \\
(\text { rat }) \\
---- \\
+ \\
(7 \text { days })^{\mathrm{c}}\end{array}$ & $\begin{array}{c}+++ \\
(3 \text { weeks })^{a}\end{array}$ & $\begin{array}{c}+ \\
(3 \text { weeks })^{\mathrm{a}} \\
--------- \\
+++ \\
(2 \text { years })^{\mathrm{b}}\end{array}$ & $\begin{array}{c}+{ }^{\mathrm{b}} \\
+++^{\mathrm{a}} \\
(2 \text { years }\end{array}$ \\
\hline 12 & & $\begin{array}{c}++ \\
(4 \text { days })^{g} \\
(\text { rat })\end{array}$ & & & \\
\hline 15 & & $\begin{array}{c}++ \\
(4 \text { days })^{g} \\
(\text { rat; } 16 \mathrm{mkd})\end{array}$ & $\begin{array}{c}+ \\
(90 \text { days })^{b} \\
-----\end{array}$ & $\begin{array}{c}- \\
(90 \text { days })^{b} \\
-----\end{array}$ & $\begin{array}{c}+++ \\
(2 \text { years })^{b}\end{array}$ \\
\hline
\end{tabular}




\begin{tabular}{|c|c|c|c|c|}
\hline & & & $\begin{array}{c}+++ \\
(2 \text { years })^{b}\end{array}$ & $\begin{array}{c}+++ \\
(2 \text { years })^{b}\end{array}$ \\
\hline 30 & $\begin{array}{c}++ \\
(8 \mathrm{hr}, 1 \text { day })^{\mathrm{f}} \\
\text { (rat) }\end{array}$ & $\begin{array}{c}++ \\
(8 \mathrm{hr})^{\mathrm{f}} \\
\text { (rat) }\end{array}$ & $\begin{array}{c}+++ \\
\text { (90 days) }\end{array}$ & $\begin{array}{c}++ \\
\text { (90 days) }\end{array}$ \\
\hline 60 & & & $\begin{array}{c}+++ \\
(90 \text { days })^{b}\end{array}$ & $\begin{array}{c}+++ \\
(90 \text { days })^{b}\end{array}$ \\
\hline
\end{tabular}

Studies: a (Moser, et al. 2009); b (NTP 1993); c (Wang, et al. 2014); d (Kedderis, et al. 1993); e (Kedderis and Held 1996); f (Hickling, et al. 2010); g (Ding, et al. 2012).

\section{Considerations for Potential Applications of the AOP (optional)}

The events described in this AOP will be useful to scientists and regulators who are interested in non- or indirectly genotoxic compounds that cause liver cancer through the cytotoxicity and sustained/persistent cellular proliferation mode of action. This group of compounds is challenging to assess because they produce negative or equivocal results in short-term genotoxicity tests, which are typically used as a first-pass screen for carcinogenicity. Therefore, this AOP that describes sets of assays that can be used to determine if compound acts via this mode of action and evaluate the weight of evidence. HCC has been used as an adverse endpoint in many hazard assessments that can be used as input to risk management decisions. The U.S. EPA Integrated Risk Information System (IRIS database) contains 111 instances wherein $\mathrm{HCC}$ has been considered in hazard assessment of environmental contaminants. For example, $\mathrm{HCC}$ in rats formed part of the weight of evidence in categorizing polychlorinated biphenyls as probable human carcinogens. These tumours, combined with other liver tumours, also formed the basis for quantitative dose-response assessment for cancer induced by polychlorinated biphenyls by the oral route (USEPA, 2014).

\section{References}

Abel, S., Gelderblom, W.C., 1998. Oxidative damage and fumonisin B1-induced toxicity in primary rat hepatocytes and rat liver in vivo. Toxicology 131, 121-131.

Bardag-Gorce, F., Yuan, Q.X., Li, J., French, B.A., Fang, C., Ingelman-Sundberg, M., French, S.W., 2000. The effect of ethanol-induced cytochrome p4502E1 on the inhibition of proteasome activity by alcohol. Biochem. Biophys. Res. Commun. 279, 23-29.

Bechtold, M.M., Gee, D.L., Bruenner, U., Tappel, A.L., 1982. Carbon tetrachloride-mediated expiration of pentane and chloroform by the intact rat: the effects of pretreatment with diethyl maleate, SKF-525A and phenobarbital. Toxicol. Lett. 11, 165-171.

Beddowes, E.J., Faux, S.P., Chipman, J.K., 2003. Chloroform, carbon tetrachloride and glutathione depletion induce secondary genotoxicity in liver cells via oxidative stress. Toxicology 187, 101-115.

Behrens, A., Sibilia, M., David, J.P., Möhle-Steinlein, U., Tronche, F., Schütz, G., Wagner, E.F., 2002. Impaired postnatal hepatocyte proliferation and liver regeneration in mice lacking c-jun in the liver. EMBO J. 21, 1782-1790.

Bondoc, F.Y., Bao, Z., Hu, W.Y., Gonzalez, F.J., Wang, Y., Yang, C.S., Hong, J.Y., 1999. Acetone catabolism by cytochrome P450 2E1: studies with CYP2E1-null mice. Biochem. Pharmacol. 58, 461-463. 
Bradford, B.U., Kono, H., Isayama, F., Kosyk, O., Wheeler, M.D., Akiyama, T.E., Bleye, L., Krausz, K.W., Gonzalez, F.J., Koop, D.R., Rusyn, I., 2005. Cytochrome P450 CYP2E1, but not nicotinamide adenine dinucleotide phosphate oxidase, is required for ethanol-induced oxidative DNA damage in rodent liver. Hepatology 41, 336-344.

Brenner, C., Galluzzi, L., Kepp, O., Kroemer, G., 2013. Decoding cell death signals in liver inflammation. J. Hepatol. 59, 583-594.

Caro, A.A., Cederbaum, A.I., 2004. Oxidative stress, toxicology, and pharmacology of CYP2E1. Annu. Rev. Pharmacol. Toxicol. 44, 27-42.

Cederbaum, A.I., Yang, L., Wang, X., Wu, D., 2012. CYP2E1 Sensitizes the Liver to LPS- and TNF alpha-Induced Toxicity via Elevated Oxidative and Nitrosative Stress and Activation of ASK-1 and JNK Mitogen-Activated Kinases. Int. J. Hepatol. 2012, 582790.

Chilakapati, J., Korrapati, M.C., Shankar, K., Hill, R.A., Warbritton, A., Latendresse, J.R., Mehendale, H.M., 2007. Role of CYP2E1 and saturation kinetics in the bioactivation of thioacetamide: Effects of diet restriction and phenobarbital. Toxicol. Appl. Pharmacol. 219, 72-84.

Constan, A.A., Sprankle, C.S., Peters, J.M., Kedderis, G.L., Everitt, J.I., Wong, B.A., Gonzalez, F.L., Butterworth, B.E., 1999. Metabolism of chloroform by cytochrome P450 2E1 is required for induction of toxicity in the liver, kidney, and nose of male mice. Toxicol. Appl. Pharmacol. 160, 120-126.

Ding, W., Petibone, D.M., Latendresse, J.R., Pearce, M.G., Muskhelishvili, L., White, G.A., Chang, C.-., Mittelstaedt, R.A., Shaddock, J.G., McDaniel, L.P., Doerge, D.R., Morris, S.M., Bishop, M.E., Manjanatha, M.G., Aidoo, A., Heflich, R.H., 2012. In vivo genotoxicity of furan in F344 rats at cancer bioassay doses. Toxicol. Appl. Pharmacol. 261, 164-171.

Dong, H., Gill, S., Curran, I.H., Williams, A., Kuo, B., Wade, M.G., Yauk, C.L., 2015. Toxicogenomic assessment of liver responses following subchronic exposure to furan in Fischer F344 rats. Arch. Toxicol.

Ekstrom, G., Ingelman-Sundberg, M., 1989. Rat liver microsomal NADPH-supported oxidase activity and lipid peroxidation dependent on ethanol-inducible cytochrome P-450 (P-450IIE1). Biochem. Pharmacol. 38, 1313-1319.

El Hadri, L., Chanas, B., Ghanayem, B.I., 2005. Comparative metabolism of methacrylonitrile and acrylonitrile to cyanide using cytochrome P4502E1 and microsomal epoxide hydrolase-null mice. Toxicol. Appl. Pharmacol. 205, 116- 125.

Fransson-Steen, R., Goldsworthy, T.L., Kedderis, G.L., Maronpot, R.R., 1997. Furan-induced liver cell proliferation and apoptosis in female B6C3F1 mice. Toxicology 118, 195-204.

Furfaro, A.L., Traverso, N., Domenicotti, C., Piras, S., Moretta, L., Marinari, U.M., Pronzato, M.A., Nitti, M., 2016. The Nrf2/HO-1 Axis in Cancer Cell Growth and Chemoresistance. Oxid Med. Cell. Longev 2016, 1958174.

Gao J, Wang Z, Wang GJ, Zhang HX, Gao N, Wang J, Wang CE, Chang Z, Fang Y, Zhang YF, Zhou J, Jin H, Qiao HL. 2018a. Higher CYP2E1 Activity Correlates with Hepatocarcinogenesis Induced by Diethylnitrosamine. J Pharmacol Exp Ther. 365(2):398-407.

Gao J, Wang Z, Wang GJ, Gao N, Li J, Zhang YF, Zhou J, Zhang HX, Wen Q, Jin H, Qiao HL. 2018b. Hepatofibrosis to hepatocarcinogenesis: Higher cytochrome P450 2E1 activity is a potential risk factor. Mol Carcinog. 57(10):1371- 1382.

Hartley, D.P., Kolaja, K.L., Reichard, J., Petersen, D.R., 1999. 4-Hydroxynonenal and malondialdehyde hepatic protein adducts in rats treated with carbon tetrachloride: immunochemical detection and lobular localization. Toxicol. Appl. Pharmacol. 161, 23-33.

Hickling, K.C., Hitchcock, J.M., Oreffo, V., Mally, A., Hammond, T.G., Evans, J.G., Chipman, J.K., 2010. Evidence of oxidative stress and associated DNA damage, increased proliferative drive, and altered gene expression in rat liver produced by the cholangiocarcinogenic agent Furan. Toxicol. Pathol. 38, 230-243. 
Hilberg, F., Aguzzi, A., Howells, N., Wagner, E.F., 1993. c-Jun is essential for normal mouse development and hepatogenesis. Nature 365, 179-181.

Hinson, J.A., Roberts, D.W., James, L.P., 2010. Mechanisms of acetaminophen-induced liver necrosis. Handb. Exp. Pharmacol. (196):369-405. doi, 369-405.

Hoffler, U., El-Masri, H.A., Ghanayem, B.I., 2003. Cytochrome P450 2E1 (CYP2E1) is the principal enzyme responsible for urethane metabolism: comparative studies using CYP2E1-null and wild-type mice. J. Pharmacol. Exp. Ther. 305, 557-564.

Hoffler, U., Ghanayem, B.I., 2005. Increased bioaccumulation of urethane in CYP2E1-/- versus CYP2E1+/+ mice. Drug Metab. Dispos. 33, 1144-1150.

Hui L, Zatloukal K, Scheuch H, Stepniak E, Wagner EF. 2008. Proliferation of human HCC cells and chemically induced mouse liver cancers requires JNK1-dependent p21 downregulation. J Clin Invest. 118(12):3943-53.

Iimuro, Y., Bradford, B.U., Yamashina, S., Rusyn, I., Nakagami, M., Enomoto, N., Kono, H., Frey, W., Forman, D., Brenner, D., Thurman, R.G., 2000. The glutathione precursor L-2-oxothiazolidine-4-carboxylic acid protects against liver injury due to chronic enteral ethanol exposure in the rat. Hepatology 31, 391-398.

Jochum, W., Passegué, E., Wagner, E.F., 2001. AP-1 in mouse development and tumorigenesis. Oncogene 20, 2401-2412.

Kadiiska, M.B., Gladen, B.C., Baird, D.D., Germolec, D., Graham, L.B., Parker, C.E., Nyska, A., Wachsman, J.T., Ames, B.N., Basu, S., Brot, N., Fitzgerald, G.A., Floyd, R.A., George, M., Heinecke, J.W., Hatch, G.E., Hensley, K., Lawson, J.A., Marnett, L.J., Morrow, J.D., Murray, D.M., Plastaras, J., Roberts, L.J.,2nd, Rokach, J., Shigenaga, M.K., Sohal, R.S., Sun, J., Tice, R.R., Van Thiel, D.H., Wellner, D., Walter, P.B., Tomer, K.B., Mason, R.P., Barrett, J.C., 2005. Biomarkers of oxidative stress study II: are oxidation products of lipids, proteins, and DNA markers of CCl4 poisoning? Free Radic. Biol. Med. 38, 698-710.

Kedderis, G.L., Carfagna, M.A., Held, S.D., Batra, R., Murphy, J.E., Gargas, M.L., 1993. Kinetic analysis of furan biotransformation by F-344 rats in vivo and in vitro. Toxicology and applied pharmacology 123, 274-282.

Kedderis, G.L., Held, S.D., 1996. Prediction of furan pharmacokinetics from hepatocyte studies: comparison of bioactivation and hepatic dosimetry in rats, mice, and humans. Toxicology and applied pharmacology 140, 124-30.

Kellert, M., Brink, A., Richter, I., Schlatter, J., Lutz, W.K., 2008. Tests for genotoxicity and mutagenicity of furan and its metabolite cis-2-butene-1,4-dial in L5178Y tk+/- mouse lymphoma cells. Mutation research 657, 127-32.

Kim, D., Ghanayem, B.I., 2006. Comparative metabolism and disposition of trichloroethylene in Cyp2e1-/-and wild-type mice. Drug Metab. Dispos. 34, 2020-2027.

Knight B, Yeoh GC, Husk KL, Ly T, Abraham LJ, Yu C, Rhim JA, Fausto N. 2000. Impaired preneoplastic changes and liver tumor formation in tumor necrosis factor receptor type 1 knockout mice. J Exp Med. 192(12):1809-18.

Lee, S.S., Buters, J.T., Pineau, T., Fernandez-Salguero, P., Gonzalez, F.J., 1996. Role of CYP2E1 in the hepatotoxicity of acetaminophen. J. Biol. Chem. 271, 12063-12067.

Letteron, P., Labbe, G., Degott, C., Berson, A., Fromenty, B., Delaforge, M., Larrey, D., Pessayre, D., 1990. Mechanism for the protective effects of silymarin against carbon tetrachloride-induced lipid peroxidation and hepatotoxicity in mice. Evidence that silymarin acts both as an inhibitor of metabolic activation and as a chainbreaking antioxidant. Biochem. Pharmacol. 39, 2027-2034.

Lieber, C.S., 1997. Cytochrome P-4502E1: its physiological and pathological role. Physiol. Rev. 77, 517-544.

Linhart KB, Glassen K, Peccerella T, Waldherr R, Linhart H, Bartsch H, Seitz HK. The generation of carcinogenic etheno-DNA adducts in the liver of patients with nonalcoholic fatty liver disease. Hepatobiliary Surg Nutr. 2015 Apr;4(2):117-23. doi: 10.3978/j.issn.2304-3881.2015.01.14. PMID: 26005678; PMCID: PMC4405412. 
Luedde, T., Kaplowitz, N., Schwabe, R.F., 2014. Cell death and cell death responses in liver disease: mechanisms and clinical relevance. Gastroenterology 147, 765-783.e4.

Ma, Q., He, X., 2012. Molecular basis of electrophilic and oxidative defense: promises and perils of Nrf2. Pharmacol. Rev. 64, 1055-1081.

Manibusan, M.K., Odin, M., Eastmond, D.A., 2007. Postulated carbon tetrachloride mode of action: A review. Journal of Environmental Science and Health - Part C Environmental Carcinogenesis and Ecotoxicology Reviews 25, 185- 209.

Martinez, M., Mourelle, M., Muriel, P., 1995. Protective effect of colchicine on acute liver damage induced by CCl4. Role of cytochrome P-450. J. Appl. Toxicol. 15, 49-52.

Meek, M,.E., Bucher, J.R., Cohen, S.M., Dellarco, V., Hill, R.N., Lehman-McKeeman, L.D., Longfellow, D.G., Pastoor, T., Seed, J., Patton, D.E. 2003, A Framework for Human Relevance Analysis of Information on Carcinogenic Modes of Action, Critical Reviews in Toxicology, 33:6, 591-653.

Melnick RL, Huff J. 1993. Liver carcinogenesis is not a predicted outcome of chemically induced hepatocyte proliferation. Toxicol Ind Health. 9(3):415-38.

Moser, G.J., Foley, J., Burnett, M., Goldsworthy, T.L., Maronpot, R., 2009. Furan-induced dose-response relationships for liver cytotoxicity, cell proliferation, and tumorigenicity (furan-induced liver tumorigenicity). Experimental and Toxicologic Pathology 61, 101-111.

Mourelle, M., Fraginals, R., Rodriguez, L., Favari, L., Perez-Alvarez, V., 1989. Protective effect of colchiceine against acute liver damage. Life Sci. 45, 891-900.

Mueller S, Peccerella T, Qin H, Glassen K, Waldherr R, Flechtenmacher C, Straub BK, Millonig G, Stickel F, Bruckner T, Bartsch H, Seitz HK. 2018. Carcinogenic Etheno DNA Adducts in Alcoholic Liver Disease: Correlation with Cytochrome P-4502E1 and Fibrosis. Alcohol Clin Exp Res. 42(2):252-259.

Naugler, W.E., Sakurai, T., Kim, S., Maeda, S., Kim, K., Elsharkawy, A.M., Karin, M., 2007. Gender disparity in liver cancer due to sex differences in MyD88-dependent IL-6 production. Science 317, 121-124.

Park, W.J., Kim, S.Y., Kim, Y.R., Park, J.W., 2016. Bortezomib alleviates drug-induced liver injury by regulating CYP2E1 gene transcription. Int. J. Mol. Med. 37, 613-622.

Peccerella T, Arslic-Schmitt T, Mueller S, Linhart KB, Seth D, Bartsch H, Seitz HK. 2018. Chronic Ethanol Consumption and Generation of Etheno-DNA Adducts in Cancer-Prone Tissues. Adv Exp Med Biol. 1032:81-92.

Poungpairoj, P., Whongsiri, P., Suwannasin, S., Khlaiphuengsin, A., Tangkijvanich, P., Boonla, C., 2015. Increased Oxidative Stress and RUNX3 Hypermethylation in Patients with Hepatitis B Virus-Associated Hepatocellular Carcinoma (HCC) and Induction of RUNX3 Hypermethylation by Reactive Oxygen Species in HCC Cells. Asian Pac. J. Cancer. Prev. 16, 5343-5348.

Powley, M.W., Carlson, G.P., 2001. Hepatic and pulmonary microsomal benzene metabolism in CYP2E1 knockout mice. Toxicology 169, 187-194.

Rudolph, D., Yeh, W.-., Wakeham, A., Rudolph, B., Nallainathan, D., Potter, J., Elia, A.J., Mak, T.W., 2000. Severe liver degeneration and lack of NF- $\mathrm{kB}$ activation in NEMO/IKK $\gamma$ - deficient mice. Genes and Development $14,854-862$.

Schrum, L.W., Black, D., Iimuro, Y., Rippe, R.A., Brenner, D.A., Behrns, K.E., 2000. c-Jun does not mediate hepatocyte apoptosis following NFKB inhibition and partial hepatectomy. J. Surg. Res. 88, 142-149.

Seitz HK, Mueller S. 2019. The role of Cytochrom P4502E1 in Alcoholic Liver Disease and alcohol mediated carcinogenesis. Z Gastroenterol. 57(1):37-45.

Smith, M.T., Guyton, K.Z., Gibbons, C.F., Fritz, J.M., Portier, C.J., Rusyn, I., DeMarini, D.M., Caldwell, J.C., Kavlock, R.J., Lambert, P., Hecht, S.S., Bucher, J.R., Stewart, B.W., Baan, R., Cogliano, V.J., Straif, K., 2015. 
Key Characteristics of Carcinogens as a Basis for Organizing Data on Mechanisms of Carcinogenesis. Environ. Health Perspect.

Smith, M.T., Loveridge, N., Wills, E.D., Chayen, J., 1979. The distribution of glutathione in the rat liver lobule. Biochem. J. 182, 103-108.

Sporn, M.B., Liby, K.T., 2012. NRF2 and cancer: the good, the bad and the importance of context. Nat. Rev. Cancer. 12, 564-571.

Song BJ, Abdelmegeed MA, Cho YE, Akbar M, Rhim JS, Song MK, Hardwick JP. 2019. Contributing Roles of CYP2E1 and Other Cytochrome P450 Isoforms in Alcohol-Related Tissue Injury and Carcinogenesis. Adv Exp Med Biol. 1164:73-87.

Takahashi, S., Takahashi, T., Mizobuchi, S., Matsumi, M., Morita, K., Miyazaki, M., Namba, M., Akagi, R., Hirakawa, M., 2002. Increased cytotoxicity of carbon tetrachloride in a human hepatoma cell line overexpressing cytochrome P450 2E1. J. Int. Med. Res. 30, 400-405.

Tanaka, E., Terada, M., Misawa, S., 2000. Cytochrome P450 2E1: its clinical and toxicological role. J. Clin. Pharm. Ther. 25, 165-175.

Tkachev, V.O., Menshchikova, E.B., Zenkov, N.K., 2011. Mechanism of the Nrf2/Keap1/ARE signaling system. Biochemistry (Mosc) 76, 407-422.

Tomasetti, C., Vogelstein, B., 2015. Cancer etiology. Variation in cancer risk among tissues can be explained by the number of stem cell divisions. Science 347, 78-81.

Wang, E., Chen, F., Hu, X., Yuan, Y., 2014. Protective effects of apigenin against furan-induced toxicity in mice. Food Funct. 5, 1804-1812.

Wang, S., Sugamori, K.S., Tung, A., McPherson, J.P., Grant, D.M., 2015. N-Hydroxylation of 4-Aminobiphenyl by CYP2E1 Produces Oxidative Stress in a Mouse Model of Chemically Induced Liver Cancer. Toxicol. Sci.

Wu, D., Cederbaum, A.I., 2008. Development and properties of HepG2 cells that constitutively express CYP2E1. Methods Mol. Biol. 447, 137-150.

Wu, D., Cederbaum, A.I., 2005. Oxidative stress mediated toxicity exerted by ethanol-inducible CYP2E1. Toxicol. Appl. Pharmacol. 207, 70-76.

Wu, D., Cederbaum, A.I., 1996. Ethanol cytotoxicity to a transfected HepG2 cell line expressing human cytochrome P4502E1. J. Biol. Chem. 271, 23914-23919.

Wu, S., Powers, S., Zhu, W., Hannun, Y.A., 2016. Substantial contribution of extrinsic risk factors to cancer development. Nature 529, 43-47.

Yang, L., Wu, D., Wang, X., Cederbaum, A.I., 2011. Depletion of cytosolic or mitochondrial thioredoxin increases CYP2E1-induced oxidative stress via an ASK-1-JNK1 pathway in HepG2 cells. Free Radic. Biol. Med. 51, 185-196.

Younes, M., Siegers, C.P., 1985. The role of iron in the paracetamol- and CCl4-induced lipid peroxidation and hepatotoxicity. Chem. Biol. Interact. 55, 327-334.

Zaher, H., Buters, J.T., Ward, J.M., Bruno, M.K., Lucas, A.M., Stern, S.T., Cohen, S.D., Gonzalez, F.J., 1998. Protection against acetaminophen toxicity in CYP1A2 and CYP2E1 double-null mice. Toxicol. Appl. Pharmacol. 152, $193-199$. 
Appendix 1- MIE, KEs and AO

\section{List of MIEs in this AOP}

Event: 1391: Activation of Cyp2E1 (https://aopwiki.org/events/1391)

Short Name: Activation of Cyp2E1

AOPs Including This Key Event

\begin{tabular}{|l|l|}
\hline AOP ID and Name & Event Type \\
\hline Aop:220 - Cyp2E1 Activation Leading to Liver Cancer (https://aopwiki.org/aops/220) & $\begin{array}{l}\text { Molecular Initiating } \\
\text { Event }\end{array}$ \\
\hline
\end{tabular}

Stressors

\begin{tabular}{|l|}
\hline Name \\
\hline Chloroform \\
\hline Acetaminophen \\
\hline furan \\
\hline Ethanol \\
\hline acetone \\
\hline
\end{tabular}

Biological Context

Level of Biological Organization

Molecular

Evidence for Perturbation by Stressor

\section{Overview for Molecular Initiating Event}

A variety of substrates have been described (Lieber 1997, Tanaka, et al. 2000). There are $>85$ known Cyp2E1 substrates. They are low molecular weight compounds, including: molecular oxygen, acetone (Bondoc, et al. 1999), acetaminophen (Lee, et al. 1996, Zaher, et al. 1998), carbon tetrachloride (Wong, et al. 1998), pyrazole, vinyl chloride, furan, chloroform, ethanol (Bardag-Gorce, et al. 2000), benzene (Powley and Carlson 2001), acrylonitrile (El Hadri, et al. 2005), trichloroethylene (Kim and Ghanayem 2006), aniline, N-nitrosodimethylamine, Nnitrosodiethylamine, diethylnitrosamine, thioacetamide (Chilakapati, et al. 2007), urethane (Hoffler, et al. 2003, Hoffler and Ghanayem 2005), and toluene.

\section{Domain of Applicability}

Taxonomic Applicability

\begin{tabular}{|l|l|l|l|}
\hline Term & $\begin{array}{l}\text { Scientific } \\
\text { Term }\end{array}$ & $\begin{array}{l}\text { Evidenc } \\
\text { e }\end{array}$ & Links \\
\hline rodents & rodents & High & $\begin{array}{l}\text { NCBI } \\
\text { (http://www.ncbi.nlm.nih.gov/Taxonomy/Browser/wwwtax.cgi?mode=Info\&i } \\
\text { d=0) }\end{array}$ \\
\hline
\end{tabular}




\begin{tabular}{|l|l|l|l|}
\hline $\begin{array}{l}\text { Homo } \\
\text { sapiens }\end{array}$ & Homo sapiens & High & $\begin{array}{l}\text { NCBI } \\
\text { (http://www.ncbi.nlm.nih.gov/Taxonomy/Browser/wwwtax.cgi?mode=Info\&i } \\
\text { d=9606) }\end{array}$ \\
\hline
\end{tabular}

Life Stage Applicability

\begin{tabular}{|l|l|}
\hline Life Stage & Evidence \\
\hline All life stages & High \\
\hline
\end{tabular}

Sex Applicability

\begin{tabular}{|l|l|}
\hline Sex & Evidence \\
\hline Mixed & High \\
\hline
\end{tabular}

Taxonomic applicability: The Cyp2E1 gene is present across a variety of taxa including humans and primates, mice and rats. AceView (http://www.ncbi.nlm.nih.gov/IEB/Research/Acembly/index.html) indicates high levels of Cyp2E1 expression from RNA-seq experiments in liver across primate species. Cype2E1 is also present in frogs (Fort, et al. 2003, Saito, et al. 1997) and fish (Howarth, et al. 2011).

Life stages: Studies are primarily on adult liver tissues.

Sex applicability: Cyp2E1 is expressed in both males and females.

\section{Key Event Description}

Cyp2E1 is a membrane-bound monooxygenase that is primarily located in zone 3 hepatocytes (Ingelman-Sundberg, et al. 1988, Tsutsumi, et al. 1989). Although it is also expressed in other tissues (http://www.genecards.org/cgibin/carddisp.pl?gene $=$ CYP2E1), the body of literature on CYP2E1 is focussed on measurement in liver. CYP2E1 is primarily located in the endoplasmic reticulum, but can also be present in the mitochondria. It is a phase I metabolism enzyme that catalyzes the oxidation of low molecular weight substrates. Unlike most cytochrome P450 enzymes, Cyp2E1 is constitutively expressed (i.e., its expression is not transcriptionally controlled by substratebound nuclear receptors). Alternatively, exposure to a substrate increases its activity through post-translational stabilization of the molecule. Thus, the presence of substrate significantly increases the half-life of the Cyp2E1 enzyme thereby allowing it to be active for a longer period of time (Gonzalez 2007, Song, et al. 1989). The sustained activation of Cyp2E1 due to the presence of the chemical substrate is required for this MIE to produce downstream adverse effects.

Cyp2E1 is also regulated by the ubiquitin-proteasome pathway and the involvement of hsp-based chaperone (Morishima et al. 2005); however, this mechanism of regulation is not discussed further herein.

\section{How it is Measured or Detected}

- Mixed function oxidase catalytic activity. These assays have been thoroughly reviewed by Cederbaum (2014). The paper describes preparation of microsomes from both liver homogenates and cell cultures for testing Cyp2E1 activity. Briefly, the ratio of 6-hydroxychlorzoxazone/chlorzoxazone can be used to estimate levels of CYP2E1 in humans (Girre, et al. 1994). In addition, the oxidation of para-nitrophenol (PNP) to para nitrocatechol is an efficient and relatively specific assay to determine catalytic activity dependent on CYP2E1 [e.g., (Koop 1986, Koop, et al. 1989, Reinke and Moyer 1985)]. Other assays are described within the review article by Cederbaum.

- Western blot or Immunohistochemistry. Following chemical treatment, Cyp2E1 protein levels should increase if it is involved in the metabolism of that substrate. Western blot (of protein extracted from liver or 
cultured cells) or immunohistochemistry (of fixed liver or cultured cells) using anti-Cyp2E1 antibodies is the most straightforward approach for directly measuring increased levels of Cyp2E1.

- HepG2 cells. A compound's Cyp2E1-dependence can be determined by comparing toxic effects in HepG2 versus HepG2-E47 cells. HepG2 cells are immortalized human hepatoma cells that do not express Cyp2E1; whereas, HepG2-E47 cells over-express Cyp2E1 (by recombinant retroviral infection). Chemicals that are metabolically activated by Cyp2E1 will cause cytotoxicity and oxidative stress in the E47 cells only. Toxicity can be blocked by treatment with antioxidants or Cyp2E1 inhibitors. Toxicity is exacerbated when glutathione is depleted ( $\mathrm{Wu}$ and Cederbaum 2005) (e.g., ethanol (Cederbaum, et al. 2001, Chen and Cederbaum 1998, Chen, et al. 1998, Dai, et al. 1993).

- Measurement of chemical oxidation by Cyp2E1 in liver microsomes; described in the methodology review by Cederbaum (Cederbaum 2014). Reactions use specific probes to confirm that the compound undergoes oxidation, and that this oxidation reaction is catalyzed by Cyp2E1. See also: (Koop 1986, Koop, et al. 1989, Reinke and Moyer 1985).

- Cyp2E1 knock-out mouse. Chemical exposures in knockout mice are conducted and the production of the anticipated metabolites is measured. Lack of metabolite production indicates that Cyp2E1 is required for the chemical's metabolism. Effects in knock-out mice are always measured in reference to wild-type (control) mice, which allows investigators to attribute the altered phenotype to the gene that has been knocked-out. Studies in Cyp2E1 knockout mice indicate the following chemicals interact with it: carbon tetrachloride (Wong, et al. 1998), acetone (Bondoc, et al. 1999), benzene (Powley and Carlson 2001), thioacetamide (Chilakapati, et al. 2007), trichloroethylene (Kim and Ghanayem 2006), acrylonitrile (El Hadri, et al. 2005), urethane (Hoffler, et al. 2003, Hoffler and Ghanayem 2005), acetaminophen (Lee, et al. 1996, Zaher, et al. 1998), and ethanol (Bardag-Gorce, et al. 2000).

- Humanized Cyp2E1 mice. Two transgenic mice with human Cyp2E1 have been created. The first mouse reproduces and develops normally, and demonstrates Cyp2E1-dependent toxicity (Morgan, et al. 2002). However, these mice express human and endogenous Cyp2E1, which is not ideal. A true 'humanized' Cyp2E1 transgenic mouse was produced by the Gonzalez lab in which the endogenous Cyp2E1 gene was replaced with the human Cyp2E1 gene (Cheung, et al. 2005, Cheung and Gonzalez 2008). Studies in these mice are conducted in order to provide evidence that the Cyp2E1-dependent effects observed in experimental animals will also occur in humans.

- 2-Piperidone. 2-Piperidone is a newly proposed biomarker of Cyp2E1 activity that is detected in urine (Cheng, et al. 2013).

\section{References}

Bardag-Gorce, F., Yuan, Q.X., Li, J., French, B.A., Fang, C., Ingelman-Sundberg, M., French, S.W., 2000. The effect of ethanol-induced cytochrome p4502E1 on the inhibition of proteasome activity by alcohol. Biochem. Biophys. Res. Commun. 279, 23-29.

Bondoc, F.Y., Bao, Z., Hu, W.Y., Gonzalez, F.J., Wang, Y., Yang, C.S., Hong, J.Y., 1999. Acetone catabolism by cytochrome P450 2E1: studies with CYP2E1-null mice. Biochem. Pharmacol. 58, 461-463.

Cederbaum, A.I., 2014. Methodology to assay CYP2E1 mixed function oxidase catalytic activity and its induction. Redox Biol. 2C, 1048-1054.

Cheng, J., Chen, C., Kristopher, K.W., Manna, S.K., Scerba, M., Friedman, F.K., Luecke, H., Idle, J.R., Gonzalez, F.J., 2013. Identification of 2-piperidone as a biomarker of CYP2E1 activity through metabolomic phenotyping. Toxicol. Sci. 135, 37-47. 
Cheung, C., Gonzalez, F.J., 2008. Humanized mouse lines and their application for prediction of human drug metabolism and toxicological risk assessment. J. Pharmacol. Exp. Ther. 327, 288-299.

Chilakapati, J., Korrapati, M.C., Shankar, K., Hill, R.A., Warbritton, A., Latendresse, J.R., Mehendale, H.M., 2007. Role of CYP2E1 and saturation kinetics in the bioactivation of thioacetamide: Effects of diet restriction and phenobarbital. Toxicol. Appl. Pharmacol. 219, 72-84.

El Hadri, L., Chanas, B., Ghanayem, B.I., 2005. Comparative metabolism of methacrylonitrile and acrylonitrile to cyanide using cytochrome P4502E1 and microsomal epoxide hydrolase-null mice. Toxicol. Appl. Pharmacol. 205, 116- 125.

Fort, D.J., McLaughlin, D.W., Rogers, R.L., Buzzard, B.O., 2003. Evaluation of the developmental toxicities of ethanol, acetaldehyde, and thioacetamide using FETAX. Drug Chem. Toxicol. 26, 23-34.

Girre, C., Lucas, D., Hispard, E., Menez, C., Dally, S., Menez, J.F., 1994. Assessment of cytochrome P4502E1 induction in alcoholic patients by chlorzoxazone pharmacokinetics. Biochem. Pharmacol. 47, 1503-1508.

Gonzalez, F.J., 2007. The 2006 Bernard B. Brodie Award Lecture. Cyp2e1. Drug metabolism and disposition: the biological fate of chemicals $35,1-8$.

Hoffler, U., El-Masri, H.A., Ghanayem, B.I., 2003. Cytochrome P450 2E1 (CYP2E1) is the principal enzyme responsible for urethane metabolism: comparative studies using CYP2E1-null and wild-type mice. J. Pharmacol. Exp. Ther. 305, 557-564.

Hoffler, U., Ghanayem, B.I., 2005. Increased bioaccumulation of urethane in CYP2E1-/- versus CYP2E1+/+ mice. Drug Metab. Dispos. 33, 1144-1150.

Howarth, D.L., Passeri, M., Sadler, K.C., 2011. Drinks Like a Fish: Using Zebrafish to Understand Alcoholic Liver Disease. Alcohol. Clin. Exp. Res. 35, 826-829.

Ingelman-Sundberg, M., Johansson, I., Penttila, K.E., Glaumann, H., Lindros, K.O., 1988. Centrilobular expression of ethanol-inducible cytochrome P-450 (IIE1) in rat liver. Biochem. Biophys. Res. Commun. 157, 55-60.

Kim, D., Ghanayem, B.I., 2006. Comparative metabolism and disposition of trichloroethylene in Cyp2e1-/-and wild-type mice. Drug Metab. Dispos. 34, 2020-2027.

Koop, D.R., 1986. Hydroxylation of p-nitrophenol by rabbit ethanol-inducible cytochrome P-450 isozyme 3a. Mol. Pharmacol. 29, 399-404.

Koop, D.R., Laethem, C.L., Tierney, D.J., 1989. The utility of p-nitrophenol hydroxylation in P450IIE1 analysis. Drug Metab. Rev. 20, 541-551.

Lee, S.S., Buters, J.T., Pineau, T., Fernandez-Salguero, P., Gonzalez, F.J., 1996. Role of CYP2E1 in the hepatotoxicity of acetaminophen. J. Biol. Chem. 271, 12063-12067.

Lieber, C.S., 1997. Cytochrome P-4502E1: its physiological and pathological role. Physiol. Rev. 77, 517-544.

Morishima, Y., Peng, H-M., Lin, H-L., Hollenberg, P.F., Sunahara, R., K., Osawa, Y., Pratt, W.B. Regulation of Cytochrome P450 2E1 by Heat Shock Protein 90-Dependent Stabilization and CHIP-Dependent Proteasomal Degradation. 2005. Biochemistry. 44, 49, 16333-16340.

Morgan, K., French, S.W., Morgan, T.R., 2002. Production of a cytochrome P450 2E1 transgenic mouse and initial evaluation of alcoholic liver damage. Hepatology 36, 122-134.

Powley, M.W., Carlson, G.P., 2001. Hepatic and pulmonary microsomal benzene metabolism in CYP2E1 knockout mice. Toxicology 169, 187-194.

Reinke, L.A., Moyer, M.J., 1985. p-Nitrophenol hydroxylation. A microsomal oxidation which is highly inducible by ethanol. Drug Metab. Dispos. 13, 548-552. 
Saito, H., Ohi, H., Sugata, E., Murayama, N., Fujita, Y., Higuchi, S., 1997. Purification and characterization of a cytochrome P450 from liver microsomes of Xenopus laevis. Arch. Biochem. Biophys. 345, 56-64.

Song, B.J., Veech, R.L., Park, S.S., Gelboin, H.V., Gonzalez, F.J., 1989. Induction of rat hepatic Nnitrosodimethylamine demethylase by acetone is due to protein stabilization. J. Biol. Chem. 264, 3568-3572.

Tanaka, E., Terada, M., Misawa, S., 2000. Cytochrome P450 2E1: its clinical and toxicological role. J. Clin. Pharm. Ther. 25, 165-175.

Tsutsumi, M., Lasker, J.M., Shimizu, M., Rosman, A.S., Lieber, C.S., 1989. The intralobular distribution of ethanolinducible P450IIE1 in rat and human liver. Hepatology 10, 437-446.

Wu, D., Cederbaum, A.I., 2005. Oxidative stress mediated toxicity exerted by ethanol-inducible CYP2E1. Toxicol. Appl. Pharmacol. 207, 70-76.

Zaher, H., Buters, J.T., Ward, J.M., Bruno, M.K., Lucas, A.M., Stern, S.T., Cohen, S.D., Gonzalez, F.J., 1998. Protection against acetaminophen toxicity in CYP1A2 and CYP2E1 double-null mice. Toxicol. Appl. Pharmacol. 152, 193- 199.

\section{List of Key Events in the AOP}

Event: 1392: Oxidative Stress (https://aopwiki.org/events/1392)

Short Name: Oxidative Stress

AOPs Including This Key Event

\begin{tabular}{|l|l|}
\hline AOP ID and Name & $\begin{array}{l}\text { Event } \\
\text { Type }\end{array}$ \\
\hline Aop:220 - Cyp2E1 Activation Leading to Liver Cancer (https://aopwiki.org/aops/220) & KeyEvent \\
\hline $\begin{array}{l}\text { Aop:17 - Binding of electrophilic chemicals to SH(thiol)-group of proteins and /or to seleno-proteins } \\
\text { involved in protection against oxidative stress during brain development leads to impairment of } \\
\text { learning and memory (https://aopwiki.org/aops/17) }\end{array}$ & KeyEvent \\
\hline $\begin{array}{l}\text { Aop:284 - Binding of electrophilic chemicals to SH(thiol)-group of proteins and /or to seleno-proteins } \\
\text { involved in protection against oxidative stress leads to chronic kidney disease } \\
\text { (https://aopwiki.org/aops/284) }\end{array}$ & KeyEvent \\
\hline
\end{tabular}

Stressors

Name

Acetaminophen

Chloroform

furan

Biological Context

Level of Biological Organization

Molecular 


\section{Domain of Applicability}

Taxonomic Applicability

\begin{tabular}{|l|l|l|l|}
\hline Term & $\begin{array}{l}\text { Scientific } \\
\text { Term }\end{array}$ & $\begin{array}{l}\text { Evidenc } \\
\text { e }\end{array}$ & Links \\
\hline rodents & rodents & High & $\begin{array}{l}\text { NCBI } \\
\text { (http://www.ncbi.nlm.nih.gov/Taxonomy/Browser/wwwtax.cgi?mode=Info\&i } \\
\mathrm{d}=0 \text { ) }\end{array}$ \\
\hline $\begin{array}{l}\text { Homo } \\
\text { sapiens }\end{array}$ & Homo sapiens & High & $\begin{array}{l}\text { NCBI } \\
\text { (http://www.ncbi.nlm.nih.gov/Taxonomy/Browser/wwwtax.cgi?mode=Info\&i } \\
\text { d=9606) }\end{array}$ \\
\hline
\end{tabular}

Life Stage Applicability

Life Stage

Evidence

All life stages

High

Sex Applicability

\begin{tabular}{|l|l|}
\hline Sex & Evidence \\
\hline Mixed & High \\
\hline
\end{tabular}

Oxidative stress is produced in, and can occur in, any species from bacteria through to humans.

\section{Key Event Description}

Oxidative stress is defined as an imbalance in the production of reactive oxygen species (ROS) and antioxidant defenses. High levels of oxidizing free radicals can be very damaging to cells and molecules within the cell. As a result, the cell has important defense mechanisms to protect itself from ROS. For example, Nrf2 is a transcription factor and master regulator of the oxidative stress response. During periods of oxidative stress, Nrf2-dependent changes in gene expression are important in regaining cellular homeostasis (Nguyen, et al. 2009) and can be used as indicators of the presence of oxidative stress in the cell.

In addition to the directly damaging actions of ROS, cellular oxidative stress also changes cellular activities on a molecular level. Redox sensitive proteins have altered physiology in the presence and absence of ROS, which is caused by the oxidation of sulfhydryls to disulfides (2SH àSS) on neighboring amino acids (Antelmann and Helmann 2011). Importantly Keap1, the negative regulator of Nrf2, is regulated in this manner (Itoh, et al. 2010).

Protection against oxidative stress is relevant for all tissues and organs, although some tissues may be more susceptible. For example, the brain possesses several key physiological features, such as high O2 utilization, high polyunsaturated fatty acids content, presence of autooxidable neurotransmitters, and low antioxidant defenses as compared to other organs, that make it highly susceptible to oxidative stress (Halliwell, 2006; Emerit and al., 2004; Frauenberger et al., 2016).

\section{How it is Measured or Detected}

Oxidative Stress. Direct measurement of ROS is difficult because ROS are unstable. The presence of ROS can be assayed indirectly by measurement of cellular antioxidants, or by ROS-dependent cellular damage:

Detection of ROS 
Glutathione (GSH) depletion. GSH can be measured by assaying the ratio of reduced to oxidized glutathione (GSH:GSSG) using a commercially available kit (e.g., http:/www.abcam.com/gshgssg-ratio-detection-assay-kitfluorometric-green-ab138881.html)

TBARS. Oxidative damage to lipids can be measured by assaying for lipid peroxidation using TBARS (thiobarbituric acid reactive substances) using a commercially available kit.

8-oxo-dG. Oxidative damage to nucleic acids can be assayed by measuring 8-oxo-dG adducts (for which there are a number of ELISA based commercially available kits), or HPLC, described in Chepelev et al. (Chepelev, et al. 2015).

\section{Molecular Biology: Nrf2. Nrf2's transcriptional activity is controlled post-translationally by oxidation of Keap1. Assay for Nrf2 activity include:}

Immunohistochemistry for increases in Nrf2 protein levels and translocation into the nucleus;

Western blot for increased Nrf2 protein levels;

Western blot of cytoplasmic and nuclear fractions to observe translocation of Nrf2 protein from the cytoplasm to the nucleus;

- qPCR of Nrf2 target genes (e.g., Nqo1, Hmox-1, Gcl, Gst, Prx, TrxR, Srxn), or by commercially available pathwaybased qPCR array (e.g., oxidative stress array from SABiosciences)

Whole transcriptome profiling by microarray or RNA-seq followed by pathway analysis (in IPA, DAVID, metacore, etc.) for enrichment of the Nrf2 oxidative stress response pathway (e.g., Jackson et al. 2014);

OECD TG422D describes an ARE-Nrf2 Luciferase test method;

In general, there are a variety of commercially available colorimetric or fluorescent kits for detecting Nrf2 activation.

\section{References}

Antelmann, H., Helmann, J.D., 2011. Thiol-based redox switches and gene regulation. Antioxid. Redox Signal. 14, 1049-1063.

Chepelev, N.L., Kennedy, D.A., Gagne, R., White, T., Long, A.S., Yauk, C.L., White, P.A., 2015. HPLC Measurement of the DNA Oxidation Biomarker, 8-oxo-7,8-dihydro-2'-deoxyguanosine, in Cultured Cells and Animal Tissues. J. Vis. Exp. (102):e52697. doi, e52697.

Emerit, J., Edeas, M., Bricaire, F., 2004. Neurodegenerative diseases and oxidative stress. Biomed. Pharmacotherapy. 58(1): 39-46.

Frauenberger, E.A., Scola, G., Laliberté, V.L.M., Duong, A., Andreazza, A.C., 2015. Redox modulations, Antioxidants, and Neuropsychitrica Disorders. Ox. Med. Cell. Longevity. Vol. 2016, Article ID 4729192. Halliwell, B., 2006. Oxidative stress and neurodegeneration: where are we now? J. Neurochem. 97(6):1634-1658.

Itoh, K., Mimura, J., Yamamoto, M., 2010. Discovery of the negative regulator of Nrf2, Keap1: a historical overview. Antioxid. Redox Signal. 13, 1665-1678.

Jackson, A.F., Williams, A., Recio, L., Waters, M.D., Lambert, I.B., Yauk, C.L., 2014. Case study on the utility of hepatic global gene expression profiling in the risk assessment of the carcinogen furan. Toxicol. Applied Pharmacol.274, 63-77.

Nguyen, T., Nioi, P., Pickett, C.B., 2009. The Nrf2-antioxidant response element signaling pathway and its activation by oxidative stress. J. Biol. Chem. 284, 13291-13295.

OECD (2018), Test No. 442D: In Vitro Skin Sensitisation: ARE-Nrf2 Luciferase Test Method, OECD Guidelines for the Testing of Chemicals, Section 4, OECD Publishing, Paris, https://doi.org/10.1787/9789264229822-en.

OECD (2019), Test No. 495: Ros (Reactive Oxygen Species) Assay for Photoreactivity, OECD Guidelines for the Testing of Chemicals, Section 4, OECD Publishing, Paris, https://doi.org/10.1787/915e00ac-en. 
Event: 1393: Hepatocytotoxicity (https://aopwiki.org/events/1393)

Short Name: Hepatocytotoxicity

AOPs Including This Key Event

\begin{tabular}{|l|l|}
\hline AOP ID and Name & Event Type \\
\hline Aop:220 - Cyp2E1 Activation Leading to Liver Cancer (https://aopwiki.org/aops/220) & KeyEvent \\
\hline
\end{tabular}

Stressors

\begin{tabular}{|l|}
\hline Name \\
\hline Ethanol \\
\hline acetone \\
\hline
\end{tabular}

Chloroform

Acetaminophen

furan

Biological Context

Level of Biological Organization

Cellular

Cell term

Cell term

hepatocyte

Organ term

Organ term

liver

Domain of Applicability

Taxonomic Applicability

\begin{tabular}{|l|l|l|l|}
\hline Term & $\begin{array}{l}\text { Scientific } \\
\text { Term }\end{array}$ & $\begin{array}{l}\text { Evidenc } \\
\mathrm{e}\end{array}$ & Links \\
\hline rodents & rodents & High & $\begin{array}{l}\text { NCBI } \\
\text { (http://www.ncbi.nlm.nih.gov/Taxonomy/Browser/wwwtax.cgi?mode=Info\&i } \\
\mathrm{d}=0 \text { ) }\end{array}$ \\
\hline $\begin{array}{l}\text { Homo } \\
\text { sapiens }\end{array}$ & Homo sapiens & High & $\begin{array}{l}\text { NCBI } \\
\text { (http://www.ncbi.nlm.nih.gov/Taxonomy/Browser/wwwtax.cgi?mode=Info\&i } \\
\mathrm{d}=9606)\end{array}$ \\
\hline
\end{tabular}

Life Stage Applicability

\begin{tabular}{|l|l|}
\hline Life Stage & Evidence \\
\hline All life stages & High \\
\hline
\end{tabular}

Sex Applicability

\begin{tabular}{|l|l}
\hline Sex & Evidence \\
\hline
\end{tabular}


Cytotoxicity can occur in any species from bacteria through to humans. Hepatocytotoxicity can occur in any species with a liver.

\section{Key Event Description}

Taxonomic Applicability: Hepatotoxicity can occur in any species that has a liver.

Sex applicability: It can occur in both sexes

How it works: Hepatotoxicity occurs through three main mechanisms: apoptosis, necrosis, and necroptosis. (1) During programmed cell death, apoptotic cells are 'disassembled' and cellular components 'bleb' off as large vacuoles, which can be eliminated by phagocytosis. Apoptosis is activated via the extrinsic pathway (mediated through a death receptor, Tumor Necrosis Factor Receptor, TNFR) or intrinsic pathway (mediated through the mitochondria), each of which activate the caspase cascade (Riedl and Shi 2004). (2) Necrosis is an unregulated, accidental form of cell death that occurs when severe damage to cellular components causes the cell to die abruptly and spill its contents into the extracellular space.

Released cellular components include damage-associated molecular patterns (DAMPs) that trigger an inflammatory response. (3) The third type of cell death is necroptosis, or programmed necrosis, which uses the same death receptor that is upstream to the extrinsic pathway of apoptosis, but signaling results in a necrotic outcome. The decision for TNFR to signal for apoptosis or necroptosis is thought to depend on the receptor protein kinases 1 and 3 (RIP1, RIP3), which are part of the protein complex that forms on the intra-cellular portion of the TNFR. Activation of caspase-8 cleaves the RIP1-RIP3 complex and favours apoptosis, whereas inhibition of caspase- 8 favours the RIP1RIP3 complex (called the 'necrosome'). As per standard necrosis, necroptosis results in DAMP release, which triggers inflammation. Necroptosis has been reviewed (Vandenabeele, et al. 2010). Cell death mechanisms in the liver and in liver disease have also been reviewed (Eguchi, et al. 2014, Luedde, et al. 2014).

The mitochondrial permeability transition (MPT) is an important process that leads to necrosis or apoptosis. When the mitogen activated protein kinase (MAPK) cascade is triggered (ASK1MKK4JNK), Bcl-2-associated X protein (Bax) is recruited to the outer mitochondrial membrane (Youle and Strasser 2008). Bax triggers the opening of the mitochondrial permeability transition pore (MTP), through which cytochrome $\mathrm{c}$ is released, which triggers the caspase cascade and apoptosis. Alternatively, when the MTP opens across the inner and outer mitochondrial membranes, mitochondrial swelling and decoupling of oxidative phosphorylation (i.e., loss of ATP generation) leads to cell death by necrosis (Pessayre, et al. 2010, Rasola and Bernardi 2007).

\section{How it is Measured or Detected}

\section{In vivo (liver):}

- Hematoxylin and eosin (H\&E) stained liver sections can be examined by a pathologist for the presence of cytotoxicity;

- Serum levels of alanine aminotransferase (ALT) can be used as an indicator of hepatotoxicity. Serum levels of aspartate aminotransferase (AST) can also be used; however, AST is considered to be less 'liver specific' than ALT. Therefore, an AST/ALT ratio is often used. ALT and AST are typically measured using a commercial kit (e.g., from Sigma Aldrich or Roche); protocol: www.bio-protocol.org/e931.

- Additional serum biomarkers of liver cell death have been reviewed in: (Eguchi, et al. 2014), and include: miRNAs (including mir-122), soluble death receptors (sTNFR, sTRAIL, sFas), microparticles (small vesicles released from dying cells), and other soluble proteins (including High mobility group box 1, HMGB1, and cleaved keratin 18, K18). 


\section{- In vivo or in vitro:}

- Lactate dehydrogenase (LDH) leakage. LDH leakage is a measure of necrotic cell death, which can be detected using a colorimetric absorbance assay based on MTT reduction (Chan, et al. 2013).

- Trypan Blue Exclusion. Trypan blue is a commercially available dye that only stains dead cells;

- Apoptosis can be assayed by measuring caspase activation. There are a number of commercially available caspase assay kits:

- The TUNEL assay is commonly used to measure DNA fragmentation that results from apoptotic signaling cascades (Lozano, et al. 2009)

- This assay measures the presence of nicks in the DNA that are identified by terminal deoxynucleotidyl transferase or TdT, an enzyme that catalyzes the addition of dUTPs that are secondarily labeled with a marker;

- In the MTT assay in which viable cells (with active metabolism) convert MTT into a purple compound (formazan), whereas dead cells remain colourless (Riss, et al. 2004); Trypan blue assay: non -viable cells takeup trypan blue, whereas viable cells remain colourless (Strober 2015).

\section{References}

Chan, F.K., Moriwaki, K., De Rosa, M.J., 2013. Detection of necrosis by release of lactate dehydrogenase activity. Methods Mol. Biol. 979, 65-70.

Eguchi, A., Wree, A., Feldstein, A.E., 2014. Biomarkers of liver cell death. J. Hepatol. 60, 1063-1074.

Lozano, G.M., Bejarano, I., Espino, J., Gonzalez, D., Ortiz, A., Garcia, J.F., Rodriguez, A.B., Pariente, J.A., 2009. Relationship between caspase activity and apoptotic markers in human sperm in response to hydrogen peroxide and progesterone. J. Reprod. Dev. 55, 615-621.

Luedde, T., Kaplowitz, N., Schwabe, R.F., 2014. Cell death and cell death responses in liver disease: mechanisms and clinical relevance. Gastroenterology 147, 765-783.e4.

Pessayre, D., Mansouri, A., Berson, A., Fromenty, B., 2010. Mitochondrial involvement in drug-induced liver injury. Handb. Exp. Pharmacol. (196):311-65. doi, 311-365.

Rasola, A., Bernardi, P., 2007. The mitochondrial permeability transition pore and its involvement in cell death and in disease pathogenesis. Apoptosis 12, 815-833.

Riedl, S.J., Shi, Y., 2004. Molecular mechanisms of caspase regulation during apoptosis. Nat. Rev. Mol. Cell Biol. 5, 897-907.

Riss, T.L., Moravec, R.A., Niles, A.L., Duellman, S., Benink, H.A., Worzella, T.J., Minor, L., 2004. Cell Viability Assays, in: Sittampalam, G.S., Coussens, N.P., Nelson, H., Arkin, M., Auld, D., Austin, C., Bejcek, B., Glicksman, M., Inglese, J., Iversen, P.W., Li, Z., McGee, J., McManus, O., Minor, L., Napper, A., Peltier, J.M., Riss, T., Trask OJ, J., Weidner, J. (Eds.), Assay Guidance Manual, Bethesda (MD).

Strober, W., 2015. Trypan Blue Exclusion Test of Cell Viability. Curr. Protoc. Immunol. 111, A3.B.1-3.

Vandenabeele, P., Galluzzi, L., Vanden Berghe, T., Kroemer, G., 2010. Molecular mechanisms of necroptosis: an ordered cellular explosion. Nat. Rev. Mol. Cell Biol. 11, 700-714.

Youle, R.J., Strasser, A., 2008. The BCL-2 protein family: opposing activities that mediate cell death. Nat. Rev. Mol. Cell Biol. 9, 47-59. 
Event: 1394: Induction, persistant proliferation/sustained proliferation (https://aopwiki.org/events/1394)

Short Name: Sustained proliferation

Key Event Component

\begin{tabular}{|l|l|l|}
\hline Process & Object & Action \\
\hline cellular response to oxidative stress & & increased \\
\hline macrophage activation involved in immune response & macrophage & increased \\
\hline hypoxia & hypoxia-inducible factor 1-alpha & decreased \\
\hline hypoxia & von Hippel-Lindau disease tumor suppressor & decreased \\
\hline
\end{tabular}

AOPs Including This Key Event

AOP ID and Name

Aop:220 - Cyp2E1 Activation Leading to Liver Cancer (https://aopwiki.org/aops/220) Event Type KeyEvent

Stressors

\begin{tabular}{|l|}
\hline Name \\
\hline Acetaminophen \\
\hline Chloroform \\
\hline Ethanol \\
\hline furan \\
\hline
\end{tabular}

Biological Context

Level of Biological Organization

Cellular

\section{Domain of Applicability}

Taxonomic Applicability

\begin{tabular}{|l|l|l|l|}
\hline Term & $\begin{array}{l}\text { Scientific } \\
\text { Term }\end{array}$ & $\begin{array}{l}\text { Evidenc } \\
\text { e }\end{array}$ & Links \\
\hline rodents & rodents & High & $\begin{array}{l}\text { NCBI } \\
\text { (http://www.ncbi.nlm.nih.gov/Taxonomy/Browser/wwwtax.cgi?mode=Info\&i } \\
\mathrm{d}=0 \text { ) }\end{array}$ \\
\hline $\begin{array}{l}\text { Homo } \\
\text { sapiens }\end{array}$ & Homo sapiens & High & $\begin{array}{l}\text { NCBI } \\
(\mathrm{http} / / \text { www.ncbi.nlm.nih.gov/Taxonomy/Browser/wwwtax.cgi?mode=Info\&i } \\
\mathrm{d}=9606)\end{array}$ \\
\hline
\end{tabular}

Life Stage Applicability

\begin{tabular}{|l|l|}
\hline Life Stage & Evidence \\
\hline All life stages & High \\
\hline
\end{tabular}

Sex Applicability

\begin{tabular}{|l|l|}
\hline Sex & Evidence \\
\hline Mixed & High \\
\hline
\end{tabular}


This key event has been well studied in mice, rats (Taub 2004), and zebrafish (Cox and Goessling 2015, Goessling and Sadler 2015), which are all systems that are thought to work in a similar way to human liver cell proliferation and regeneration (Kwon, et al. 2015).

\section{Key Event Description}

Cellular proliferation rates increase in response to cell death in the liver in order to replace the dying cells. Cellular proliferation refers to the production of new cells to maintain a balance of cell division and cell loss. This key event describes conditions under which this process is persistent or sustained because of chronic exposure. This process is analogous to liver regenerative proliferation (e.g., regenerating liver cells following partial hepatectomy), which is often used as a model.

The liver has two modes of regenerating lost cells: (1) via cellular hypertrophy and division of existing cells; or (2) via proliferation of a population of facultative stem cells, called biliary epithelial cells (BECs), located at the Canals of Hering (in zone 1 where canaliculi join and drain into the main bile duct). Facultative stem cells are functional, differentiated cells that will dedifferentiate in response to tissue damage, thereby becoming a population of progenitor cells that can redifferentiate to replace multiple lost cell types. In a process known as ductal expansion, BECs dedifferentiate into oval cells, which then redifferentiate into hepatocytes or BECs in order to regenerate damaged liver tissue. Liver regeneration has been reviewed (Mao, et al. 2014, Stanger 2015, Yanger and Stanger 2011).

At the molecular level, two dimeric transcription factors, AP-1 (particularly the c-Jun monomer) and NF-kappaB, are key players during liver cellular proliferation and regeneration. While neither is expressed in normal liver tissue, they are upregulated during normal hepatic regeneration, and are required for regeneration (Alcorn, et al. 1990, Cressman, et al. 1994, FitzGerald, et al. 1995). Indeed, rodents lacking AP-1 or NF-kappaB display impaired liver regeneration, often leading to death (Behrens, et al. 2002, Schrum, et al. 2000). Both NF-kappaB and c-Jun (AP-1) are required for embryonic liver development, and a loss of either one is embryonic lethal due to widespread cell death and liver degeneration (Behrens, et al. 2002, Eferl, et al. 1999, Jochum, et al. 2001, Li, et al. 1999, Rudolph, et al. 2000).

A causal network for sustained proliferation and regenerative proliferation in liver can also occur via WNT signaling and the following pathways: the network begins with oxidative stress or other mechanisms causing liver tissue injury which in turn causes (2) activation of macrophages and wound repair (Boulter et al., 2012), (3) increased hypoxia through diminished blood supply or activity of reactive oxygen species (Ju et al., 2016, Gonzalez et al., 2018) and (4) increased expression of Wnt ligands (Okabe et al., 2016). The activation of macrophages causes (5) activation of Wnt proteins and Wnt signaling (Boulter et al., 2012, Vanella and Wynn 2017). The activation and/or increased expression of Wnt signaling ligands causes (6) binding of the Wnt ligand to the co-receptors Frizzled (FZD family) and (7) Low-density lipoprotein receptor-related proteins 5 and 6 (LRP5/6) which then (8) recruit and phosphorylate Dishevelled (DVL1) and the scaffold protein Axin (Takigawa and Brown 2008).

The phosphorylation and recruitment of Axin (AXIN1, AXIN2), (33) inhibits formation of the beta-catenin destruction complex, composed of AXIN1 or AXIN2, adenomatosis polyposis coli (APC), beta-catenin (CTNNB1) and glycogen synthase kinase 3 (GSK3), which (10) targets beta-catenin for degradation. Inhibiting formation of the destruction complex increases the amount of available beta-catenin to (11) interact and complex with the transcription factor 7 and lymphoid enhancer-binding factor (TCF/LEF) family of transcription factors (TF7, TCF7L1, TCF7L2, LEF1; Takigawa and Brown 2008). The TCF/LEF:beta-catenin complex then (12) activates transcription of MYC proto-oncogene (MYC) and (13) cyclin D1 or CCND1 (Schuijers et al 2014; Katoh 2017). Activation of Wnt signaling (14) inhibits GSK3 phosphorylation activity which then (15) represses forkhead box M1 (FOXM1) activity, (34) causes increased turnover of CCND1 and (35) increases proteolysis of MYC (Katoh 2017, Gregory et al., 2003). 
FOXM1 activates (16) transcription of MYC and (17) transcription of MAPK8, the mitogen-activated protein kinase (also known as JNK1; Wierstra and Alves 2007; Wang et al., 2008). Transcriptional activation of MAPK8 then leads to (36) transcriptional activation of CCND1 (Wang et al., 2008). Transcriptional activation of MYC causes (18) transcription of cyclin-dependent kinase 4 (CDK4) which leads to $(19,20)$ formation of a CDK4 and CCND1 complex (Wang et al 2011). The cyclin-CDK complex then (21) inhibits activity of the retinoblastoma (RB1) transcriptional corepressor 1 which (22) negatively regulates the cell cycle (Burkhart and Sage 2008). Dysregulation of G1/S transition by inhibition of RB1 and/or FOXM1 (23) leads to cell proliferation (Wierstra and Alves 2007; Burkhart and Sage 2008).

MYC can also be activated via hypoxia signaling where an increase in hypoxia (24) decreases the activity of oxygen sensor hypoxia-inducible factor 1 alpha inhibitor (HIF1AN) thereby reducing the ability of HIF1AN to (25) hydroxylate and inhibit hypoxia-inducible factor 1 alpha (HIF1A) activity (Whyte et al., 2012; Mahon et al., 2001). Hypoxia also can (26) inhibit activity of the von Hippel-Lindau (VHL) tumor suppressor protein which has been shown to (27) hydroxylate HIF1A in an O2 dependent manner marking HIF1A for degradation and inactivation in addition to inhibiting expression of HIF1A (Mahon et al., 2001). In stem cells, activated HIF1A (28) increases expression of TCF/LEF leading to increased expression of genes including MYC (Whyte et al., 2012; Tiburcio et al., 2014).

The long WNT Signaling Pathway Activating noncoding RNA WSPAR is often highly expressed in hepatocellular carcinoma cells and has been found to (29) activate expression of members of the TCF/LEF family (Zhan et al 2017). TCF/LEF transcription factors (30) increase transcription of AXIN2 and increase destruction of beta-catenin in a Wnt signaling negative feedback loop (Jho et al., 2002). TCF/LEF transcription factors form a negative feedback loop that inhibits Wnt signaling by (31) activating transcription of the dickkopf Wnt signaling pathway inhibitor 1 (DKK1) which then (32) binds to the LRP co-receptor (Takigawa and Brown 2008). Finally, cellular G1/S transition can also be dysregulated by (35) phosphorylation of RB1 by the 26S proteasome non-ATPase regulatory subunit 10 (PSMD10) which results in an increase in proteosomal degradation of RB1 (Higashitsuji et al., 2005).

\section{How it is Measured or Detected}

- Proliferation. In vivo or in vitro cellular proliferation can be measured following a multiday 5-bromo-2'deoxyuridine (BrdU) exposure and quantification of BrdU incorporation in DNA by immunohistochemistry. Alternatively, cells or tissue sections may be stained for Ki-67 or proliferating cell nuclear antigen (PCNA) for a snapshot of cellular proliferation. Use of BrdU, Ki-67, and PCNA in risk assessment has been described in detail (Wood, et al. 2015). A variety of commercial kits exist for this assay.

- Regeneration. Liver regeneration can be observed following partial hepatectomy. Method for 2/3 partial hepatectomy have been described (Mitchell and Willenbring 2008, Mitchell and Willenbring 2014)

- Gene expression analysis can be conducted to demonstrate increased expression of AP-1 or NF-kappaB monomers, or decreased expression of negative regulators, which can be used as an indicator that there is increased cellular proliferation in the liver.

- A BrdU-ELISA incorporation in vivo test method is also described in OECD TG 442B (The Local Lymph Node Assay, which is for skin sensitization).

\section{References}

Alcorn, J.A., Feitelberg, S.P., Brenner, D.A., 1990. Transient induction of c-jun during hepatic regeneration. Hepatology 11, 909-915. 
Behrens, A., Sibilia, M., David, J.P., Möhle-Steinlein, U., Tronche, F., Schütz, G., Wagner, E.F., 2002. Impaired postnatal hepatocyte proliferation and liver regeneration in mice lacking c-jun in the liver. EMBO J. 21, 1782-1790.

Boulter L, Govaere O, Bird TG, Radulescu S, Ramachandran P, Pellicoro A, Ridgway RA, et al. Macrophagederived Wnt opposes Notch signaling to specify hepatic progenitor cell fate in chronic liver disease. Nat Med. 2012 Mar 4;18(4):572-9. doi: 10.1038/nm.2667.

Burkhart DL, Sage J. Cellular mechanisms of tumour suppression by the retinoblastoma gene. Nat Rev Cancer. 2008 Sep;8(9):671-82. doi: 10.1038/nrc2399.

Cox, A.G., Goessling, W., 2015. The lure of zebrafish in liver research: regulation of hepatic growth in development and regeneration. Curr. Opin. Genet. Dev. 32, 153-161.

Cressman, D.E., Greenbaum, L.E., Haber, B.A., Taub, R., 1994. Rapid activation of post-hepatectomy factor/nuclear factor $\mathrm{\kappa B}$ in hepatocytes, a primary response in the regenerating liver. J. Biol. Chem. 269, 3042930435 .

Eferl, R., Sibilia, M., Hilberg, F., Fuchsbichler, A., Kufferath, I., Guertl, B., Zenz, R., Wagner, E.F., Zatloukal, K., 1999. Functions of c-Jun in liver and heart development. J. Cell Biol. 145, 1049-1061.

FitzGerald, M.J., Webber, E.M., Donovan, J.R., Fausto, N., 1995. Rapid DNA binding by nuclear factor $\kappa B$ in hepatocytes at the start of liver regeneration. Cell Growth and Differentiation 6, 417-427.

Goessling, W., Sadler, K.C., 2015. Zebrafish: an important tool for liver disease research. Gastroenterology 149, 1361-1377.

Gregory MA, Qi Y, Hann SR. Phosphorylation by glycogen synthase kinase- controls c-myc proteolysis and subnuclear localization. J Biol Chem. 2003 Dec 19;278(51):51606-12. Epub 2003 Oct 16. PubMed PMID: 14563837.

Higashitsuji H, Liu Y, Mayer RJ, Fujita J. The oncoprotein gankyrin negatively regulates both p53 and RB by enhancing proteasomal degradation. Cell Cycle. 2005 Oct;4(10):1335-7. Epub 2005 Oct 17. PubMed PMID: 16177571.

Jho EH, Zhang T, Domon C, Joo CK, Freund JN, Costantini F. Wnt/beta-catenin/Tcf signaling induces the transcription of Axin2, a negative regulator of the signaling pathway. Mol Cell Biol. 2002 Feb;22(4):1172-83.

Katoh M. Canonical and non-canonical WNT signaling in cancer stem cells and their niches: Cellular heterogeneity, omics reprogramming, targeted therapy and tumor plasticity (Review). Int J Oncol. 2017 Nov;51(5):1357-1369. doi: 10.3892/ijo.2017.4129.

Jochum, W., Passegué, E., Wagner, E.F., 2001. AP-1 in mouse development and tumorigenesis. Oncogene 20, 2401-2412. Kwon, Y.J., Lee, K.G., Choi, D., 2015. Clinical implications of advances in liver regeneration. Clin. Mol. Hepatol. 21, 7-13.

Li, Q., Van Antwerp, D., Mercurio, F., Lee, K.F., Verma, I.M., 1999. Severe liver degeneration in mice lacking the IkappaB kinase 2 gene. Science 284, 321-325.

Mao, S.A., Glorioso, J.M., Nyberg, S.L., 2014. Liver regeneration. Transl. Res. 163, 352-362.

Mitchell, C., Willenbring, H., 2008. A reproducible and well-tolerated method for 2/3 partial hepatectomy in mice. Nat. Protoc. 3, 1167-1170.

Mitchell, C., Willenbring, H., 2014. Addendum: A reproducible and well-tolerated method for 2/3 partial hepatectomy in mice. Nat. Protoc. 9, 10.1038/nprot.2014.122.

OECD (2018), Test No. 442B: Skin Sensitization: Local Lymph Node Assay: BrdU-ELISA or -FCM, OECD Guidelines for the Testing of Chemicals, Section 4, OECD Publishing, Paris, https://doi.org/10.1787/9789264090996-en. 
Rudolph, D., Yeh, W.-., Wakeham, A., Rudolph, B., Nallainathan, D., Potter, J., Elia, A.J., Mak, T.W., 2000. Severe liver degeneration and lack of NF- $\mathrm{KB}$ activation in NEMO/IKK $\gamma$ - deficient mice. Genes and Development 14, 854- 862 .

Schrum, L.W., Black, D., Iimuro, Y., Rippe, R.A., Brenner, D.A., Behrns, K.E., 2000. c-Jun does not mediate hepatocyte apoptosis following NFKB inhibition and partial hepatectomy. J. Surg. Res. 88, 142-149.

Schuijers J, Mokry M, Hatzis P, Cuppen E, Clevers H. Wnt-induced transcriptional activation is exclusively mediated by TCF/LEF. EMBO J. 2014 Jan 13;33(2):146-56. doi: 10.1002/embj.201385358.

Stanger, B.Z., 2015. Cellular homeostasis and repair in the mammalian liver. Annu. Rev. Physiol. 77, 179-200.

Takigawa Y, Brown AM. Wnt signaling in liver cancer. Curr Drug Targets. 2008; 9:1013-24

Tiburcio PD, Choi H, Huang LE. Complex role of HIF in cancer: the known, the unknown, and the unexpected. Hypoxia (Auckl). 2014 Jun 18;2:59-70.

Vannella KM, Wynn TA. Mechanisms of Organ Injury and Repair by Macrophages. Annu Rev Physiol. 2017 Feb 10;79:593-617. doi:10.1146/annurev-physiol-022516-034356.

Wang C, Lisanti MP, Liao DJ. Reviewing once more the c-myc and Ras collaboration: converging at the cyclin D1CDK4 complex and challenging basic concepts of cancer biology. Cell Cycle. 2011 Jan 1;10(1):57-67.

Wang IC, Chen YJ, Hughes DE, Ackerson T, Major ML, Kalinichenko VV, Costa RH, Raychaudhuri P, Tyner AL, Lau LF. FoxM1 regulates transcription of JNK1 to promote the G1/S transition and tumor cell invasiveness. J Biol Chem. 2008 Jul 25;283(30):20770-8. doi: 10.1074/jbc.M709892200.

Whyte JL, Smith AA, Helms JA. Wnt signaling and injury repair. Cold Spring Harb Perspect Biol. 2012 Aug 1;4(8):a008078. doi: 10.1101/cshperspect.a008078.

Wierstra I, Alves J. FOXM1, a typical proliferation-associated transcription factor. Biol Chem. 2007 Dec;388(12):1257-74.

Wierstra I, Alves J. FOXM1c is activated by cyclin E/Cdk2, cyclin A/Cdk2, and cyclin A/Cdk1, but repressed by GSK-3alpha. Biochem Biophys Res Commun. 2006 Sep15;348(1):99-108.

Wood, C.E., Hukkanen, R.R., Sura, R., Jacobson-Kram, D., Nolte, T., Odin, M., Cohen, S.M., 2015. Scientific and Regulatory Policy Committee (SRPC) Review: Interpretation and Use of Cell Proliferation Data in Cancer Risk Assessment. Toxicol. Pathol. 43, 760-775.

Yanger, K., Stanger, B.Z., 2011. Facultative stem cells in liver and pancreas: fact and fancy. Dev. Dyn. 240, 521-529.

Zhan T, Rindtorff N, Boutros M. Wnt signaling in cancer. Oncogene. 2017;36:146-1473. 


\section{List of Adverse Outcomes in this AOP}

Event: 1395: Liver Cancer (https://aopwiki.org/events/1395)

Short Name: Liver Cancer

AOPs Including This Key Event

\begin{tabular}{|l|l|}
\hline AOP ID and Name & Event Type \\
\hline Aop:220 - Cyp2E1 Activation Leading to Liver Cancer (https:/aopwiki.org/aops/220) & AdverseOutcome \\
\hline
\end{tabular}

Stressors

Name

Chloroform

furan

too many stressors to list

Biological Context

Level of Biological Organization

Organ

Organ term

Organ term

liver

\section{Evidence for Perturbation by Stressor}

Too many stressors to list.

There are many chemicals and substances that have been tested in the two year cancer bioassay and have been demonstrated to cause liver cancer. The results of two year cancer bioassay data can be reviewed in Lhasa's carcinogenicity potency database: https://carcdb.lhasalimited.org/carcdb-frontend/

\section{Domain of Applicability}

Taxonomic Applicability

\begin{tabular}{|l|l|l|l|}
\hline Term & $\begin{array}{l}\text { Scientific } \\
\text { Term }\end{array}$ & Evidence & Links \\
\hline rodents & rodents & High & $\begin{array}{l}\text { NCBI } \\
\text { (http://www.ncbi.nlm.nih.gov/Taxonomy/Browser/wwwtax.cgi?mode=Info\&id= } \\
0)\end{array}$ \\
\hline
\end{tabular}

Life Stage Applicability

\begin{tabular}{|l|l|}
\hline Life Stage & Evidence \\
\hline All life stages & High \\
\hline
\end{tabular}

Sex Applicability 


\begin{tabular}{|l|l|}
\hline Sex & Evidence \\
\hline Mixed & High \\
\hline
\end{tabular}

Hepatocellular carcinoma occurs in many vertebrate species including birds, fish, and mammals such as humans.

\section{Key Event Description}

Liver cancer is among the most common forms of cancer and the second leading cause of cancer death. It is more prevalent in males than females; however, prevalence has been increasing in both genders over the last two decades (Ellison, L.F., Wilkins, K. 2012). Hepatocellular carcinoma (HCC) is a primary cancer of the hepatocytes that is typically a progression from the benign hepatocellular adenoma (HCA). The most common risk factor for developing hepatocellular carcinoma is chronic liver injury and inflammation (caused by persistent infection, fatty liver disease, or chemical exposure). This disease is almost always lethal in the absence of extreme intervention measures (e.g., surgery, liver transplant).

\section{How it is Measured or Detected}

- In animal models, the presence of HCA and HCC are measured histologically following the standard two-year rodent bioassay, which is conducted according to OECD Test Guideline 451 (OECD 2009).

- In humans, liver cancer is detected by abdominal CT scan followed by biopsy and pathological examination. Symptoms of liver cancer include: jaundice, abdominal pain, nausea, and liver dysfunction. Liver cancer is more common in patients with risk factors that include: viral hepatitis, non-viral hepatitis, chronic alcoholism, obesity leading to steatohepatitis, cirrhosis, and liver fluke infection (Bonder and Afdhal 2012, Paradis 2013, Venkatesh, et al. 2014).

\section{Regulatory Significance of the AO}

Any cancer endpoint is considered to be adverse from a regulatory perspective. Substances causing cancer are regulated such that the general population is not exposed to levels that exceed the carcinogenic dose. The standard assay for carcinogens is the two-year rodent bioassay, which is conducted by the National Toxicology Program in the U.S.A. (https://ntp.niehs.nih.gov/). The International Agency on Research on Cancer (IARC; https://www.iarc.fr/) categorizes substances based on available evidence pointing to their ability to cause cancer in humans and/or animals.

\section{References}

Bonder, A., Afdhal, N., 2012. Evaluation of liver lesions. Clin. Liver Dis. 16, 271-283.

Ellison, L.F., Wilkins, K., 2012. Canadian Trends in Cancer Prevalence. Health Reports 23.

OECD, 2009. OECD Guideline for the Testing of Chemicals: Carcinogenicity Studies (Test Guideline 451).

Paradis, V., 2013. Histopathology of hepatocellular carcinoma. Recent Results Cancer Res. 190, 21-32.

Venkatesh, S.K., Chandan, V., Roberts, L.R., 2014. Liver masses: a clinical, radiologic, and pathologic perspective. Clin. Gastroenterol. Hepatol. 12, 1414-1429. 
Appendix 2: List of Key Event Relationships in the AOP

\section{List of Adjacent Key Event Relationships}

Relationship: 1512: Activation of Cyp2E1 leads to Oxidative Stress

(https://aopwiki.org/relationships/1512)

AOPs Referencing Relationship

\begin{tabular}{|l|l|l|l|}
\hline AOP Name & $\begin{array}{l}\text { Adjacen } \\
\text { cy }\end{array}$ & $\begin{array}{l}\text { Weight of } \\
\text { Evidence }\end{array}$ & $\begin{array}{l}\text { Quantitative } \\
\text { Understanding }\end{array}$ \\
\hline $\begin{array}{l}\text { Cyp2E1 Activation Leading to Liver Cancer } \\
\text { (https://aopwiki.org/aops/220) }\end{array}$ & adjacent & High & Not Specified \\
\hline
\end{tabular}

\section{Evidence Supporting Applicability of this Relationship}

Sex Applicability

\begin{tabular}{|l|l|}
\hline Sex & Evidence \\
\hline Mixed & High \\
\hline
\end{tabular}

\section{Key Event Relationship Description}

Cyp2E1 activation has two major outcomes: (1) the production of reactive, electrophilic metabolites, and (2) a significant increase in the half-life of the Cyp2E1 enzyme (Gonzalez 2007, Song, et al. 1989). The former is important because metabolites can go on to produce cellular damage by reacting with cellular nucleophiles. The latter is important because the Cyp2E1 catalytic cycle is prone to uncoupling (i.e., instead of incorporating an oxygen atom in to the substrate, the catalytic cycle is interrupted because a superoxide radical is released), which results in the release of reactive oxygen species (ROS) and an increase in cellular oxidative stress (Lieber 1999).

\section{Evidence Supporting this KER}

\section{Biological Plausibility}

It is well known that uncoupling of Cyp2E1 catalytic cycle results in the release of harmful reactive oxygen species in the cell (Lieber 1999).

Oxidative stress is produced during chronic activation (and uncoupling) of the Cyp2E1 catalytic cycle. The cytochrome P-450 catalytic cycle is known to undergo uncoupling leading to the production of ROS (Gorsky, et al. 1984, Loida and Sligar 1993, Meunier, et al. 2004). If this uncoupling occurs, a molecule of superoxide radical is released, which has the effect of interrupting the P450 catalytic cycle and releasing harmful ROS into the cell. Typically superoxide is converted to hydrogen peroxide (H2O2) by superoxide dismutase (SOD), which is further reduced into the hydroxyl radical $(\mathrm{OH} \bullet)$, and then to water. Other relevant cellular antioxidants include glutathione, thioredoxin, and peroxiredoxins. However, it is also possible for these ROS to scavenge electrons from cellular macromolecules (proteins, lipids, nucleic acids). Because Cyp2E1 is membrane-bound, ROS most commonly react with lipids and initiate lipid peroxidation. Further, Cyp2E1 can undergo NADPH-dependent 'futile cycling', which produces ROS and contributes to the occurrence of lipid peroxidation (Ekstrom and Ingelman-Sundberg 1989). The cellular sources and effects of ROS, as well as the corresponding enzymes and antioxidants are have been thoroughly reviewed (Nakazawa, et al. 1996). 


\section{Empirical Evidence}

Empirical data collected from different experiments strongly supports that oxidative stress and cytotoxicity are downstream of Cyp2E1 activation. Evidence of both temporal and dose-response concordance are available for a variety of chemical exposures.

Cyp2E1 protein levels increase when its substrates are present in a tissue. Therefore, prolonged exposure to substrate leads to prolonged activation of Cyp2E1, which is related to a substantial increase in cellular oxidative stress. For example:

-Treatment with acetone or ethanol in male Sprague-Dawley rats results in an increase in Cyp2E1 protein levels in the liver. Increasing Cyp2E1 levels are linearly correlated to concomitant increases in NADPH oxidase, superoxide radical, hydrogen peroxide, and lipid peroxidation (TBARS).

-Both hydrogen peroxide production and lipid peroxidation are blocked in rat microsomes following inhibition of Cyp2E1 with anti-Cyp2E1 IgG (Ekstrom and Ingelman-Sundberg 1989).

.Ethanol treatment leads to correlated increases in both Cyp2E1 protein and lipid peroxidation in male Wister rats, C57BL/129SV mice, and superoxide dismutase (Sod) knockout mice (Kessova, et al. 2003, Nanji, et al. 1994).

.Wild type and humanized Cype2E1 knock-in mice have dose-dependent increases in Cyp2E1 protein and activity levels when exposed to ethanol, whereas Cyp2E1 knock-out mice do not. Further, the humanized mice show the largest increases in necrosis, inflammation, AST, ALT and TBARS, and the largest decrease in GSH levels of all three groups (Lu, et al. 2010).

.Exposure of male Sprague-Dawley rats to 95\% oxygen results in a time-dependent increase in Cyp2E1 protein levels, superoxide radical production, and lipid peroxidation (TBARS) (various time-points over 78 hours).

.Lipid peroxidation is further increased following treatment of rat microsomes with carbon tetrachloride, or cotreatment of rats with oxygen, acetone and/or carbon tetrachloride (Tindberg and Ingelman-Sundberg 1989), established Cyp2E1 substrates.

.Cyp2E1 expressing HepG2 cells (called E47 cells) have higher baseline expression of anti-oxidant molecules thioredoxin and glutathione compared to non-Cyp2E1 expressing HepG2 cells (called C34 cells); they also have higher levels of ROS and lipid peroxidation (Yang, et al. 2011).

-Studies of ethanol- and Cyp2E1-dependent oxidative injury in HepG2 E47 and C34 cells, and in the liver, have been reviewed previously (Caro and Cederbaum 2004, Lu and Cederbaum 2008).

-At the molecular level, global gene expression profiling of mice exposed to a carcinogenic dose of furan (a Cyp2E1 substrate) demonstrated that the most perturbed molecular pathway was the Nrf2 Oxidative Stress Response pathway (Jackson, et al. 2014).

\section{Uncertainties and Inconsistencies}

None. 


\section{References}

Caro, A.A., Cederbaum, A.I., 2004. Oxidative stress, toxicology, and pharmacology of CYP2E1. Annu. Rev. Pharmacol. Toxicol. 44, 27-42.

Ekstrom, G., Ingelman-Sundberg, M., 1989. Rat liver microsomal NADPH-supported oxidase activity and lipid peroxidation dependent on ethanol-inducible cytochrome P-450 (P-450IIE1). Biochem. Pharmacol. 38, 1313-1319.

Gonzalez, F.J., 2007. The 2006 Bernard B. Brodie Award Lecture. Cyp2e1. Drug metabolism and disposition: the biological fate of chemicals $35,1-8$.

Gorsky, L.D., Koop, D.R., Coon, M.J., 1984. On the stoichiometry of the oxidase and monooxygenase reactions catalyzed by liver microsomal cytochrome P-450. Products of oxygen reduction. J. Biol. Chem. 259, 6812-6817.

Jackson, A.F., Williams, A., Recio, L., Waters, M.D., Lambert, I.B., Yauk, C.L., 2014. Case study on the utility of hepatic global gene expression profiling in the risk assessment of the carcinogen furan. Toxicol. Appl. Pharmacol. 274, 63-77.

Kessova, I.G., Ho, Y.S., Thung, S., Cederbaum, A.I., 2003. Alcohol-induced liver injury in mice lacking Cu, Znsuperoxide dismutase. Hepatology 38, 1136-1145.

Lieber, C.S., 1999. Microsomal ethanol-oxidizing system (MEOS): The first 30 years (1968- 1998) - A review. Alcohol. Clin. Exp. Res. 23, 991-1007.

Lu, Y., Cederbaum, A.I., 2008. CYP2E1 and oxidative liver injury by alcohol. Free Radical Biology and Medicine 44, 723-738.

Lu, Y., Wu, D., Wang, X., Ward, S.C., Cederbaum, A.I., 2010. Chronic alcohol-induced liver injury and oxidant stress are decreased in cytochrome P4502E1 knockout mice and restored in humanized cytochrome P4502E1 knockin mice. Free Radic. Biol. Med. 49, 1406-1416.

Meunier, B., de Visser, S.P., Shaik, S., 2004. Mechanism of oxidation reactions catalyzed by cytochrome p450 enzymes. Chem. Rev. 104, 3947-3980.

Nakazawa, H., Genka, C., Fujishima, M., 1996. Pathological aspects of active oxygens/free radicals. Jpn. J. Physiol. $46,15-32$.

Nanji, A.A., Zhao, S., Sadrzadeh, S.M., Dannenberg, A.J., Tahan, S.R., Waxman, D.J., 1994. Markedly enhanced cytochrome P450 2E1 induction and lipid peroxidation is associated with severe liver injury in fish oil-ethanol-fed rats. Alcohol. Clin. Exp. Res. 18, 1280-1285.

Song, B.J., Veech, R.L., Park, S.S., Gelboin, H.V., Gonzalez, F.J., 1989. Induction of rat hepatic Nnitrosodimethylamine demethylase by acetone is due to protein stabilization. J. Biol. Chem. 264, 3568-3572.

Tindberg, N., Ingelman-Sundberg, M., 1989. Cytochrome P-450 and oxygen toxicity. Oxygen-dependent induction of ethanol-inducible cytochrome P-450 (IIE1) in rat liver and lung. Biochemistry 28, 4499-4504.

Yang, L., Wu, D., Wang, X., Cederbaum, A.I., 2011. Depletion of cytosolic or mitochondrial thioredoxin increases CYP2E1-induced oxidative stress via an ASK-1-JNK1 pathway in HepG2 cells. Free Radic. Biol. Med. 51, 185-196. 
AOPs Referencing Relationship

\begin{tabular}{|l|l|l|l|}
\hline AOP Name & $\begin{array}{l}\text { Adjacen } \\
\text { cy }\end{array}$ & $\begin{array}{l}\text { Weight of } \\
\text { Evidence }\end{array}$ & $\begin{array}{l}\text { Quantitative } \\
\text { Understanding }\end{array}$ \\
\hline $\begin{array}{l}\text { Cyp2E1 Activation Leading to Liver Cancer } \\
\text { (https://aopwiki.org/aops/220) }\end{array}$ & adjacent & High & Not Specified \\
\hline
\end{tabular}

\section{Key Event Relationship Description}

Oxidative stress leads directly to hepatotoxicity through lipid peroxidation. Lipid peroxidation occurs when ROS scavenge electrons from poly-unsaturated fatty acids (PUFA), including membrane phospholipids. Lipid peroxidation occurs in three steps: initiation (in which the PUFA radical is produced), propagation (in which PUFA radicals react with molecular oxygen and a non-radical molecule to produce a lipid peroxide and lipid radical), and termination (in which two radicals combine to form a non-radical). Left unchecked, the propagation chain reaction is highly damaging to cellular membranes. Lipid peroxidation of mitochondrial membranes has been shown to result in both necrosis and apoptosis. The former occurs due to decreased mitochondrial membrane potential leading to decreased ATP production. The latter is a result of mitochondrial permeability transition (MPT). MPT is a process that can lead to necrosis or apoptosis. It is an important cell death mechanism because it is sensitive to redox conditions. Accumulation of ROS and depletion of glutathione trigger the mitogen activated protein kinase (MAPK) cascade (ASK1-->MKK4-->JNK), which recruits Bax to the outer mitochondrial membrane (Youle and Strasser 2008). Bax triggers the opening of mitochondrial permeability transition pore (MTP), through which cytochrome c is released, which triggers the caspase cascade and apoptosis. Alternatively, when the MTP opens across the inner and outer mitochondrial membranes, mitochondrial swelling and decoupling of oxidative phosphorylation (i.e., loss of ATP generation) leads to cell death by necrosis (Pessayre, et al. 2010, Rasola and Bernardi 2007).

In parallel, oxidative stress triggers cytotoxicity indirectly by modifying redox sensitive cellular molecules. Proteins with neighboring cysteine residues sense ROS through the oxidation of adjacent thiol groups ( $2 \mathrm{SH}$, reduced; $\mathrm{S}=\mathrm{S}$, oxidized). Examples of this include: (1) the cellular anti-oxidant glutathione (GSH), which acts to 'mop up' ROS (GSH oxidized to GS=SG), and its depletion is associated with elevated cytotoxicity because ROS levels remain elevated or increase; (2) the cellular anti-oxidant thioredoxin, which inhibits the apoptosis signaling kinase 1 (Ask1) in its reduced form, but not in its oxidized form (Liu, et al. 2000, Saitoh, et al. 1998); and, (3) the mitochondrial permeability transition pore, which opens when oxidized (Petronilli, et al. 1994). Oxidative stress can also produce cell death through the production of oxidative damage to DNA, which can lead to apoptosis through p53 signalling. Examples of types of oxidative DNA damage include: (Sharma, et al. 2012, Shukla, et al. 2013, Skipper, et al. 2016).

\section{Evidence Supporting this KER}

\section{Biological Plausibility}

Strong. It is well known that cellular oxidative damage, especially by lipid peroxidation, is cytotoxic.

\section{Empirical Evidence}

Strong. This is an extremely data-rich KER. A large number of studies have taken measures of both oxidative stress and cytotoxicity within the same study. Below, we summarize a few examples, in vitro and in vivo, to demonstrate some empirical data that provides strong support for this KER.

For example, exposure of HepG2 cells to the pesticide malathion demonstrates a relationship between ROS and cytotoxicity at higher levels of exposure (Moore, et al. 2010). After $48 \mathrm{~h}$ of exposure to $0,6,12$, 18, and $24 \mathrm{mM}$ 
malathion, lipid peroxidation increases from the first concentration, whereas cytoxicity (MTT assay) does not significantly increase until 18 and $24 \mathrm{mM}$.

Similarly, treatment of cultured premonocytic U937 cells with increasing concentrations of lipid peroxidationinducing agents (tert-butylhydroperoxide and 2,2'-azobis (2-amindinopropane) hydrochloride) results in increased lipid peroxidation within $30 \mathrm{~min}$, and subsequent declines in relative survival (trypan blue assay) six hours postexposure (Park, et al. 2002). In parallel, the major anti-oxidant enzymes catalase, SOD, glucose-6-phosphatedehydrogenase, and glutathione peroxidase are deactivated in a dose-dependent fashion that is concordant with declines in relative survival.

Studies on primary rat hepatocytes show that a dose-dependent increase in TBARS is associated with a concomitant increase in cytotoxicity following exposure to fumonisin B1 (FB1) (Abel and Gelderblom 1998). Moreover, addition of the antioxidant alpha-tocopherol significantly decreases cytotoxicity and decreases TBARS to basal levels, supporting that lipid peroxidation contributes to the cytotoxic effects of FB1.

In female Wistar rat hepatocyte cultures, exposure to chloroform causes a small dose-dependent increase in M(1)dG adducts (a marker of lipid perodixation; occurs at $4 \mathrm{mM}$ and above), DNA strand breakage ( $8 \mathrm{mM}$ and above) and lipid peroxidation (at $4 \mathrm{mM}$ and above). GSH depletion occurs in association with cytotoxicity (20 $\mathrm{mM}$; lactate dehydrogenase release). Carbon tetrachloride ( 1 and $4 \mathrm{mM}$ ) exposure produces a small elevation in $\mathrm{M}(1) \mathrm{dG}$ adducts and increases in 8-oxodG occur at the threshold of, and concomitant with, cytotoxicity (4 mM). (Beddowes, et al. 2003).

Similarly, exposure of 12-week old male Long Evans rats to increasing doses of cadmium (Cd) (i.p. injection) reveals that lipid peroxidation (TBARS) occurs in liver at low to medium doses, below those inducing tissue necrosis (Manca, et al. 1991). In this study, liver injury occurred above $125 \mathrm{ug} \mathrm{Cd} / \mathrm{kg}$ (increased serum ALT and SDH). Levels of TBARS were similar in both the 125 and the $250 \mathrm{ug} / \mathrm{doses}$, though only reached statistical significance relative to controls at $250 \mathrm{ug} / \mathrm{kg}$ in the liver. However, subsequent time-series analysis revealed increased liver TBARS after $2 \mathrm{~h}$ exposure to both 25 and $500 \mathrm{ug} \mathrm{Cd} / \mathrm{kg}$, prior to any changes in serum ALT, SDH, and tissue ALP (at the low dose, ALP was the only marker that was slightly increased at 6 hour). Therefore, lipid peroxidation precedes liver damage in this study.

\section{Uncertainties and Inconsistencies}

There exist some examples where measures of cytotoxicity could be observed below doses where assays for endpoints of oxidative stress were measured. However, it is difficult to compare endpoints measured using assays with different specificities and sensitivities. Quite generally, there is a high degree of association between measures of oxidative stress and cytotoxicity across tissues and species.

\section{References}

Abel, S., Gelderblom, W.C., 1998. Oxidative damage and fumonisin B1-induced toxicity in primary rat hepatocytes and rat liver in vivo. Toxicology 131, 121-131.

Beddowes, E.J., Faux, S.P., Chipman, J.K., 2003. Chloroform, carbon tetrachloride and glutathione depletion induce secondary genotoxicity in liver cells via oxidative stress. Toxicology 187, 101-115.

Liu, H., Nishitoh, H., Ichijo, H., Kyriakis, J.M., 2000. Activation of apoptosis signal-regulating kinase 1 (ASK1) by tumor necrosis factor receptor-associated factor 2 requires prior dissociation of the ASK1 inhibitor thioredoxin. Mol. Cell. Biol. 20, 2198-2208.

Manca, D., Ricard, A.C., Trottier, B., Chevalier, G., 1991. Studies on lipid peroxidation in rat tissues following administration of low and moderate doses of cadmium chloride. Toxicology 67, 303-323. 
Moore, P.D., Yedjou, C.G., Tchounwou, P.B., 2010. Malathion-induced oxidative stress, cytotoxicity, and genotoxicity in human liver carcinoma (HepG2) cells. Environ. Toxicol. 25, 221-226. Park, J.E., Yang, J.H., Yoon, S.J., Lee, J.H., Yang, E.S., Park, J.W., 2002. Lipid peroxidation-mediated cytotoxicity and DNA damage in U937 cells. Biochimie 84, 1199-1205.

Pessayre, D., Mansouri, A., Berson, A., Fromenty, B., 2010. Mitochondrial involvement in drug-induced liver injury. Handb. Exp. Pharmacol. (196):311-65. doi, 311-365. Rasola, A., Bernardi, P., 2007. The mitochondrial permeability transition pore and its involvement in cell death and in disease pathogenesis. Apoptosis 12, 815-833.

Saitoh, M., Nishitoh, H., Fujii, M., Takeda, K., Tobiume, K., Sawada, Y., Kawabata, M., Miyazono, K., Ichijo, H., 1998. Mammalian thioredoxin is a direct inhibitor of apoptosis signal-regulating kinase (ASK) 1. EMBO Journal 17, 2596- 2606.

Sharma, V., Singh, P., Pandey, A.K., Dhawan, A., 2012. Induction of oxidative stress, DNA damage and apoptosis in mouse liver after sub-acute oral exposure to zinc oxide nanoparticles. Mutat. Res. 745, 84-91. Shukla, R.K., Kumar, A., Gurbani, D., Pandey, A.K., Singh, S., Dhawan, A., 2013. TiO(2) nanoparticles induce oxidative DNA damage and apoptosis in human liver cells. Nanotoxicology 7, 48-60.

Skipper, A., Sims, J.N., Yedjou, C.G., Tchounwou, P.B., 2016. Cadmium Chloride Induces DNA Damage and Apoptosis of Human Liver Carcinoma Cells via Oxidative Stress. Int. J. Environ. Res. Public. Health. 13, 10.3390/ijerph13010088.

Youle, R.J., Strasser, A., 2008. The BCL-2 protein family: opposing activities that mediate cell death. Nat. Rev. Mol. Cell Biol. 9, 47-59.

Relationship: 1514: Hepatocytotoxicity leads to Sustained proliferation (https://aopwiki.org/relationships/1514)

AOPs Referencing Relationship

\begin{tabular}{|l|l|l|l|}
\hline AOP Name & $\begin{array}{l}\text { Adjacen } \\
\text { cy }\end{array}$ & $\begin{array}{l}\text { Weight of } \\
\text { Evidence }\end{array}$ & $\begin{array}{l}\text { Quantitative } \\
\text { Understanding }\end{array}$ \\
\hline $\begin{array}{l}\text { Cyp2E1 Activation Leading to Liver Cancer } \\
\text { (https://aopwiki.org/aops/220) }\end{array}$ & adjacent & High & Not Specified \\
\hline
\end{tabular}

Evidence Supporting Applicability of this Relationship

Sex Applicability

\begin{tabular}{|l|l|}
\hline Sex & Evidence \\
\hline Mixed & Moderate \\
\hline
\end{tabular}

Relevant to any species with a liver.

\section{Key Event Relationship Description}

Hepatocytes are typically quiescent, with only about 1-2\% turnover. However, under cytotoxic conditions, the liver has a remarkable ability to replace dead or dying cells through induction of cellular proliferation to create new liver cells and maintain homeostasis. Indeed, following surgical resection or chemically induced injury, the liver is able to activate cell division and regenerate itself.

The liver replaces dead cells via two main pathways: (1) hypertrophy and division of existing cells; or (2) proliferation of a population of facultative stem cells, called biliary epithelial cells (BECs), located at the Canals of 
Hering (in zone 1 where canaliculi join and drain into the main bile duct). Facultative stem cells are functional, differentiated cells that will dedifferentiate in response to tissue damage, thereby becoming a population of progenitor cells that can redifferentiate to replace multiple lost cell types. In a process known as ductal expansion, BECs dedifferentiate into oval cells, which then redifferentiate into hepatocytes or BECs in order to regenerate damaged liver tissue. Liver cell proliferation and regeneration has been extensively reviewed (Mao, et al. 2014, Stanger 2015, Yanger and Stanger 2011).

On a molecular level, how liver cell proliferation occurs is less completely understood. Molecular signals that are released from dying cells trigger proliferation of existing cells. Important players include the transcription factors AP-1 (particularly the c-Jun monomer) and NF-kappaB, both of which are not normally expressed in adult liver, but are up-regulated following partial hepatectomy and are required for hepatic regeneration.

Liver cell proliferation has been well studied in mice, rats, and zebrafish (Cox and Goessling 2015, Goessling and Sadler 2015), which are all systems that are thought to work in a similar way to human livers (Kwon, et al. 2015). Liver regeneration can be observed following partial hepatectomy. Methods for $2 / 3$ partial hepatectomy have been described (Mitchell and Willenbring 2008, Mitchell and Willenbring 2014).

\section{Evidence Supporting this KER}

\section{Biological Plausibility}

Strong. The liver is well known to regenerate itself following chemical or surgical injury. It is widely accepted that significant cytotoxicity to the liver leads to cellular proliferation (Forbes and Newsome 2016). If this occurs during chronic exposure these effects would persist or be sustained.

\section{Empirical Evidence}

Strong. That chronic hepatotoxicity leads to persistent proliferation/sustained proliferation has been widely reported for a number of liver toxicants (as well as surgical resection of the liver). This is a very data-rich field. Below we summarize a few examples of the empirical data supporting this relationship.

Furan is a rodent hepatocarcinogenic chemical that is proposed to operate through a mode of action involving cytotoxicity followed by cellular proliferation (Fransson-Steen, et al. 1997, Moser, et al. 2009). In support of the relationship between hepatotoxicity and persistent proliferation/sustained proliferation, mice and rats exposed to dose ranges of furan present with cytotoxicity at lower doses than the doses at which they present regenerative proliferation. Mice exposed to a dose range of $0,0.5,1,2,4,8 \mathrm{mkd}$ had significant levels of liver cytotoxicity (measured by serum ALT) beginning at $1 \mathrm{mkd}$, and significant levels of cellular proliferation (measured by BrdU incorporation) at $8 \mathrm{mkd}$ (Moser, et al. 2009). F344 rats exposed to 0-16 mkd furan showed significant increases in cell death starting at 2-4 mkd, and proliferation at 8-16 mkd (Ding, et al. 2012). Cytotoxicity also begins at earlier time points than proliferation. Cell death and proliferation were also measured in male Sprague-Dawley rats exposed to $30 \mathrm{mkd}$ furan over a three month time course. Apoptosis was detected after one day, whereas proliferation began to occur after three days (Hickling, et al. 2010).

Male Wistar rats treated with a single, necrogenic dose of thioacetamide had serum AST levels of approximately: 500, 2250, 1900 and $500 \mathrm{IU} / \mathrm{L}$ serum at 12, 24 (peak), 48 and 72 hours post-exposure; levels were restored to normal after 96 hours. Levels of cellular proliferation followed closely after, and peaked at 48 hours; thereby demonstrating a temporal concordance between cytotoxicity and cellular proliferation (Bautista, et al. 2010). Rats exposed to thioacetamide presented with hepatotoxicity (increased ALT) beginning at 24 hours post-exposure followed by increased cellular proliferation at 36 hours post-exposure (samples were taken over the following timecourse: $6,12,24,36,48,72$ and 96 hours); thereby demonstrating a temporal concordance between cytotoxicity and cellular proliferation (Mangipudy, et al. 1995). 
B6C3F1 mice were exposed to $0,34,90,138$, or $277 \mathrm{mg} / \mathrm{kg} /$ day of chloroform for 4 days or for 5 days/week for 3 weeks. Hepatic necrosis was observed to be elevated above control in all dose groups at both time points. Cellular proliferation (by labelling index, BrdU incorporation) in the liver increased in a dose-dependent manner at both time points ( 4 days and 3 weeks), but were first significantly increased above control levels at $34 \mathrm{mg} / \mathrm{kg}$ bw (4 day group) or $138 \mathrm{mg} / \mathrm{kg}$ bw (3 week group). These data demonstrate the temporal concordance between cytotoxicity and cellular proliferation of hepatocytes; the trend is particularly clear at the 3 week time-point (Larson, et al. 1994).

The temporal concordance between cytotoxicity and cellular proliferation has also been well documented following exposure to carbon tetrachloride (Benson and Springer 1999, Doolittle, et al. 1987, Eschenbrenner and Miller 1946, Lee, et al. 1998, Nakata, et al. 1985).

\section{Uncertainties and Inconsistencies}

We are not aware of any instance in which significant amounts of hepatotoxicity (in genetically normal livers) would not lead to cellular proliferation.

\section{Quantitative Understanding of the Linkage}

Unable to determine.

\section{Time-scale}

This KER is relevant for sustained or persistent exposures.

\section{References}

Bautista, M., Andres, D., Cascales, M., Morales-Gonzalez, J.A., Sanchez-Reus, M.I., 2010. Effect of gadolinium chloride on liver regeneration following thioacetamide-induced necrosis in rats. Int. J. Mol. Sci. 11, 4426-4440.

Benson, J., Springer, D., 1999. Improved risk estimates for carbon tetrachloride. Final Report. Project No., 54940. DE-FC04-96AL76406.

Ding, W., Petibone, D.M., Latendresse, J.R., Pearce, M.G., Muskhelishvili, L., White, G.A., Chang, C.-., Mittelstaedt, R.A., Shaddock, J.G., McDaniel, L.P., Doerge, D.R., Morris, S.M., Bishop, M.E., Manjanatha, M.G., Aidoo, A., Heflich, R.H., 2012. In vivo genotoxicity of furan in F344 rats at cancer bioassay doses. Toxicol. Appl. Pharmacol. 261, 164-171.

Doolittle, D.J., Muller, G., Scribner, H.E., 1987. Relationship between hepatotoxicity and induction of replicative DNA synthesis following single or multiple doses of carbon tetrachloride. J. Toxicol. Environ. Health 22, 63-78.

Eschenbrenner, A.B., Miller, E., 1946. Liver necrosis and the induction of carbon tetrachloride hepatomas in strain A mice. J. Natl. Cancer Inst. 6, 325-341.

Forbes, S.J., Newsome, P.N., 2016. Liver regeneration - mechanisms and models to clinical application. Nat. Rev. Gastroenterol. Hepatol. 13, 473-485.

Fransson-Steen, R., Goldsworthy, T.L., Kedderis, G.L., Maronpot, R.R., 1997. Furan-induced liver cell proliferation and apoptosis in female B6C3F1 mice. Toxicology 118, 195-204.

Hickling, K.C., Hitchcock, J.M., Oreffo, V., Mally, A., Hammond, T.G., Evans, J.G., Chipman, J.K., 2010. Evidence of oxidative stress and associated DNA damage, increased proliferative drive, and altered gene expression in rat liver produced by the cholangiocarcinogenic agent Furan. Toxicol. Pathol. 38, 230-243. 
Larson, J.L., Wolf, D.C., Butterworth, B.E., 1994. Induced cytolethality and regenerative cell proliferation in the livers and kidneys of male B6C3F1 mice given chloroform by gavage. Fundamental and applied toxicology : official journal of the Society of Toxicology 23, 537-43.

Lee, V.M., Cameron, R.G., Archer, M.C., 1998. Zonal location of compensatory hepatocyte proliferation following chemically induced hepatotoxicity in rats and humans. Toxicol. Pathol. 26, 621-627. Mangipudy, R.S., Chanda, S., Mehendale, H.M., 1995. Tissue repair response as a function of dose in thioacetamide hepatotoxicity. Environ. Health Perspect. 103, 260-267.

Moser, G.J., Foley, J., Burnett, M., Goldsworthy, T.L., Maronpot, R., 2009. Furan-induced dose-response relationships for liver cytotoxicity, cell proliferation, and tumorigenicity (furan-induced liver tumorigenicity). Experimental and Toxicologic Pathology 61, 101-111.

Nakata, R., Tsukamoto, I., Miyoshi, M., Kojo, S., 1985. Liver regeneration after carbon tetrachloride intoxication in the rat. Biochem. Pharmacol. 34, 586-588. Stanger, B.Z., 2015. Cellular homeostasis and repair in the mammalian liver. Annu. Rev. Physiol. 77, 179-200.

\section{List of Non Adjacent Key Event Relationships}

Relationship: 1515: Activation of Cyp2E1 leads to Hepatocytotoxicity

(https://aopwiki.org/relationships/1515)

AOPs Referencing Relationship

\begin{tabular}{|l|l|l|l|}
\hline AOP Name & Adjacency & $\begin{array}{l}\text { Weight of } \\
\text { Evidence }\end{array}$ & $\begin{array}{l}\text { Quantitative } \\
\text { Understanding }\end{array}$ \\
\hline $\begin{array}{l}\text { Cyp2E1 Activation Leading to Liver Cancer } \\
\text { (https://aopwiki.org/aops/220) }\end{array}$ & $\begin{array}{l}\text { non- } \\
\text { adjacent }\end{array}$ & High & Not Specified \\
\hline
\end{tabular}

\section{Evidence Supporting Applicability of this Relationship}

Taxonomic Applicability

\begin{tabular}{|l|l|l|l|}
\hline Term & $\begin{array}{l}\text { Scientific } \\
\text { Term }\end{array}$ & $\begin{array}{l}\text { Evidenc } \\
\text { e }\end{array}$ & Links \\
\hline $\begin{array}{l}\text { Rodentia } \\
\text { sp. }\end{array}$ & Rodentia sp. & High & $\begin{array}{l}\text { NCBI } \\
\text { (http://www.ncbi.nlm.nih.gov/Taxonomy/Browser/wwwtax.cgi?mode=Info\&id } \\
=69158)\end{array}$ \\
\hline
\end{tabular}

Life Stage Applicability

\begin{tabular}{|l|l|}
\hline Life Stage & Evidence \\
\hline All life stages & High \\
\hline
\end{tabular}

Sex Applicability

\begin{tabular}{|l|l|}
\hline Sex & Evidence \\
\hline Mixed & High \\
\hline
\end{tabular}

\section{Key Event Relationship Description}

Metabolism of xenobiotics by cytochrome P450 mono-oxygenases produces reactive metabolites. Under normal circumstances, these metabolites immediately become conjugated to molecules like glutathione or glucuronic acid, which facilitates their excretion. However, these metabolites can react with off-target cellular molecules, which in 
extreme cases (e.g., at toxic doses or following glutathione depletion during periods of oxidative stress) cause damage that results in hepatotoxicity. Typically, the unmetabolised Cyp2E1 substrates are inert, whereas their metabolites are highly cytotoxic; e.g., furan and its metabolite cis-2-butene-1,4-dial (BDA); ethanol (EtOH) and acetaldehyde; carbon tetrachloride and trichloromethyl radical (which forms the trichloromethyl peroxy radical); and, chloroform and phosgene. Lipid peroxidation in the context of Cyp2E1 has been reviewed (Caro and Cederbaum 2004). Moreover, chronic exposure to Cyp2E1 agonists depletes of conjugating enzymes and diminishes capacity to deal with reactive metabolites in the cell.

\section{Evidence Supporting this KER}

\section{Biological Plausibility}

Strong. Metabolite-dependent toxicity and adduct formation are well known side-effects of cytochrome P450 monooxygenase metabolism of xenobiotics in the liver. Because primary metabolites are more reactive than the parent compound, they often create adducts to cellular proteins or DNA. In both cases, this prevents the normal functioning of the molecules. In extreme cases this will lead to hepatocytotoxicity due to: (1) the large number of adducts, (2) the loss of function of important cellular proteins and the related cellular processes, and (3) the loss of function of important genes due to DNA damage and mutation.

\section{Empirical Evidence}

Strong. There is a large amount of published data that demonstrate the cytotoxic effects of Cyp2E1 substrates following metabolic activation.

Cyp2E1 converts furan to BDA. While furan can be tolerated by cells at extremely high doses, BDA is cytotoxic at much lower doses (Kellert, et al. 2008). Furan treatment causes dose-dependent increases in hepatotoxicity in mice (Moser, et al. 2009), which can be prevented by co-treatment with a Cyp2E1 inhibitor (Fransson-Steen, et al. 1997).

Cyp2E1 converts carbon tetrachloride to the trichloromethyl radical. Trichloromethyl radical reacts with oxygen to form the trichloromethyl peroxy radical. Carbon tetrachloride-dependent cytotoxicity is preventable by pre-treatment with cytochrome P450 inhibitors (Bechtold, et al. 1982, Letteron, et al. 1990, Martinez, et al. 1995), and is exacerbated in cells that over-express Cyp2E1 (Takahashi, et al. 2002). Carbon tetrachloride produces hepatotoxicity in wild-type mice, but not in Cyp2E1-null mice (Wong, et al. 1998).

Cyp2E1 converts chloroform to phosgene. Phosgene protein adducts are co-localized to regions of chloroformdependent cytotoxicity (Fabrizi, et al. 2001, Ilett, et al. 1973) and protein adducts occur prior to hepatotoxicity (Stevens and Anders 1981). Chloroform-dependent hepatotoxicity increases with dose (Larson, et al. 1994) and levels of cytotoxicity are related to the rate of chloroform biotransformation by Cyp2E1 (Brown, et al. 1974).

Blocking Cyp2E1 gene transcription (using the drug Bortezomib) blocks acetaminophen-, carbon tetrachloride-, and thioacetamide-dependent hepatotoxicity in a dose and time dependent manner (Park, et al. 2016).

\section{Uncertainties and Inconsistencies}

While the prevailing opinion in the literature is that the toxicity of these metabolites is the result of non-genotoxic mechanisms, there are studies that argue in favour of direct genotoxic effects. It is widely thought that any observed genotoxicity is actually 'indirect' and is the product of oxidative stress. 


\section{References}

Bechtold, M.M., Gee, D.L., Bruenner, U., Tappel, A.L., 1982. Carbon tetrachloride-mediated expiration of pentane and chloroform by the intact rat: the effects of pretreatment with diethyl maleate, SKF-525A and phenobarbital. Toxicol. Lett. 11, 165-171.

Brown, B.R.,Jr, Sipes, I.G., Sagalyn, A.M., 1974. Mechanisms of acute hepatic toxicity: chloroform, halothane, and glutathione. Anesthesiology 41, 554-561. Caro, A.A., Cederbaum, A.I., 2004. Oxidative stress, toxicology, and pharmacology of CYP2E1. Annu. Rev. Pharmacol. Toxicol. 44, 27-42.

Fabrizi, L., Taylor, G.W., Edwards, R.J., Boobis, A.R., 2001. Adducts of the chloroform metabolite phosgene. Adv. Exp. Med. Biol. 500, 129-132.

Fransson-Steen, R., Goldsworthy, T.L., Kedderis, G.L., Maronpot, R.R., 1997. Furan-induced liver cell proliferation and apoptosis in female B6C3F1 mice. Toxicology 118, 195-204.

Kellert, M., Brink, A., Richter, I., Schlatter, J., Lutz, W.K., 2008. Tests for genotoxicity and mutagenicity of furan and its metabolite cis-2-butene-1,4-dial in L5178Y tk+/- mouse lymphoma cells. Mutation research 657, 127-32.

Larson, J.L., Wolf, D.C., Butterworth, B.E., 1994. Induced cytolethality and regenerative cell proliferation in the livers and kidneys of male B6C3F1 mice given chloroform by gavage. Fundamental and applied toxicology : official journal of the Society of Toxicology 23, 537-43.

Letteron, P., Labbe, G., Degott, C., Berson, A., Fromenty, B., Delaforge, M., Larrey, D., Pessayre, D., 1990. Mechanism for the protective effects of silymarin against carbon tetrachloride-induced lipid peroxidation and hepatotoxicity in mice. Evidence that silymarin acts both as an inhibitor of metabolic activation and as a chainbreaking antioxidant. Biochem. Pharmacol. 39, 2027-2034.

Martinez, M., Mourelle, M., Muriel, P., 1995. Protective effect of colchicine on acute liver damage induced by CCl4. Role of cytochrome P-450. J. Appl. Toxicol. 15, 49-52.

Moser, G.J., Foley, J., Burnett, M., Goldsworthy, T.L., Maronpot, R., 2009. Furan-induced dose-response relationships for liver cytotoxicity, cell proliferation, and tumorigenicity (furan-induced liver tumorigenicity). Experimental and Toxicologic Pathology 61, 101-111.

Park, W.J., Kim, S.Y., Kim, Y.R., Park, J.W., 2016. Bortezomib alleviates drug-induced liver injury by regulating CYP2E1 gene transcription. Int. J. Mol. Med. 37, 613-622. Stevens, J.L., Anders, M.W., 1981. Effect of cysteine, diethyl maleate, and phenobarbital treatments on the hepatotoxicity of $[1 \mathrm{H}]$ chloroform. Chem. Biol. Interact. 37 , 207-217.

Takahashi, S., Takahashi, T., Mizobuchi, S., Matsumi, M., Morita, K., Miyazaki, M., Namba, M., Akagi, R., Hirakawa, M., 2002. Increased cytotoxicity of carbon tetrachloride in a human hepatoma cell line overexpressing cytochrome P450 2E1. J. Int. Med. Res. 30, 400-405.

Relationship: 1516: Oxidative Stress leads to Liver Cancer (https://aopwiki.org/relationships/1516)

AOPs Referencing Relationship

\begin{tabular}{|l|l|l|l|}
\hline AOP Name & Adjacency & $\begin{array}{l}\text { Weight of } \\
\text { Evidence }\end{array}$ & $\begin{array}{l}\text { Quantitative } \\
\text { Understanding }\end{array}$ \\
\hline $\begin{array}{l}\text { Cyp2E1 Activation Leading to Liver Cancer } \\
\text { (https://aopwiki.org/aops/220) }\end{array}$ & $\begin{array}{l}\text { non- } \\
\text { adjacent }\end{array}$ & Moderate & Not Specified \\
\hline
\end{tabular}




\section{Key Event Relationship Description}

There are a variety of ways in which oxidative stress can lead indirectly to cancer. The main routes involve: (a) reactive oxygen species (ROS) that cause cytotoxicity, followed by regenerative proliferation leading to cancer; (b) ROS- induced DNA damage leading to mutations in cancer-driver genes and subsequently cancer; and (c) oncogenic effects of the up-regulation of NRF2. The focus of this iKER is on (b) and (c), as the details of (a) are mapped out elsewhere.

\section{Evidence Supporting this KER}

\section{Biological Plausibility}

Moderate.

The types of genotoxic oxidative DNA damage that may occur following exposure to ROS have been extensively reviewed previously (Dizdaroglu 2012, Dizdaroglu 2015). Briefly, ROS can react with nitrogenous bases to produce various adducts that may be converted into a mutation following DNA replication. Further, ROS can damage the sugar phosphate backbone of DNA leading to abasic sites and strand breaks. If DNA damage leads to mutations that increases the expression of oncogenes or decreases the expression of tumour suppressor or DNA damage repair genes, they will transform normal cells into malignant cells. It is generally thought that liver cancer results from an accumulation of mutations in key cancer-driving genes such as TP53 and CTNNB1 (Fujimoto, et al. 2016, Shibata and Aburatani 2014a) (http://atlasgeneticsoncology.org/Tumors/HepatoCarcinID5039.html).

In addition to DNA damage, at the molecular level, chronic activation of the Nrf2 oxidative stress response has been linked to promoting malignant transformation in pre-cancerous cells. Persistent Nrf2 activation results in the longterm up-regulation of antioxidant genes (which protect cancer cells that are known to have elevated ROS) and phase II metabolism genes (which facilitate the rapid metabolism of chemotherapeutics) (Kansanen, et al. 2013) providing a favourable environment for growth of pre-cancerous cells. The connection between chronically activated Nrf2 and cancer has been extensively studied and reviewed, most recently by Furfaro et al. (2016) and Karin and Dhar (2016).

Further, Nrf2 control over cellular proliferation and differentiation has also been studied; reviewed most recently by Murakami and Motohashi (2015).

\section{Empirical Evidence}

Moderate.

Carcinogens that cause cancer by 'cytotoxicity and regenerative proliferation' are generally accepted to be indirectly genotoxic. The most plausible source of indirect genotoxicity for these compounds are ROS. The following examples involve chemicals that are known rodent and/or human carcinogens. These data demonstrate that exposure leads to oxidative DNA damage, which may cause mutations required for malignant transformation. Overall, a variety of lines of evidence support the relationship between oxidative stress with the development and progression of hepatocellular carcinoma in humans. For example, reduced superoxide dismutase 2 (an antioxidant gene) mRNA and protein expression is correlated with mortality of hepatitis B virus-associated hepatocellular carcinoma patients in a mutant p53-dependent manner (Wang, et al. 2016b). This decrease in expression is accompanied by decreased copy number of the gene in tumours, supporting a genetic basis for the molecular phenotype. Plasma protein carbonyl content (biomarker of oxidative stress) is significantly higher, whereas plasma TAC (biomarker of antioxidant capacity) is significantly lower in hepatitis B virus-associated HCC patients with than healthy controls (Poungpairoj, et al. 2015). Exposure of human HepG2 cells to 2-Amino-9H-pyrido[2,3-b]indole (AaC) leads to increased levels of ROS and 8-Hydroxydesoxyguanosin (8-OHdG), and decreased GSH/GSSG ratio (Zhang, et al. 2015). Subsequent investigations showed that the concentration of $8-\mathrm{OHdG}$ was positively related to DNA damage measured by the comet assay, indicating a role for genotoxicity in cancer for this compound. 
Furan is not directly genotoxic; any observed genotoxicity following furan exposure is thought to be due to ROSinduced DNA damage. Oxidative DNA adducts (8-oxo-dG) have been observed following a three month exposure to a high dose of furan (30 mkd) (Hickling, et al. 2010). These 8-oxo-dG adducts were observed together with high levels of Cyp2E1 expression (the potential source of the ROS), apoptosis, necrosis, and proliferation in rat livers. Male mice exposed to a carcinogenic dose of furan $(8 \mathrm{mkd})$ presented with increased levels of 8-OHdG DNA adducts, which could be prevented through co-treatment with apigenin (Wang, et al. 2014); global gene expression analysis of mice exposed at $8 \mathrm{mkd}$ have also been shown to have increased expression of the Nrf2 oxidative stress response pathway (Jackson, et al. 2014). Rats exposed to furan $(0,2,4,8,12$ and $16 \mathrm{mkd}$ ) presented with dosedependent increases in oxidized nitrogenous bases and double strand breaks, which were repaired in a timedependent manner and in conjunction with an increase in expression of DNA repair genes (Ding, et al. 2012). Increases in DNA oxidative lesions, and supporting evidence from measures of gene expression changes, occur at doses that are aligned with those causing liver cancer in the same rodent models (furan-dependent liver cancer occurs at $2 \mathrm{mkd}$ and up in rats and $4 \mathrm{mkd}$ in mice) (Moser, et al. 2009, NTP 1993). Further, they occur at earlier time points than the corresponding carcinogenesis.

By-products of lipid peroxidation (Malondialdehyde (MDA), 4-Hydroxynonenal (4-HNE)) react with DNA to form etheno-DNA adducts (particularly, $\varepsilon \mathrm{dA}$ and $\varepsilon \mathrm{dC}$ ), these adducts have been observed in vitro and in human patients, and are correlated with hepatocarcinogenesis (Linhart, et al. 2014, Wang, et al. 2009, Winczura, et al. 2012). Male Wistar rats exposed for one month to $35 \%$ ethanol had abasic sites, Ogg1-sensitive sites, and increased expression of base excision repair (BER) genes in liver DNA; this ROS-dependent DNA damage occurs at earlier time points than the corresponding carcinogenesis.

Chloroform and carbon tetrachloride cause GSH depletion in human HepG2 cells, which leads to ROS and subsequent DNA strand breaks, 8-oxodeoxyguanosine (8-oxodG) DNA adducts, malondialde hydedeoxyguanosine (M1dG) DNA adducts, and lipid peroxidation (Beddowes, et al. 2003). Using cultured hepatocytes from female Wistar rats, the same study reported dose-dependent increases in glutathione depletion and lipid peroxidation (LPO) following treatment with chloroform $(0,0.8,2.4,4,8,20 \mathrm{mM}$; results reported 2 hours following exposure) or carbon tetrachloride (0, 0.25, 1, $4 \mathrm{mM}$; results reported 2 hours following exposure). Further, the chloroform-exposed cells had dose-dependent increases in M1dG adducts and DNA strand breakage; and the carbon tetrachloride-exposed cells had dose-dependent increases in M1dG adducts, DNA strand breaks, and 8-oxodG adducts. Dose concordance of chloroform was demonstrated and significant changes occurred at the following doses: LPO (4, 8, $20 \mathrm{mM})$, decreased cell viability (20 mM), GSH depletion (20 mM), COMET (8, $20 \mathrm{mM})$, M1dG levels (4, 8, $20 \mathrm{mM})$. Further, GSH depletion was measured over a 24 hour period and was significantly decreased at 4, 8 and 24 hours following exposure to chloroform. Similar results were reported for carbon tetrachloride; however the data was not shown. Significant changes were reported for: LPO (4mM mM), decreased cell viability (4 mM), COMET (1 and $4 \mathrm{mM}$ ), M1dG levels (1 and $4 \mathrm{mM}$ ), and 8-oxo-dG (4 mM) following exposure to carbon tetrachloride (Beddowes, et al. 2003). Carbon tetrachloride-dependent oxidative adducts have also been reported elsewhere (Takahashi, et al. 1998, Wacker, et al. 2001). These studies demonstrate that oxidative damage to DNA occurs before liver cancer.

The transcriptional actions of chronic Nrf2 activation provide a molecular environment that promotes malignant transformation (Furfaro, et al. 2016, Jaramillo and Zhang 2013, Xiang, et al. 2014). Most recently, this relationship was outlined in an award-winning article that was published in the journal Carcinogenesis: The 2016 Carcinogenesis Award Winners "Liver carcinogenesis: from naughty chemicals to soothing fat and the surprising role of NRF2" (Karin and Dhar 2016). Following the analysis of the empirical data, the authors conclude that NRF2 is required for hepatocellular carcinoma precursor cells (HcPC) to progress to become hepatocellular carcinoma cells; in fact, without NRF2 excess ROS accumulate and kill the HcPC cells. Importantly, sequencing of human hepatocellular carcinoma patients has demonstrated NRF2 activation (Schulze, et al. 2015, Shibata and Aburatani 2014b, Totoki, et al. 2014).

Following furan exposure at carcinogenic doses $(4,8 \mathrm{mkd})$, the NRF2 oxidative stress pathway was the most highly implicated molecular pathway following microarray analysis of gene expression in mice exposed for three weeks (Jackson, et al. 2014), which demonstrates that the NRF2 oxidative stress pathway becomes active after chemical 
exposure and before the development of hepatocellular carcinoma. Further, the level of induction of the NRF2 pathway (i.e., the number of implicated genes) increased with dose, which demonstrates dose dependence of the response, which is concordant with the dose-dependent increases in hepatocellular adenoma and carcinoma. While the mechanistic details remain under investigation, there is clearly an important interplay between the two branches of this response (i.e., ROS-dependent mutations and the NRF2 oxidative stress response).

\section{Uncertainties and Inconsistencies}

Not all agents that cause ROS in the liver cause liver cancer. Thus, there are additional modulating factors that must be considered when determining whether a ROS-producing chemical will cause liver cancer.

Overall, ROS-dependent DNA damage causing harmful mutations is known to occur. However, the specific mechanism and the quantitative relationships by which these mutations promote malignant transformation are incompletely understood.

Increase in NRF2 expression is associated with occurrence and recurrence of hepatocellular carcinoma; however, the mechanism is incompletely understood.

\section{References}

Beddowes, E.J., Faux, S.P., Chipman, J.K., 2003. Chloroform, carbon tetrachloride and glutathione depletion induce secondary genotoxicity in liver cells via oxidative stress. Toxicology 187, 101-115.

Ding, W., Petibone, D.M., Latendresse, J.R., Pearce, M.G., Muskhelishvili, L., White, G.A., Chang, C.-., Mittelstaedt, R.A., Shaddock, J.G., McDaniel, L.P., Doerge, D.R., Morris, S.M., Bishop, M.E., Manjanatha, M.G., Aidoo, A., Heflich, R.H., 2012. In vivo genotoxicity of furan in F344 rats at cancer bioassay doses. Toxicol. Appl. Pharmacol. 261, 164-171.

Dizdaroglu, M., 2015. Oxidatively induced DNA damage and its repair in cancer. Mutat. Res. Rev. Mutat. Res. 763, 212-245. Dizdaroglu, M., 2012. Oxidatively induced DNA damage: mechanisms, repair and disease. Cancer Lett. 327, 26-47.

Fujimoto, A., Furuta, M., Totoki, Y., Tsunoda, T., Kato, M., Shiraishi, Y., Tanaka, H., Taniguchi, H., Kawakami, Y., Ueno, M., Gotoh, K., Ariizumi, S., Wardell, C.P., Hayami, S., Nakamura, T., Aikata, H., Arihiro, K., Boroevich, K.A., Abe, T., Nakano, K., Maejima, K., Sasaki-Oku, A., Ohsawa, A., Shibuya, T., Nakamura, H., Hama, N., Hosoda, F., Arai, Y., Ohashi, S., Urushidate, T., Nagae, G., Yamamoto, S., Ueda, H., Tatsuno, K., Ojima, H., Hiraoka, N., Okusaka, T., Kubo, M., Marubashi, S., Yamada, T., Hirano, S., Yamamoto, M., Ohdan, H., Shimada, K., Ishikawa, O., Yamaue, H., Chayama, K., Miyano, S., Aburatani, H., Shibata, T., Nakagawa, H., 2016. Whole-genome mutational landscape and characterization of noncoding and structural mutations in liver cancer. Nat. Genet. 48, 500-509.

Furfaro, A.L., Traverso, N., Domenicotti, C., Piras, S., Moretta, L., Marinari, U.M., Pronzato, M.A., Nitti, M., 2016. The Nrf2/HO-1 Axis in Cancer Cell Growth and Chemoresistance. Oxid Med. Cell. Longev 2016, 1958174.

Hickling, K.C., Hitchcock, J.M., Oreffo, V., Mally, A., Hammond, T.G., Evans, J.G., Chipman, J.K., 2010. Evidence of oxidative stress and associated DNA damage, increased proliferative drive, and altered gene expression in rat liver produced by the cholangiocarcinogenic agent Furan. Toxicol. Pathol. 38, 230-243.

Jackson, A.F., Williams, A., Recio, L., Waters, M.D., Lambert, I.B., Yauk, C.L., 2014. Case study on the utility of hepatic global gene expression profiling in the risk assessment of the carcinogen furan. Toxicol. Appl. Pharmacol. 274, 63-77. 
Jaramillo, M.C., Zhang, D.D., 2013. The emerging role of the Nrf2-Keap1 signaling pathway in cancer. Genes Dev. 27, 2179-2191.

Kansanen, E., Kuosmanen, S.M., Leinonen, H., Levonen, A.L., 2013. The Keap1-Nrf2 pathway: Mechanisms of activation and dysregulation in cancer. Redox Biol. 1, 45-49. Karin, M., Dhar, D., 2016. Liver carcinogenesis: from naughty chemicals to soothing fat and the surprising role of NRF2. Carcinogenesis 37, 541-546.

Linhart, K., Bartsch, H., Seitz, H.K., 2014. The role of reactive oxygen species (ROS) and cytochrome P-450 2E1 in the generation of carcinogenic etheno-DNA adducts. Redox Biol. 3, 56-62.

Moser, G.J., Foley, J., Burnett, M., Goldsworthy, T.L., Maronpot, R., 2009. Furan-induced dose-response relationships for liver cytotoxicity, cell proliferation, and tumorigenicity (furan-induced liver tumorigenicity). Experimental and Toxicologic Pathology 61, 101-111.

Murakami, S., Motohashi, H., 2015. Roles of Nrf2 in cell proliferation and differentiation. Free Radic. Biol. Med. $88,168-178$.

Poungpairoj, P., Whongsiri, P., Suwannasin, S., Khlaiphuengsin, A., Tangkijvanich, P., Boonla, C., 2015. Increased Oxidative Stress and RUNX3 Hypermethylation in Patients with Hepatitis B Virus-Associated Hepatocellular Carcinoma (HCC) and Induction of RUNX3 Hypermethylation by Reactive Oxygen Species in HCC Cells. Asian Pac. J. Cancer. Prev. 16, 5343-5348.

Schulze, K., Imbeaud, S., Letouze, E., Alexandrov, L.B., Calderaro, J., Rebouissou, S., Couchy, G., Meiller, C., Shinde, J., Soysouvanh, F., Calatayud, A.L., Pinyol, R., Pelletier, L., Balabaud, C., Laurent, A., Blanc, J.F., Mazzaferro, V., Calvo, F., Villanueva, A., Nault, J.C., Bioulac-Sage, P., Stratton, M.R., Llovet, J.M., ZucmanRossi, J., 2015. Exome sequencing of hepatocellular carcinomas identifies new mutational signatures and potential therapeutic targets. Nat. Genet. 47, 505-511.

Takahashi, S., Hirose, M., Tamano, S., Ozaki, M., Orita, S., Ito, T., Takeuchi, M., Ochi, H., Fukada, S., Kasai, H., Shirai, T., 1998. Immunohistochemical detection of 8-hydroxy-2'-deoxyguanosine in paraffin-embedded sections of rat liver after carbon tetrachloride treatment. Toxicol. Pathol. 26, 247-252.

Totoki, Y., Tatsuno, K., Covington, K.R., Ueda, H., Creighton, C.J., Kato, M., Tsuji, S., Donehower, L.A., Slagle, B.L., Nakamura, H., Yamamoto, S., Shinbrot, E., Hama, N., Lehmkuhl, M., Hosoda, F., Arai, Y., Walker, K., Dahdouli, M., Gotoh, K., Nagae, G., Gingras, M.C., Muzny, D.M., Ojima, H., Shimada, K., Midorikawa, Y., Goss, J.A., Cotton, R., Hayashi, A., Shibahara, J., Ishikawa, S., Guiteau, J., Tanaka, M., Urushidate, T., Ohashi, S., Okada, N., Doddapaneni, H., Wang, M., Zhu, Y., Dinh, H., Okusaka, T., Kokudo, N., Kosuge, T., Takayama, T., Fukayama, M., Gibbs, R.A., Wheeler, D.A., Aburatani, H., Shibata, T., 2014. Trans-ancestry mutational landscape of hepatocellular carcinoma genomes. Nat. Genet. 46, 1267-1273.

Wacker, M., Wanek, P., Eder, E., 2001. Detection of 1,N2-propanodeoxyguanosine adducts of trans-4-hydroxy-2nonenal after gavage of trans-4-hydroxy-2-nonenal or induction of lipid peroxidation with carbon tetrachloride in F344 rats. Chem. Biol. Interact. 137, 269-283.

Wang, E., Chen, F., Hu, X., Yuan, Y., 2014. Protective effects of apigenin against furan-induced toxicity in mice. Food Funct. 5, 1804-1812.

Wang, Y., Millonig, G., Nair, J., Patsenker, E., Stickel, F., Mueller, S., Bartsch, H., Seitz, H.K., 2009. Ethanolinduced cytochrome P4502E1 causes carcinogenic etheno-DNA lesions in alcoholic liver disease. Hepatology 50, 453-461. Winczura, A., Zdzalik, D., Tudek, B., 2012. Damage of DNA and proteins by major lipid peroxidation products in genome stability. Free Radic. Res. 46, 442-459.

Xiang, M., Namani, A., Wu, S., Wang, X., 2014. Nrf2: Bane or blessing in cancer? J. Cancer Res. Clin. Oncol. $140,1251-1259$.

Zhang, T.T., Zhao, G., Li, X., Xie, F.W., Liu, H.M., Xie, J.P., 2015. Genotoxic and oxidative stress effects of 2amino-9H-pyrido[2,3-b]indole in human hepatoma G2 (HepG2) and human lung alveolar epithelial (A549) cells. Toxicol. Mech. Methods 25, 212-222. 
AOPs Referencing Relationship

\begin{tabular}{|l|l|l|l|}
\hline AOP Name & Adjacency & $\begin{array}{l}\text { Weight of } \\
\text { Evidence }\end{array}$ & $\begin{array}{l}\text { Quantitative } \\
\text { Understanding }\end{array}$ \\
\hline $\begin{array}{l}\text { Cyp2E1 Activation Leading to Liver Cancer } \\
\text { (https://aopwiki.org/aops/220) }\end{array}$ & $\begin{array}{l}\text { non- } \\
\text { adjacent }\end{array}$ & Moderate & Not Specified \\
\hline
\end{tabular}

\section{Key Event Relationship Description}

Cell death by necrosis and necroptosis produces DAMPs that trigger inflammation. Inflammation is widely considered to be an important risk factor that sets the stage for malignant transformation; however, mechanistically, it is unclear how it does so.

\section{Evidence Supporting this KER}

\section{Biological Plausibility}

Moderate.

Cell death by necrosis and necroptosis produces DAMPs that trigger inflammation. Inflammation is widely considered to be an important risk factor that sets the stage for malignant transformation; however, mechanistically, it is unclear how it does so.

\section{Empirical Evidence}

Moderate.

Empirical evidence broadly supports the notion that cytotoxicity occurs at doses lower than those that cause liver cancer, and at early time points. A few examples are shown below.

F344 rats exposed for 13 weeks to furan (0-60 mkd, gavage) showed a dose dependent increase in degeneration and necrosis of hepatocytes beginning at $8 \mathrm{mkd}$ and $15 \mathrm{mkd}$, in males and females, respectively. A second group of rats (exposed to 0-8 mkd furan) was studied at nine months, fifteen months, and two years. After nine months, degeneration and necrosis were observed in the hepatocytes of all animals in the 4 and 8 mkd groups. After fifteen months, these endpoints were significantly increased in all animals (male and female) of each dose group. After two years, rats developed hepatocellular adenomas and carcinomas beginning at $4 \mathrm{mkd}$ in male and female rats (NTP 1993).

Thus, cytotoxicity precedes cancer and occurs at similar doses and the empirical evidence is concordant with a relationship between cytotoxicity and cancer.

In a study conducted by the NTP (1993), B6C3F1 mice (male and female) were exposed for 13 weeks to the hepatocarcinogen furan $(0,4,8,15,30,60 \mathrm{mkd}$, gavage; $\mathrm{n}=10$ per group) (nine male and four female mice exposed to $60 \mathrm{mkd}$ died before the end of the study). Toxic lesions were seen in the liver at all doses and severity increased with dose, bile duct hyperplasia and cholangiofibrosis were observed at 30 and $60 \mathrm{mkd}$ (NTP 1993). A two year study was conducted using a lower dose range $(0,4,8,15 \mathrm{mkd})$. Kaplan Meier survival curves showed a dosedependent decrease in survivorship with increasing dose of furan. There was a dose dependent increase in hepatocellular adenoma and carcinoma in male and female mice (NTP 1993).

Empirical evidence supporting an underlying mechanism relating to inflammation as a mitigating factor in this relationship is less clear. Inflammation in response to furan exposure occurs in mice at around the same dose as cytotoxicity and increases in a dose and time dependent manner (Fransson-Steen, et al. 1997, Moser, et al. 2009, NTP 1993). Inflammation is accompanied by an increase of circulating inflammatory markers (Wang, et al. 2014), 
and changes in inflammation-associated gene expression (Jackson, et al. 2014). In Moser et al. (2009) mild inflammation arose at very low doses $(0.5 \mathrm{mkd})$, was moderate at $1 \mathrm{mkd}$, and was marked at $4 \mathrm{mkd}$; whereas hepatocellular adenomas and carcinomas were not observed until 4 and $8 \mathrm{mkd}$, respectively.

Most recently, the relationship between chemically induced hepatocellular carcinoma and inflammation was outlined in an award-winning article that was published in the journal Carcinogenesis: The 2016 Carcinogenesis Award Winners "Liver carcinogenesis: from naughty chemicals to soothing fat and the surprising role of NRF2" (Karin and Dhar 2016). Studies in which diethylnitrosamine (DEN, a liver carcinogen) was given to male mice demonstrated that induction of hepatocellular carcinoma is dependent upon induction of inflammation. A liver myeloid cell-specific ablation of IKK-beta was sufficient to inhibit DEN-dependent carcinogenesis, whereas its deletion in hepatocytes enhanced carcinogenesis (Maeda, et al. 2005). The latter was due to an increase in cell death, which caused a subsequent increase of the cytokine and tumour protomtor interleukin 6 (IL-6) (Maeda, et al. 2009). IL-6 is known to be inhibited by estrogen, which could account for the higher prevalence of hepatocellular carcinoma in males (Naugler, et al. 2007). IL-6 has been described as a "wolf in sheep's clothing" and is thought to be an important link between inflammation and cancer (Naugler and Karin 2008). IL1-alpha released from dying hepatocytes is another important promoter of hepatocellular carcinoma (Sakurai, et al. 2008).

\section{Uncertainties and Inconsistencies}

This relationship appears to be valid for toxicants that produce moderate levels of cytotoxicity. Acetaminophen is a Cyp2E1 substrate that produces extremely high levels of hepatotoxicity. Acetaminophen does not cause liver cancer because death by liver failure occurs before cancer can develop.

\section{References}

Brenner, C., Galluzzi, L., Kepp, O., Kroemer, G., 2013. Decoding cell death signals in liver inflammation. J. Hepatol. 59, 583-594. Elsharkawy, A.M., Mann, D.A., 2007. Nuclear factor-kappaB and the hepatic inflammation-fibrosiscancer axis. Hepatology 46, 590-597.

Finkin, S., Pikarsky, E., 2011. NF-kappaB in liver cancer: the plot thickens. Curr. Top. Microbiol. Immunol. 349, 185-196.

Fransson-Steen, R., Goldsworthy, T.L., Kedderis, G.L., Maronpot, R.R., 1997. Furan-induced liver cell proliferation and apoptosis in female B6C3F1 mice. Toxicology 118, 195-204.

Jackson, A.F., Williams, A., Recio, L., Waters, M.D., Lambert, I.B., Yauk, C.L., 2014. Case study on the utility of hepatic global gene expression profiling in the risk assessment of the carcinogen furan. Toxicol. Appl. Pharmacol. $274,63-77$.

Kaczmarek, A., Vandenabeele, P., Krysko, D.V., 2013. Necroptosis: the release of damage-associated molecular patterns and its physiological relevance. Immunity 38, 209-223.

Karin, M., 2009. NF-kappaB as a critical link between inflammation and cancer. Cold Spring Harb Perspect. Biol. 1.

Karin, M., 2006. Nuclear factor-kappaB in cancer development and progression. Nature 441, 431-436.

Karin, M., Dhar, D., 2016. Liver carcinogenesis: from naughty chemicals to soothing fat and the surprising role of NRF2. Carcinogenesis 37, 541-546.

Luedde, T., Kaplowitz, N., Schwabe, R.F., 2014. Cell death and cell death responses in liver disease: mechanisms and clinical relevance. Gastroenterology 147, 765-783.e4. 
Luedde, T., Schwabe, R.F., 2011. NF-kB in the liver-linking injury, fibrosis and hepatocellular carcinoma. Nature Reviews Gastroenterology and Hepatology 8, 108-118.

Maeda, S., Hikiba, Y., Sakamoto, K., Nakagawa, H., Hirata, Y., Hayakawa, Y., Yanai, A., Ogura, K., Karin, M., Omata, M., 2009. Ikappa B kinasebeta/nuclear factor-kappaB activation controls the development of liver metastasis by way of interleukin-6 expression. Hepatology 50, 1851-1860.

Maeda, S., Kamata, H., Luo, J.L., Leffert, H., Karin, M., 2005. IKKbeta couples hepatocyte death to cytokinedriven compensatory proliferation that promotes chemical hepatocarcinogenesis. Cell 121, 977-990.

Moser, G.J., Foley, J., Burnett, M., Goldsworthy, T.L., Maronpot, R., 2009. Furan-induced dose-response relationships for liver cytotoxicity, cell proliferation, and tumorigenicity (furan-induced liver tumorigenicity). Experimental and Toxicologic Pathology 61, 101-111.

Naugler, W.E., Karin, M., 2008. The wolf in sheep's clothing: the role of interleukin-6 in immunity, inflammation and cancer. Trends Mol. Med. 14, 109-119.

Naugler, W.E., Sakurai, T., Kim, S., Maeda, S., Kim, K., Elsharkawy, A.M., Karin, M., 2007. Gender disparity in liver cancer due to sex differences in MyD88-dependent IL-6 production. Science 317, 121-124.

Pikarsky, E., Ben-Neriah, Y., 2006. NF-kappaB inhibition: a double-edged sword in cancer? Eur. J. Cancer $42,779-784$.

Pikarsky, E., Porat, R.M., Stein, I., Abramovitch, R., Amit, S., Kasem, S., Gutkovich-Pyest, E., Urieli-Shoval, S., Galun, E., Ben-Neriah, Y., 2004. NF-kappaB functions as a tumour promoter in inflammation-associated cancer. Nature 431, 461-466.

Sakurai, T., He, G., Matsuzawa, A., Yu, G.Y., Maeda, S., Hardiman, G., Karin, M., 2008. Hepatocyte necrosis induced by oxidative stress and IL-1 alpha release mediate carcinogen-induced compensatory proliferation and liver tumorigenesis. Cancer. Cell. 14, 156-165.

Vainer, G.W., Pikarsky, E., Ben-Neriah, Y., 2008. Contradictory functions of NF-kappaB in liver physiology and cancer. Cancer Lett. 267, 182-188.

Vallabhapurapu, S., Karin, M., 2009. Regulation and function of NF-kappaB transcription factors in the immune system. Annu. Rev. Immunol. 27, 693-733.

Wang, E., Chen, F., Hu, X., Yuan, Y., 2014. Protective effects of apigenin against furan-induced toxicity in mice. Food Funct. 5, 1804-1812.

Wang, J., Huang, Q., Chen, M., 2003. The role of NF-kappaB in hepatocellular carcinoma cell. Chin. Med. J. (Engl) 116, 747-752.

\section{Relationship: 1518: Sustained proliferation leads to Liver Cancer (https://aopwiki.org/relationships/1518)}

AOPs Referencing Relationship

\begin{tabular}{|l|l|l|l|}
\hline AOP Name & Adjacency & $\begin{array}{l}\text { Weight of } \\
\text { Evidence }\end{array}$ & $\begin{array}{l}\text { Quantitative } \\
\text { Understanding }\end{array}$ \\
\hline $\begin{array}{l}\text { Cyp2E1 Activation Leading to Liver Cancer } \\
\text { (https://aopwiki.org/aops/220) }\end{array}$ & $\begin{array}{l}\text { non- } \\
\text { adjacent }\end{array}$ & Moderate & Not Specified \\
\hline
\end{tabular}

Evidence Supporting Applicability of this Relationship

Any species that has a liver. 


\section{Key Event Relationship Description}

Every time a cell divides, there is a small chance that a mutation might occur. Because hepatocytes are polyploid, there is an increased rate of error-prone division due to multipolar mitotic spindles, which can result in aneuploidy in daughter cells (Stanger 2015). The risk for mutation is further increased when these cells are under stress (e.g., by a chemical exposure or increased oxidative stress). While it is generally understood that increased cellular proliferation is a predisposing factor to chemical carcinogenesis - 'sustained proliferative signaling' is one of the Hallmarks of Cancer (Hanahan and Weinberg 2000, Hanahan and Weinberg 2011) and IARC identifies altered cell proliferation as a key characteristic of a carcinogen (Smith, et al. 2015) - the exact mechanism for how one leads to the other is not altogether clear. There will be many steps in between observations of overt cellular proliferation leading to hepatocellular carcinoma. Thus, we describe this as an indirect KER with the hopes that additional empirical data to support the intervening steps will be available in the future, and that these additional $\mathrm{KE}(\mathrm{R}) \mathrm{s}$ can be developed at that time.

\section{Evidence Supporting this KER}

\section{Biological Plausibility}

Strong.

It is broadly accepted that pro-proliferative signaling is activated in an attempt to compensate for increases in cell death (Stanger 2015). Increased hepatocyte proliferation on a background of polyploidy, elevated cell death and oxidative DNA damage has the effect of increasing the likelihood of fixing harmful mutations, which are necessary for malignant transformation (Celton-Morizur and Desdouets 2010, Shi and Line 2014). However, the precise mechanistic processes defining this relationship have not been mapped out.

\section{Empirical Evidence}

Moderate.

There are many examples of published studies demonstrating that cellular proliferation precedes tumour formation. For example, experiments exploring liver histopathology in rodents in parallel with the two-year rodent cancer bioassays for chloroform (NTP 1976), furan (Moser, et al. 2009, NTP 1993), carbon tetrachloride (NTP 1977) and ethanol (NTP 2004) all demonstrate an increase in cellular proliferation prior to tumour formation in mice and rats. A detailed example for the chemical furan, a rodent hepatocarcinogen proposed to operate through a mode of action associated with cytotoxicity and increased hepatocellular proliferation, is given below.

A three week exposure of female B6C3F1 mice to furan $(0,2,4,8 \mathrm{mkd}$, gavage) resulted in increased liver cell proliferation (by BrdU incorportation) at the highest dose ( $8 \mathrm{mkd}$ ). In the same study, a second set of animals was exposed for two years to furan in parallel. These animals developed hepatocellular adenoma beginning at $4 \mathrm{mkd}$ and hepatocellular carcinoma at $8 \mathrm{mkd}$ (Moser, et al. 2009). Thus, there is both temporal- and dose-concordance for liver cell proliferation and cancer in this experiment. F344 rats exposed for 13 weeks to furan (0-60 mkd, gavage) showed a dose dependent increase in hyperplasia of hepatocytes beginning at $15 \mathrm{mkd}$ and $30 \mathrm{mkd}$ in males and females, respectively (NTP 1993). A second group of rats (exposed to 0-8 mkd furan) was studied at nine months, fifteen months, and two years. Hyperplasia was observed in all animals of the 4 and 8 mkd groups by 9 months. After fifteen months, hyperplasia was significantly increased in all animals (male and female) of each dose group. After two years, rats developed hepatocellular adenomas and carcinomas beginning at $4 \mathrm{mkd}$ in male and female rats. Kaplan-Meier survival curves showed a dose-dependent decrease in survivorship with increasing dose of furan (NTP 1993).

Promotion of hepatocellular carcinoma can be achieved in rats with exposure to chemical carcinogens (diethylnitrosamine, N-methyl-N-nitrosourea, 1,2-dimethylhydrazine, or benzo(a)pyrene), which is followed by two weeks of dietary 2-acetylaminofluorene (2-AAF) plus partial hepatectomy (PHx), or the administration of a 
necrogenic dose of carbon tetrachloride (CCl4) (Solt, et al. 1983). The 2-AAF+PH or CCl4 treatments were required for the cancer phenotype, which developed months later. These experiments demonstrate that liver injury, followed by organ repair by cellular proliferation occur before carcinogenesis.

$\mathrm{Mdr}^{-/-}$mice have higher background levels of inflammation and genomic instability than wild type mice, which may lead to hepatocellular carcinoma in some cases. However, when these mice undergo PHx, which is followed by high levels of cellular replication, they have accelerated and increased tumorigenesis due to replication of cells with damaged DNA (Barash, et al. 2010). This study demonstrates that cellular proliferation occurs before carcinogenesis, and that carcinogenesis is facilitated by elevated inflammation and genomic instability.

\section{Uncertainties and Inconsistencies}

Not all cases where there is sustained cellular proliferation produce tumours (some simply regenerate the liver to its healthy form). For instance Barash et al. (2010) demonstrate that increased background levels of inflammation and genomic instability are required for the progression from sustained cellular proliferation following PHx to tumourigenesis. Therefore, it is clear that malignant transformation must be accompanied by some sort of abnormal cellular signaling or impaired homeostasis. It is well understood that 'context' plays an important, albeit poorly understood, role in malignant transformation (Bissell and Hines 2011). More work is needed in this field to determine the additional modifying factors that predict whether a chemical that induces hepatocellular proliferation will cause cancer.

\section{References}

Barash, H., Gross, E.R., Edrei, Y., Ella, E., Israel, A., Cohen, I., Corchia, N., Ben-Moshe, T., Pappo, O., Pikarsky, E., Goldenberg, D., Shiloh, Y., Galun, E., Abramovitch, R., 2010. Accelerated carcinogenesis following liver regeneration is associated with chronic inflammation-induced double-strand DNA breaks. Proc. Natl. Acad. Sci. U. S. A. $107,2207-2212$.

Bissell, M.J., Hines, W.C., 2011. Why don't we get more cancer? A proposed role of the microenvironment in restraining cancer progression. Nat. Med. 17, 320-329.

Celton-Morizur, S., Desdouets, C., 2010. Polyploidization of liver cells. Adv. Exp. Med. Biol. 675, 123-135.

Golden, R.J., Holm, S.E., Robinson, D.E., Julkunen, P.H., Reese, E.A., 1997. Chloroform mode of action: implications for cancer risk assessment. Regul. Toxicol. Pharmacol. 26, 142-155.

Hanahan, D., Weinberg, R.A., 2000. The hallmarks of cancer. Cell 100, 57-70.

Hanahan, D., Weinberg, R.A., 2011. Hallmarks of cancer: the next generation. Cell 144, 646-674.

Moser, G.J., Foley, J., Burnett, M., Goldsworthy, T.L., Maronpot, R., 2009. Furan-induced dose-response relationships for liver cytotoxicity, cell proliferation, and tumorigenicity (furan-induced liver tumorigenicity). Experimental and Toxicologic Pathology 61, 101-111.

NTP, 2004. NTP Technichal Report on the Toxicology and Carinogenesis Studies of Urethane, ethanol, and urethane/ethanol in B6C3F1 Mice (drinking water studies). NTP-TR-510. NTP, 1977. Bioassay of 1,1,1trichloroethane for possible carcinogenicity. NTP-TR-3.

NTP, 1976. Report of the Carcinogenesis Bioassay of Chloroform (CAS No. 67-66-3). TR-001.

Shi, J.-., Line, P.-., 2014. Effect of liver regeneration on malignant hepatic tumors. World J. Gastroenterol. 20, 16167-16177.

Smith, M.T., Guyton, K.Z., Gibbons, C.F., Fritz, J.M., Portier, C.J., Rusyn, I., DeMarini, D.M., Caldwell, J.C., Kavlock, R.J., Lambert, P., Hecht, S.S., Bucher, J.R., Stewart, B.W., Baan, R., Cogliano, V.J., Straif, K., 2015. 
Key Characteristics of Carcinogens as a Basis for Organizing Data on Mechanisms of Carcinogenesis. Environ. Health Perspect.

Solt, D.B., Cayama, E., Tsuda, H., Enomoto, K., Lee, G., Farber, E., 1983. Promotion of liver cancer development by brief exposure to dietary 2-acetylaminofluorene plus partial hepatectomy or carbon tetrachloride. Cancer Res. 43, 188-191.

Stanger, B.Z., 2015. Cellular homeostasis and repair in the mammalian liver. Annu. Rev. Physiol. 77, 179-200.

Templin, M.V., Jamison, K.C., Sprankle, C.S., Wolf, D.C., Wong, B.A., Butterworth, B.E., 1996. Chloroforminduced cytotoxicity and regenerative cell proliferation in the kidneys and liver of BDF1 mice. Cancer letters 108, 225-231. 